\title{
Gluten challenge in coeliac disease
}

\section{Analysis of gluten-specific T cells in blood}

Doctoral thesis by

Stephanie Zühlke

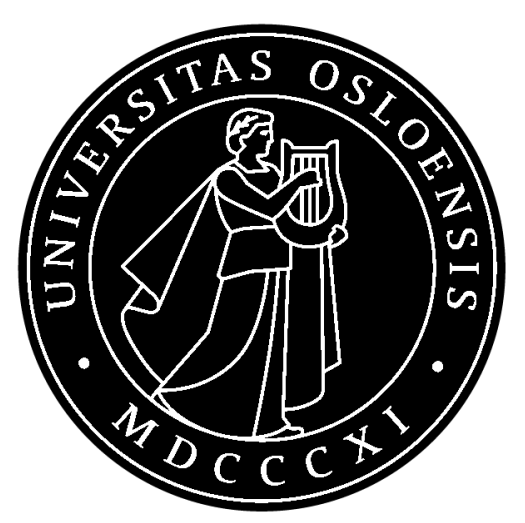

K. G. Jebsen Coeliac Disease Research Centre

Department of Immunology

Institute of Clinical Medicine

Faculty of Medicine

University of Oslo

2020 
(C) Stephanie Zühlke, 2021

Series of dissertations submitted to the Faculty of Medicine, University of Oslo

\section{ISBN 978-82-8377-813-7}

All rights reserved. No part of this publication may be reproduced or transmitted, in any form or by any means, without permission.

Cover: Hanne Baadsgaard Utigard.

Print production: Reprosentralen, University of Oslo. 


\section{CONTENTS}

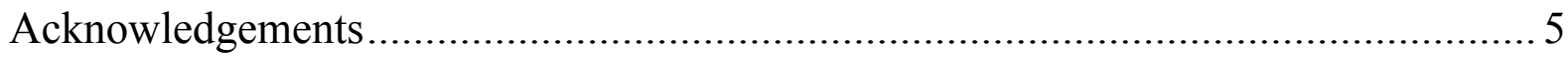

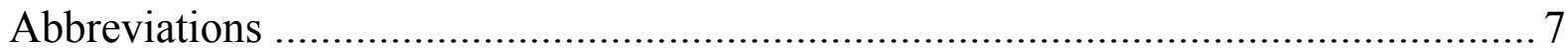

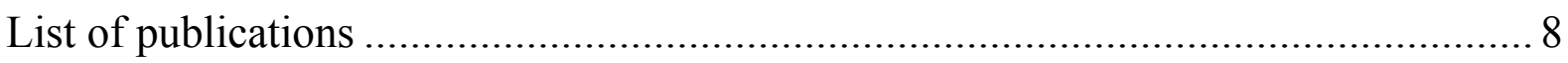

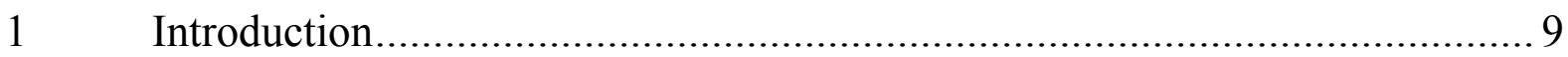

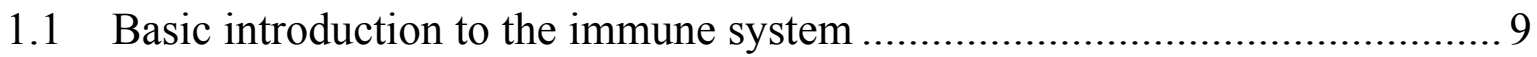

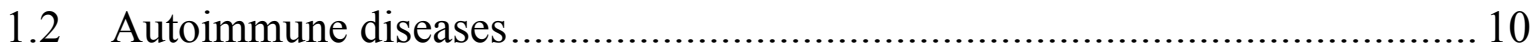

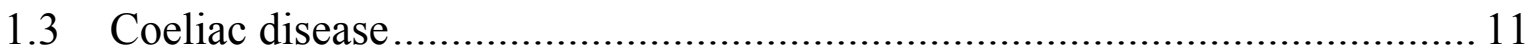

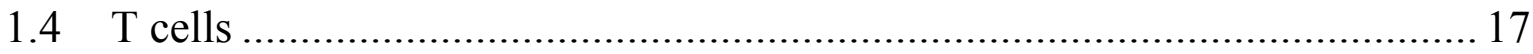

1.5 Coeliac disease from an immunological point of view................................ 25

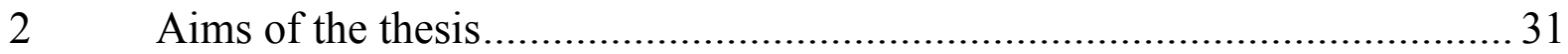

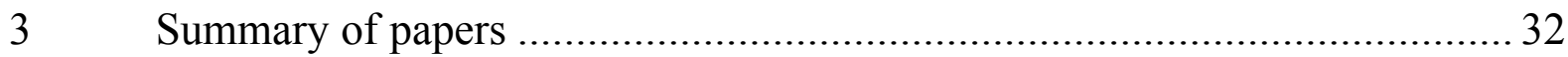

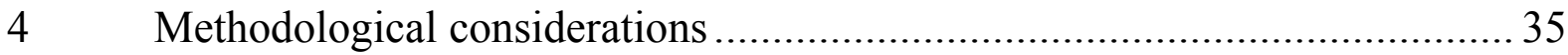

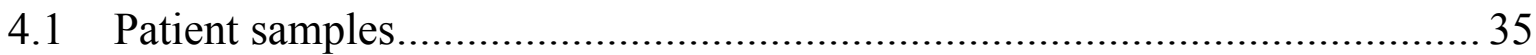

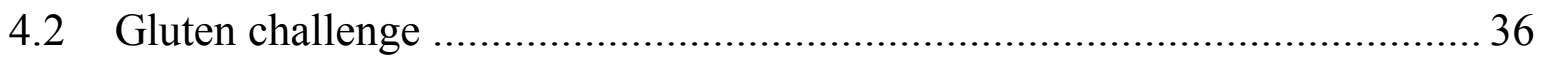

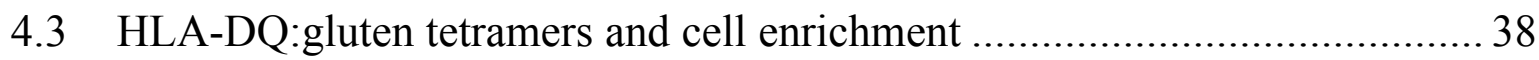

4.4 Flow cytometry, cell sorting and mass cytometry ...................................... 42

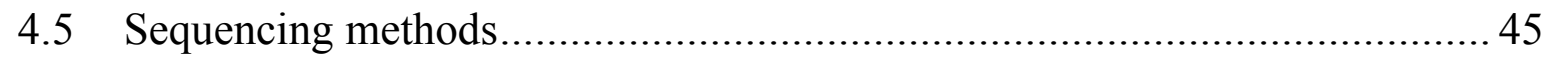

4.5.1 RNA sequencing and transcriptome analysis .................................... 45

4.5.2 T-cell receptor sequencing and repertoire analysis.............................. 47

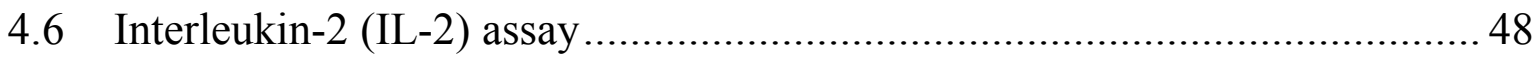

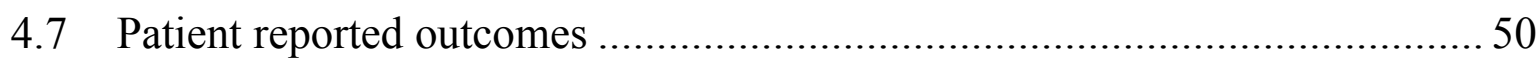

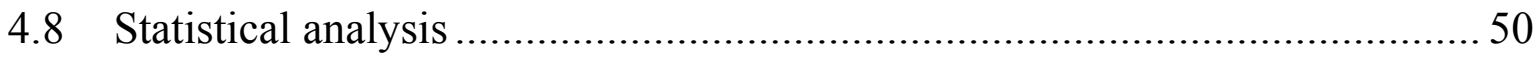

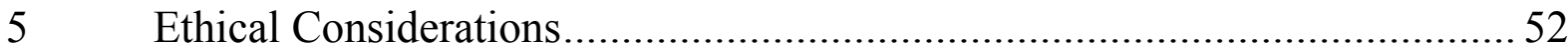

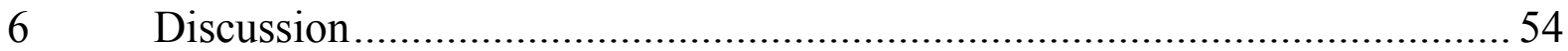




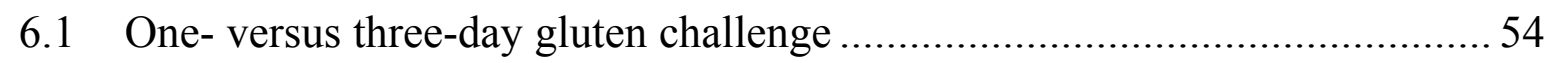

6.2 IL-2 concentration in plasma after gluten exposure ……………………...... 55

6.3 Kinetics of gluten-specific $\mathrm{CD}^{+} \mathrm{T}$ cells in response to gluten challenge...... 56

6.4 CD38 expression in response to gluten challenge ....................................57

6.5 Kinetics of $\mathrm{CD}^{+} \alpha \beta$ and $\gamma \delta \mathrm{T}$ cells in response to gluten challenge.............. 58

6.6 Transcriptome analysis of gluten-specific $\mathrm{T}$ cells ......................................58

6.7 Mass cytometry analysis of gluten-specific $\mathrm{T}$ cells .....................................59

6.8 Gluten-specific $\mathrm{T}$ cells as a new read-out for clinical drug trials .................... 60

6.9 Implications for coeliac disease and beyond - future perspectives................ 61

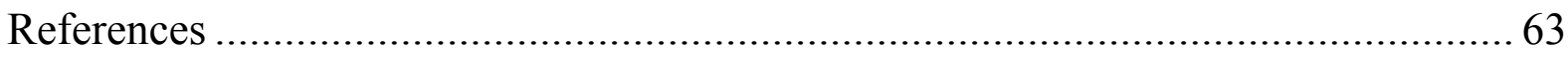




\section{ACKNOWLEDGEMENTS}

The work presented in this thesis was carried out at the Department of Immunology at Oslo University Hospital - Rikshospitalet. I was fortunate to receive a position as a $\mathrm{PhD}$ candidate financed by the K. G. Jebsen Centre for Coeliac Disease Research.

First, I would like to acknowledge my main supervisor Knut E.A. Lundin for his positivity, enthusiasm, encouraging support, knowledge and wide professional network. He has made this work possible and motivated me a lot. Knut sees possibilities, not obstacles. It has been a pleasure working together with you, Knut thank you!

My co-supervisor Ludvig M. Sollid is an outstanding expert in the field of coeliac disease research. I am thankful for the opportunity to work as a member of his group. The group is composed of many different people from a broad range of nations and with a diverge background, but still united by a common goal: solving the riddle of coeliac disease by conducting high quality research. Many of you have been very helpful throughout my work. Thank you for inspiring discussions and support especially to my co-authors Shiva, Louise, Asbjørn, Linn, Omri, Eivind and the other group members Ivana, Alisa, Fleur, Christian, Jorunn, Sunniva, Lene, Ida, Liv, Rasmus and Das. Marie and Bjørg, thank you for excellent technical help and assistance especially in the beginning of my work.

I am thankful to the staff at the gastroenterological endoscopy unit at Rikshospitalet, who provided the basis for successful clinical interaction with study participants. I especially thank Carina, Marte B. and Marte V., Siv F. and Siv I. for eagerly taking patient samples, helping to arrange various gluten challenges and nice company on scientific meetings.

I would like to acknowledge all patients who have participated in my projects. Their hope for more knowledge and new therapeutic alternatives has been a great motivation for me. 
Most of all I would like to thank my family. My parents have always backed me with an unbelievable amount of commitment - thank you for your unconditional support and advice whenever I need it. You are inspiring examples to me.

Robert, thank you for your relentless cheerfulness, support and optimism. You have been the closest and thereby most battered witness to "crime" and still dared to start a family with me. Importantly, you and my parents have - besides many other things taught me how to convey basic research to normal people.

Finally, I would like to mention our baby girl Inga Amalia, who accompanied me in the final months of this work and was born right before the finish line - you have changed my life and the order of priorities in the best possible way.

Oslo, July 2020

Stephanie Zühlke 


\begin{tabular}{|c|c|}
\hline \multicolumn{2}{|c|}{ ABBREVIATIONS } \\
\hline APC & Antigen presenting cell \\
\hline $\mathrm{BCR}$ & B cell receptor \\
\hline CCR & C-C chemokine receptor type \\
\hline cDNA & complementary deoxyribonucleic acid \\
\hline $\mathrm{CeD}$ & Coeliac disease \\
\hline $\mathrm{CD}$ & Cluster of Differentiation \\
\hline DGP & Deamidated gluten peptide \\
\hline DNA & Deoxyribonucleic acid \\
\hline ELISpot & Enzyme-linked immune absorbent spot \\
\hline FACS & Fluorescence-activated cell sorting \\
\hline FODMAP & Fermentable oligo-, di-, monosaccharides and polyols \\
\hline GFD & Gluten-free diet \\
\hline HLA & Human leukocyte antigen \\
\hline IEL & Intraepithelial lymphocyte \\
\hline IFN & Interferon \\
\hline Ig & Immunoglobulin \\
\hline IL & Interleukin \\
\hline MALDI-TOF & Matrix assisted laser desorption time of flight \\
\hline MHC & Major Histocompatibility Complex \\
\hline NK cell & Natural killer cell \\
\hline PBMC & Peripheral mononuclear blood cells \\
\hline PCR & Polymerase chain reaction \\
\hline pg & Pico gram \\
\hline RNA & Ribonucleic acid \\
\hline TCD & Treated coeliac disease \\
\hline $\mathrm{T}_{\mathrm{CM}}$ & Central memory $\mathrm{T}$ cells \\
\hline TCR & T-cell receptor \\
\hline $\mathrm{T}_{\mathrm{EM}}$ & Effector memory $\mathrm{T}$ cells \\
\hline TG2 & Transglutaminase 2 \\
\hline UCD & Untreated coeliac disease \\
\hline
\end{tabular}


LIST OF PUBLICATIONS

Paper I

CD38 expression on gluten-specific $\mathbf{T}$ cells is a robust marker of gluten reexposure in coeliac disease

Stephanie Zühlke, Louise Fremgaard Risnes, Shiva Dahal-Koirala, Asbjørn

Christophersen, Ludvig M. Sollid and Knut E.A. Lundin.

United European Gastroenterology Journal, 7(10), 1337-1344.

\section{Paper II}

Gluten-specific $\mathrm{CD4}^{+} \mathrm{T}$ cells express a distinct set of markers after gluten challenge that correlate well on the transcriptomic and phenotypic level Stephanie Zühlke, Asbjørn Christophersen, Eivind Gard Lund, Omri Snir, Louise Fremgaard Risnes, Shiva Dahal-Koirala, Linn Eggesbø, Ludvig M. Sollid and Knut E.A. Lundin.

Manuscript.

\section{Paper III}

Circulating $\mathrm{CD} 103^{+} \gamma \delta$ and $\mathrm{CD8}^{+} \mathrm{T}$ cells are clonally shared with tissue-resident intraepithelial lymphocytes in celiac disease

Linn Eggesbø, Louise F. Risnes, Stephanie Zühlke, Shiva Dahal-Koirala, Ralf S.

Neumann, Knut E. A. Lundin, Asbjørn Christophersen, Ludvig M. Sollid.

Manuscript in review. 


\section{INTRODUCTION}

\subsection{Basic introduction to the immune system}

The immune system protects us against foreign pathogens and mutated self of the host. To do that, the human body comprises of two branches of immunity. One of them is called innate immunity and is present in all animals and in plants. This system works fast and in an unspecific manner via pattern recognition of conserved features of proteins and it reacts in a conserved way to certain patterns over time (1-3). The innate immune system works hand-in-hand with the other kind, the adaptive immune system. This second branch of immunity is unique to vertebrates and based on more time-consuming cellular responses to pathogens. In contrast to innate immunity, those responses are modifiable and adapt to pathogens over time, in the sense that the immune response gets more specific towards the pathogen (1-3). The main cells involved in the adaptive immune system are $\mathrm{B}$ and $\mathrm{T}$ cells besides antigen-presenting cells (APCs). B stands for Bursa fabricii, a lymphoid organ located close to the cloaca in birds in which B cells were first described (4). However, the B is also a good mnemonic for the primary lymphoid organ in which B cells in (healthy adult) mammals develop - the bone marrow. T cells, on the other hand, develop predominantly in the thymus, another primary lymphoid organ.

During their development, B and T cells have to obtain features to distinguish between "self" and "foreign". Therefore, they undergo positive (mainly T cells) and negative selection (B and $\mathrm{T}$ cells); processes, in which cells that react to the presented antigen receive survival signals (positive selection), but cells that strongly recognize self, get apoptosis-inducing signals (negative selection). After maturation from precursor cells, naïve $B$ and $T$ cells that never have encountered antigen in the periphery, start circulating in the blood and lymph. Eventually, naïve B and T cells, home to a secondary lymphoid organ like a lymph node, the spleen or mucosa-associated lymphoid tissue, recognize the antigen fitting to their B- or T-cell receptor (BCR, TCR), cross-talk with each other and APCs and get activated by fine-tuned mechanisms, finally becoming effector cells (1-3). 
At this point, clonal selection and expansion of both B and T cells play an important role: $\mathrm{T}$ and $\mathrm{B}$ cells with a well-fitting receptor towards their antigen receive more survival/activation signals than cells with a less fitting receptor, which initiates a process called clonal expansion resulting in exponentially growth of daughter cells with the same receptor recognizing antigen. When the antigen burst is over, the clones contract and the majority of specific effector cells die off through apoptosis due to cell exhaustion and lack of survival signals while some few cells remain, composing the memory cell pool (1-3). The process of clonal contraction has several advantages: It is sparing energy and reducing the number of at that point unneeded cells in the body on one hand. On the other hand, the immune system is prepared in the case of reinfection and a well-fitting cell response can be recruited earlier than in primary infection. This mechanism has - largely based on empirical knowledge before the $20^{\text {th }}$ century - been exploited for centuries by inoculation and vaccination (5).

\subsection{Autoimmune diseases}

The main role of the immune system is to defend our body against invasive attack from foreign organisms. Yet, we live in close symbiosis with an enormous number of bacteria, fungi and viruses commonly referred to as the commensal flora, and we challenge our immune system with the various food we eat. In line with this, our immune system has to be able to differentiate between potentially harmful agents that have to be fought and harmless ones that can be tolerated or ignored.

In this sense, autoimmune diseases reflect a misconception of a harmless agent as a dangerous one by our immune system. Autoimmune diseases are generally defined as diseases in which the body attacks itself. They can be described as clinical syndromes caused by the activation of $\mathrm{T}$ cells and/or B cells in the absence of a known infection, but due to aberrant responses to particular antigens (6). The activation of the immune system in response to self-antigen is the hallmark of the autoimmune diseases and goes along with production of autoantibodies. In today's understanding, autoimmunity is a natural phenomenon, with self-reactive antibodies and autoimmune cells present to a low extent in normal individuals. Anti-self-responses are often generated in the 
process of mounting an immune response to foreign antigens, e.g. by molecular mimicry (7). However, under healthy conditions, autoimmunity is kept under control. Autoimmune disease results only if autoimmunity is poorly regulated resulting in a loss of self-tolerance $(6,8)$.

From a clinical point of view, autoimmune disorders mainly fall into two categories: systematic autoimmune diseases, which are associated with none-tissue specific autoantibodies and localized autoimmune diseases, which are associated with organspecific conditions (9). However, Davidson et al. rather suggest a division into functional categories that distinguish between diseases with a general alteration in the selection, regulation, or death of $\mathrm{T}$ or $\mathrm{B}$ cells and diseases characterized by an aberrant response to a particular (self- or foreign) antigen (6).

Autoimmune diseases affect in total around five percent of the population in Western countries with a higher frequency among women $(6,9)$. Besides symptomatic treatment or replacement therapy of mainly hormones (e.g. insulin, thyroxin or cortisol), the treatment goals for many autoimmune disorders are the reduction of chronic symptoms and the level of immune system activity while the immune system's ability to fight foreign pathogens has to be maintained. These goals may for example be achieved by blocking the recruitment of naïve cells or by preventing the activation of memory cells $(6,9)$ or by strict avoidance of the antigen, as in the case of treatment for coeliac disease $(\mathrm{CeD})$.

\subsection{Coeliac disease}

In line with the above-described, $\mathrm{CeD}$ fulfils the criteria of an autoimmune disease characterised by a foreign driver antigen (gluten), autoantibodies (against tissue transglutaminase 2, TG2) and a typical gastrointestinal manifestation (figure 1), which often is accompanied by a wide spectrum of extra-intestinal symptoms (10). Among the spectrum of autoimmune diseases, $\mathrm{CeD}$ can be assigned a special role as a model disease, as both the driving foreign and the auto-antigen are known, although the disease trigger still has not been clearly identified. The following section will elaborate on today's knowledge on CeD. 


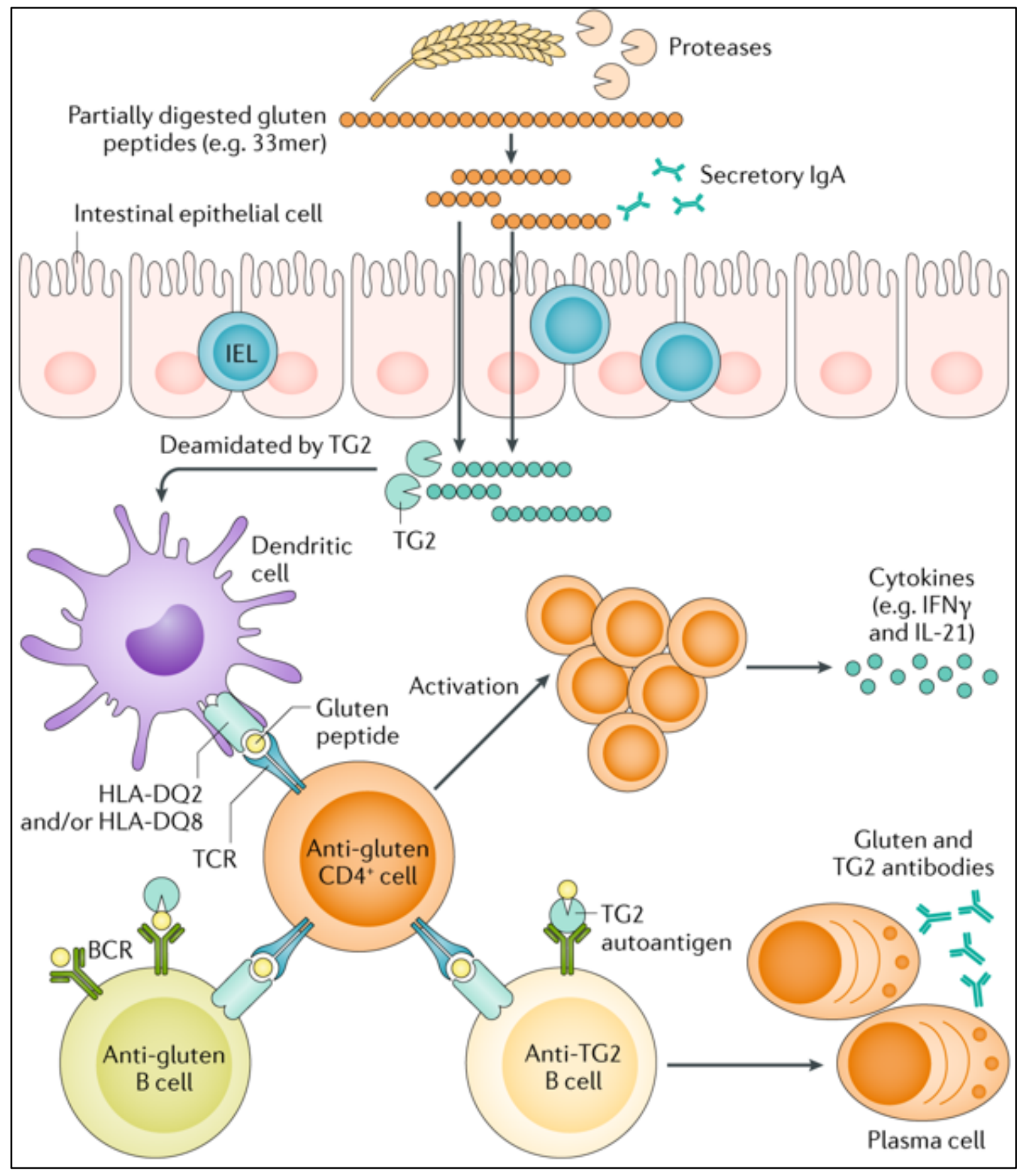

Figure 1. Overview over the adaptive immune response in CeD. Reprint with permission from Lindfors et al. Nature Reviews 2019 (10). Gluten peptides access the lamina propria and are modified by transglutaminase- 2 (TG2) that deamidates glutamine residues resulting in deamidated gluten peptides (DGP), thereby increasing their affinity to HLA-DQ2 or -DQ8. APCs take up and present the modified peptides. B cells recognize gluten peptides and TG2gliadin complexes via surface BCRs. Upon the interaction of HLA-DQ2 or -DQ8, gluten peptides and distinct TCRs, both the T and $\mathrm{B}$ cells get activated. Activated gluten-specific $\mathrm{CD}^{+} \mathrm{T}$ cells secret inflammatory cytokines creating an inflammatory milieu in the lamina propria of the small intestinal. Activated B cells can differentiate into plasma cells and secrete antibodies against DGP and TG2. Intraepithelial lymphocytes (IELs) promote epithelial cell damage, which is possibly induced by high levels of IL-15 $(11,12)$ (not shown). 


\section{Coeliac disease and gluten proteins}

$\mathrm{CeD}$ affects at least one percent of the Caucasoid population worldwide and is caused by an aberrant immune response to gluten proteins from wheat and similar prolineand glutamine-rich proteins of mainly barley and rye (13).

Gluten is the cohesive mass that remains after washing the dough to remove starch and other water-soluble components. Wheat gluten is divided into monomeric, alcohol-soluble gliadins and polymeric, alcohol-insoluble glutenins $(13,14)$. Gliadins are further subdivided into $\alpha$-, $\gamma$ - and $\omega$-gliadins and differ structurally (14). Glutenins are subdivided into high molecular weight and low molecular weight subunits. Glutenlike proteins from rye and barley are termed secalins and hordeins, respectively (14). The closely related cereal oat also harbours some gluten-like proteins termed avenins, but these are generally tolerated by coeliac disease patients (15).

\section{Epidemiology, clinical presentation and diagnosis}

$\mathrm{CeD}$ is not only a disease of developed countries, as it is also common in developing and emerging countries where wheat-based food is consumed given that diseaseassociated HLA variants are present (16). In India, for example, CeD is mainly observed in the north-western part of the country, where wheat is a basic food. The frequency of $\mathrm{CeD}$ is even increasing in many developing countries, probably due to westernization of the diet, changes in wheat production and preparation, increased awareness, or a combination of all these factors (17).

The prevalence among women is around twice as high as among men. CeD can develop at all ages (18-20).

The clinical picture of $\mathrm{CeD}$ can range from tangible symptoms such as malabsorption, diarrhoea, weight loss, and osteoporosis to vaguer symptoms such as iron and folic acid deficiency, arthralgia, fatigue, and abdominal discomfort (21). The latter two symptoms are nowadays typically observed in clinical practice, while the historically described symptoms of malabsorption and weight loss have faded into the background. Although a main symptom of malabsorption, diarrhoea is often absent in CeD. Patients may nowadays even be obese or completely asymptomatic. So, the 
range of symptoms described above makes it impossible to diagnose $\mathrm{CeD}$ on clinical grounds alone $(21,22)$.

The diagnostic work-up to confirm a $\mathrm{CeD}$ diagnosis in adults usually follows a multistep approach: Firstly, a clinical suspicion of coeliac disease should be present, although screening of individuals at risk with e.g. type 1 diabetes or Down syndrome should be performed in the absence of clinical suspicion $(23,24)$. Secondly, a serological test is done: Most recent guidelines suggest measuring IgA-TG2 (immunoglobulin A anti-transglutaminase 2) combined with IgA level determination (23). At Oslo University Hospital, however, a combination of IgA-TG2 and immunoglobulin G anti-deamidated gluten peptide (IgG-DGP) antibodies is used. Although the specificity and sensitivity of serology tests for $\mathrm{CeD}$ are impressive, the positive predictive values of these tests are less convincing (25). Thirdly, the final diagnostic step, an esophagogastroduodenoscopy including the sampling of duodenal biopsies, which are graded according to the Marsh-Oberhuber classification (26), is used to confirm the diagnosis of $\mathrm{CeD}$ in adults according to the present guidelines (23). In children, the current European guidelines state that gastroscopy can be abstained from in patients with IgA-antibodies against TG2 $\geq 10$ times the upper limit of normal and a positive anti-endomysial antibody (EMA) test in a second sample (27).

Since almost all CeD patients express a gene variant of HLA-DQ2.5, HLA-DQ8 or HLA-DQ2.2 (12, 28-30), HLA-typing can be used in the diagnostic work-up of CeD (24). However, due to HLA-DQ2 and -DQ8 prevalence up to $40 \%$ in the general population (31), the positive predictive value of HLA typing for making a CeD diagnosis is too low for clinical purposes. HLA typing has therefore its main role in excluding a $\mathrm{CeD}$ diagnosis in the case of gastrointestinal symptoms without an HLADQ2 or -DQ8 phenotype.

Clinical signs, serology, and morphology of the intestinal mucosa will return to normal with adherence to a gluten-free diet. Gluten challenge is therefore necessary to provoke a measurable immune response in the gut and blood of patients who have started a gluten-free diet before getting a proper diagnosis according to guidelines 
(23). Current practice in these cases requires an oral gluten challenge over at least two weeks, and better six weeks, whereas many patients are unwilling to prolong gluten challenge beyond the absolute necessary period of time $(22,32,33)$.

Gluten challenge has also been a useful tool for research purposes to study disease mechanisms and cells involved in pathogenesis. In our research setting, gluten challenge is often shortened to three days (34-37). The first pathophysiological changes in blood can already be detected few hours after the intake of gluten $(38,39)$ and a gluten-specific T cell response in blood can be expected on day 6 after onset of challenge (37). Mucosal changes in the gut, in contrast, seem to appear much later (40).

\section{Treatment and follow-up}

Today's standard treatment of CeD relies on a strict gluten-free diet (GFD), i.e. without ingredients derived from Triticum genus (such as wheat including spelt wheat, rye, barley, Einkorn, Khorasan or crossbred variants). A wide range of gluten-free products is specifically manufactured for patients with CeD (17). However, a minimal degree of gluten contamination is difficult to avoid (21). According to the Codex Alimentarius regulation (41), gluten-free food is defined as not derived from Triticum species and containing a maximum gluten contamination of 20 parts per million measured by R5 ELISA (Enzyme Linked Immuno-Sorbent Assay using the R5 antibody for gluten detection). This level appears to be a safe threshold even for patients who eat large amounts of wheat substitutes (42).

On a gluten-free diet, symptoms and serum antibodies gradually disappear, and healing of the intestinal damage typically occurs within 6 to 24 months after initiation of a gluten-free diet $(17,43)$ depending on the dietary compliance (44). If all patients should be followed until mucosal healing is demonstrated with repeat biopsies and included in a long-term follow-up is still controversial (45). It has however been shown that serology seems to be a poor surrogate marker for mucosal recovery on a GFD and the benefits of re-biopsy might overweigh (46). The guidelines from the British Society of Gastroenterology from 2014 recommend annual reviews of 
adherence to the diet, serologic monitoring and monitoring for associated conditions (osteoporosis and vaccination against encapsulated bacteria in hypo-splenic individuals among others) (32). This approach has been confirmed by the latest guidelines from the European Society for the Study of Coeliac Disease published in $2019(23)$.

\section{Patient-reported outcomes}

Assessing patient-reported outcomes (PROs) is a useful tool to record the symptom level of patients before and after an intervention, like for example onset of a GFD or a clinical trial intervention. PROs are directly reported by patients and thus reflect the subjectively experienced efficacy of the respective intervention.

Despite the subjectivity of PROs, they have to detect a clinically meaningful change with a certain sensitivity, accuracy and reliability. Only if these criteria are fulfilled, PROs can be trusted to measure the true benefit of the intervention and can possibly being used as outcome measures for FDA (U.S. Food and Drug Administration) approval trials (47).

A recent systematic review on PROs in regard of $\mathrm{CeD}$ (47) looked at the four PROs CeD-GSRS (Gastrointestinal Symptom Rating Scale), PGWB (Psychological General Well-Being Index), CDSD (Celiac Disease Symptom Diary) and CeD-PRO (Celiac Disease Patient Reported Outcome). The review was not able to conclude which of the PROs is most appropriate to use. According to the authors, the four PROs appear to contain appropriate content, but the optimal PRO-instrument is not agreed upon. An additional PRO, which was not examined in the review is the Celiac Symptom Index (CSI) by Leffler et al. (48). Another way to assess the symptom level of patients are visual analogue scales. They are widely used, give quick insights into patients' symptoms and are easily understandable.

Taken together, a variety of PRO tools exist to assess patients' symptoms as a subjective outcome measure, which may help to assess the efficacy of a certain intervention. 
Having provided a basic introduction to the key aspects of $\mathrm{CeD}$, I will in the following section turn back to immunology and the function of $\mathrm{T}$ cells, both in general and regarding their crucial role in $\mathrm{CeD}$ pathogenesis and disease progression.

\subsection{T cells}

\section{T-cell development}

$\mathrm{T}$ cells develop, like all other cells in the blood, from hematopoietic stem cells in the bone marrow. Immature $\mathrm{T}$ cells travel from the bone marrow to the thymus to complete maturation. At the stage of migration, T cells lack most of the surface molecules that mature $\mathrm{T}$ cells express and their receptor genes are not rearranged. After about a week with interaction with the thymus stroma, the thymocytes bear distinct T-cell markers, but do not express any of the three cell-surface markers that define mature T cells: the rearranged CD3-TCR complex and the co-receptors CD4 or CD8. Because of the absence of CD4 and CD8, the cells are called "double-negative" thymocytes (1-3). The double-negative population includes different subgroups of $\mathrm{T}$ cells: T cells with a TCR $\gamma$ and $\delta$ chain instead of the more common $\alpha \beta$ TCR chains and cells that express the NK1.1 receptor and will become natural killer (NK) cells (1). The following section will focus on $\alpha \beta$ and $\gamma \delta$ T cells.

$\gamma \delta \mathrm{T}$ cells are often referred to as the prototype of 'unconventional' T cells (49). $\gamma \delta \mathrm{T}$ cells are the first $\mathrm{T}$ cells to appear in the foetal thymus and with progressing development of $\alpha \beta$ T cells, the relative number of $\gamma \delta$ T cells decreases (50). $\gamma \delta$ T cells comprise a small subset of $\mathrm{T}$ cells in peripheral blood from humans with a mean of approximately $4 \%$ of total $\mathrm{CD}^{+}$cells (50). $\gamma \delta \mathrm{T}$ cells are involved in the early response to antigen. Cytokine production by $\gamma \delta \mathrm{T}$ cells in acute infections, mainly interleukin-17 (IL-17), often evokes without prior antigen exposure, but is required for initiation of the inflammatory response by recruitment neutrophils from the bone marrow and inducing their maturation $(50,51)$. IL-17 plays also a crucial role in the development and progression of autoimmune diseases and in this way, innate immune cells, especially the $\gamma \delta \mathrm{T}$ cell subset, contribute to autoimmune pathogenesis (52). The majority of $\gamma \delta$ T cells are activated in the absence of a major histocompatibility 
complex (MHC) molecule presenting antigen. This may together with their recognition of a broad spectrum of endogenous and exogenous antigens contribute to the fact that $\gamma \delta \mathrm{T}$ cells are rapid inducers of inflammation, also in autoimmune diseases (52). However, a recent publication showed that a small subset of $\gamma \delta \mathrm{T}$ cells from peripheral blood and tissues indeed exhibits reactivity to a MHC-related protein (53).

All $\alpha \beta$ TCR expressing T cells recognise their ligands in context of MHC molecules (49). The human MHC molecules are termed Human Leukocyte Antigen (HLA) molecules. There are two types of MHC molecules, class I and II. The most important differences between the two classes of MHC molecule lie in the origin of peptides that they trap and carry to the cell surface, where the peptides are presented to other cells: MHC class I molecules collect peptides, which originate from proteins synthesized in the cytosol. In this way they are able to display fragments of viral proteins on the cell surface. MHC class II molecules bind peptides derived from proteins in intracellular vesicles, thus displaying peptides derived from pathogens living in cellular vesicles or internalized from the extracellular milieu by phagocytic cells and B cells (1).

\section{Antigen-specificity of T cells}

A common feature of cells of the adaptive immune system is their narrow individual specificity to antigen resulting in a broad coverage of various antigens due to the amount of cells with different specificity. Specificity and receptor diversity originate from rearrangement of $\mathrm{V}$ (ariable region), $\mathrm{D}$ (iversifying region) and $\mathrm{J}$ (oining region) gene segments of both $\mathrm{B}$ and $\mathrm{T}$ cells. In addition, variable addition and subtraction of nucleotides at the junctions between $\mathrm{V}(\mathrm{D}) \mathrm{J}$ gene segments contribute to diversity. Together, these processes result in a diverse number of B- and T-cell receptor chains. Productive assembly of the chain segments leads to a functioning TCR with each an $\alpha$ and $\beta$ (or $\gamma$ and $\delta$ ) chain, while unproductive rearrangements result in apoptosis (1). In the thymus, APCs and thymic epithelial cells display a wide range of self-peptides bound to MHC complexes, a process induced by the transcription factor AIRE (autoimmune regulator) in thymic epithelial cells (54). Most of the precursor $\alpha \beta$ or $\gamma \delta$ $\mathrm{T}$ cells cannot recognise self-MHC molecules and will fail positive selection and die. 
However, those cells that recognise self-MHC with medium to high affinity, and therefore undergo positive selection, will mature. The precursor $\mathrm{T}$ cells also undergo negative selection, which eliminates those cells that strongly bind and are capable of responding to self-antigens. In this way, immunogenic tolerance to self-antigens is established, while a weak or medium response to ubiquitous peptides is not restricted (1-3). In contrast to the development of $\alpha \beta$ T cells, which is characterised by strict positive and negative selection, recent results on $\gamma \delta$ T cells suggest that once antigen specificity is generated, on $\gamma \delta \mathrm{T}$ cells it is only marginally modified by thymic selection (50).

In the end, only about $2 \%$ of the precursor $\mathrm{T}$ cells survive positive and negative selection, mature and are exported from the thymus, forming the peripheral T-cell repertoire (1-3). Mature, yet naïve, $\mathrm{T}$ cells leave the thymus via the blood stream and seem to be sustained by repeated contact with MHC:self-peptide complexes identical or similar to those that originally positively selected them (1) (figure 2). In this way, it is also possible that $\mathrm{T}$ cells encounter exogenous gluten peptides (55) similar to certain endogenous peptides in the body.

Antigens, i.e. molecules that specifically bind to a BCR or TCR, are either taken up by professional APCs, most importantly dendritic cells, macrophages or B cells that capture exogenous antigen and present it to $\mathrm{CD}^{+} \mathrm{T}$ cells by MHC class II complexes. Alternatively, antigens are taken up by non-professional cells, i.e. all nucleated cells of the body, which present antigens originated from the inside of the cell to $\mathrm{CD} 8^{+} \mathrm{T}$ cells via MHC class I (1-3). Presentation of antigen to $\mathrm{CD}^{+} \mathrm{T}$ cells leads to cell activation as a consequence of interaction between the $\mathrm{T}$ cell receptor (TCR) and a peptide:MHC class II complex, which in turn induces T-cell help for B cells and antibody generation. $\mathrm{CD} 8^{+} \mathrm{T}$ cells get antigens presented via MHC class I molecules, which induces immediate cell killing. By continuously circulating through the T cells zones of peripheral lymphatic tissue, naïve $\mathrm{T}$ cells get in touch with APCs presenting various antigens on MHC class I or II molecules (1-3). 


\section{T-cell activation and the two-signal model}

On this first activation signal delivered via TCRs upon antigen presentation, at least one additional, antigen-independent co-stimulatory signal follows to start the process of $\mathrm{T}$ cell activation according to the two-signal model $(56,57)$. In the case of $\mathrm{CD}^{+} \mathrm{T}$ cells, the second signal is provided by the ligation of Cluster of Differentiation 28 (CD28) on the surface of T cells with the ligands, CD80 and CD86, on the surface of professional APCs. Stimulation of CD28 induces the production of CTLA-4 (CD152), which dampens the activation response by competing with CD28 for CD80 and CD86. In addition to signalling via the constitutively expressed TCR and CD28, several other survival signals such as ICOS, OX40 and CD137, which are only expressed under pathological conditions, ensure that $\mathrm{T}$ cells do not respond inappropriately. Likewise, the respective ligands on APCs are only expressed in response to antigen recognition $(57,58)$.

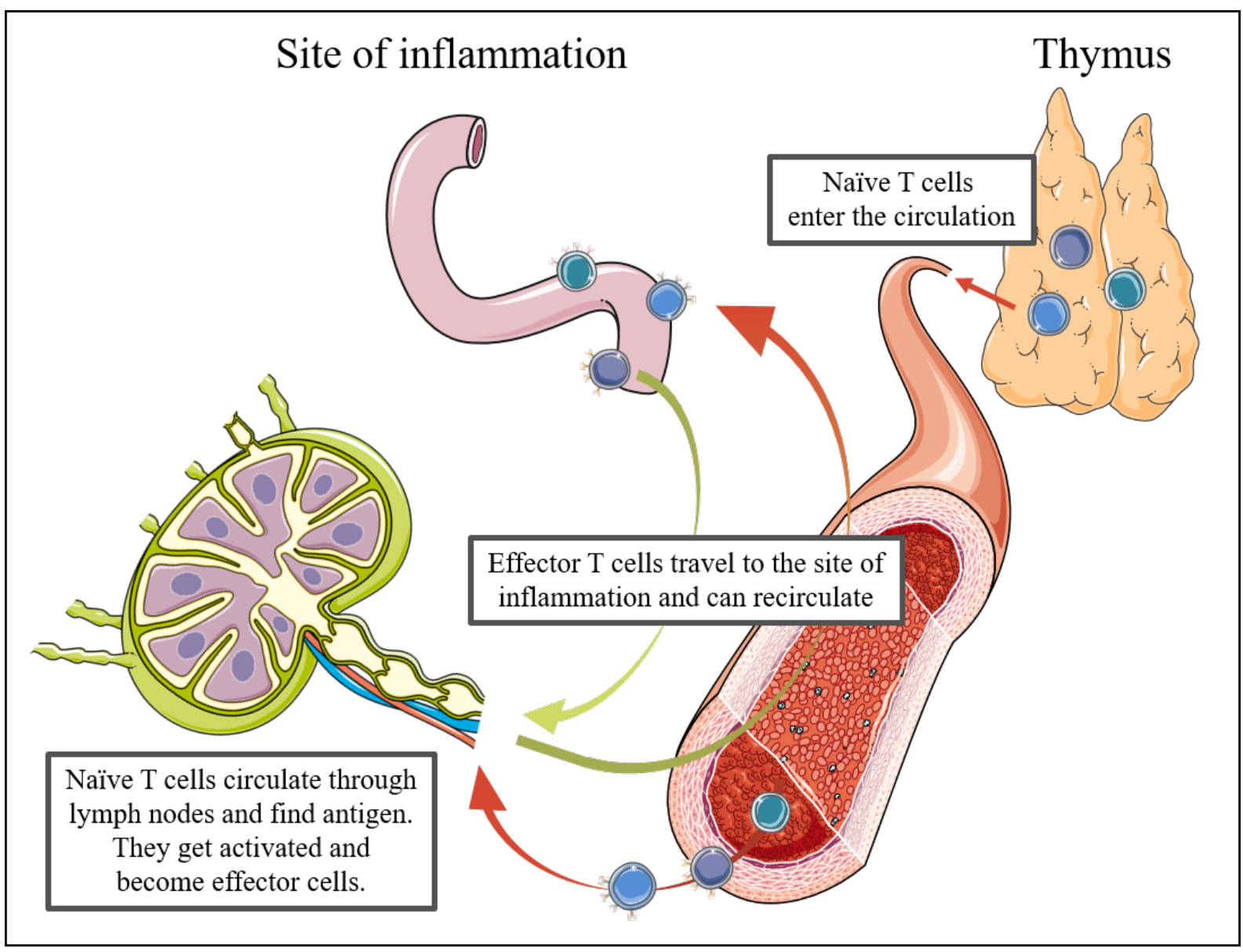

Figure 2. Simplified overview of the life and localisation of $\mathbf{T}$ cells. The figure was made using Servier Medical Art (https://smart.servier.com). 
The third signal of T-cell activation

In recent years, it has become clear that a third signal is needed to determine $\mathrm{T}$ cell differentiation into different effector types following activation. This third signal is delivered by cytokines $(59,60)$. This third cytokine signal may, at least in the early phase of an activation, be delivered by a third cell (60) besides the T cell and the APC. Cytokines influence and regulate the function of the immune system by enabling cell communication. They are soluble factors with pleiotropic functions and are produced by many cell types (59).

Historically, characteristic cytokine profiles have been used to classify $\mathrm{CD}^{+} \mathrm{T}$ (helper) into two major subpopulations, $T_{h} 1$ and $T_{h} 2$ cells $(61) . T_{h} 1$ cells, which support defence against intracellular parasites and are associated with organ-specific autoimmunity, secrete mainly interferon- $\gamma$ (IFN- $\gamma$ ), IL-2 and tumour necrosis factor- $\beta$ (TNF- $\beta$ ). $\mathrm{T}_{\mathrm{h}} 2$ cells, that mount a response to extracellular pathogens and helminths, secrete mainly IL-4, IL-5 and IL-13, and are also observed in the context of allergic inflammation $(61,62)$.

Since the early 2000s however, several other T helper cell subtypes have been described in addition to $T_{h} 1$ and $T_{h} 2$ cells: regulatory $T$ cells secreting IL-10 and transforming growth factor $\beta$ (TGF- $\beta$ ) that are responsible for the maintenance of immunologic tolerance to self and foreign antigen; $\mathrm{T}_{\mathrm{h}} 17$ cells secreting IL-17, IL-21 and TGF- $\beta$, which account for defence against extracellular bacteria and fungi, but are also involved in autoimmunity; $\mathrm{T}_{\mathrm{h}} 9$ cells secreting IL-4, IL-9 and TGF- $\beta$ that are responsible for skin homeostasis and observed in tissue inflammation; IL-22 cells secreting IL-22 in the context of tissue inflammation; and finally follicular helper T cells secreting IL-6 and IL-21 that support B cells maturation and immunoglobulin class switch $(62,63)$. Recently, an additional phenotype of so-called peripheral helper $\mathrm{T}$ cells, which share similarities with follicular helper $\mathrm{T}$ cells, has been described in association with the autoimmune diseases rheumatoid arthritis and coeliac disease (CeD) $(64,65)$. 
In parallel with the emergence of more sophisticated methods for defining $\mathrm{T}$ cell populations and thereby additional $\mathrm{T}$ helper cell subtypes over the last decade, it has become a prevailing opinion in the field that $\mathrm{T}$ cells exhibit plasticity. Under the influence of certain cytokines, $T$ cells have been shown to switch their characteristic cytokine profile and, as a consequence, exhibit different effector functions. Therefore, $\mathrm{T}$ helper cell subtypes should rather be considered as different states of a $\mathrm{T}$ helper cell, than a terminally differentiated phenotypic feature $(62,66)$.

\section{Cytokines}

As described in the previous text, cytokines play an important role in defining and tuning the T cell subtype. In the following section, I will give a short overview over cytokine signalling in general and cytokines that play a role in $\mathrm{CeD}$ pathogenesis in particular.

A common cytokine signalling mechanism used by many cytokines, among them IL2, IL-4, IL-6, IL-7, IL-10, IL-12, IL-13, IL-15 and the interferons, starts with dimerization of receptor chains upon ligand binding. Then, different types of receptorassociated Janus family tyrosine kinases (Jak) are activated, phosphorylate the receptor chains and allow the recruitment and activation of other kinases and transcription factors, e.g. those of the signal transducer and activator of transcription (Stat) family. These proteins are then rapidly translocated to the nucleus and stimulate target gene transcription. Several cytokines utilize a common $\gamma$ chain (CD132) in their receptor: IL-2, IL-4, IL-7, IL-9, IL-13, IL-15 and IL-21. These cytokines initiate lymphocyte activation and differentiation, and also reflect some redundant biological function possessing a common receptor subunit $(59,67)$.

IL-2 is secreted by T cells following antigenic or mitogenic stimulation, which leads to clonal expansion. IL-2 is therefore commonly regarded as an auto- and paracrine T cell growth factor, but has also effects on many other cell types, such as B cells, NK cells, macrophages and neutrophils $(59,67)$. Recent evidence has also added one 
important aspect of IL-2 to its long-known functions: the maintenance of regulatory T cells (68), which are responsible for the maintenance of immunologic tolerance. IL-2 can be detected in plasma samples from treated CeD patients as fast as four hours after intake of gluten $(38,69)$. This indicates that gluten-specific $\mathrm{CD}^{+} \mathrm{T}$ cells are rapidly reactivated by antigen-exposure (38). In addition, a systemic cytokine release cannot be detected in individuals with self-reported gluten sensitivity (69) and is thereby a means to differentiate $\mathrm{CeD}$ from gluten sensitivity.

IL-15 shares biological activities with IL-2, as it stimulates NK cells, B cells and activated $\mathrm{T}$ cells. It is produced by activated monocytes and epithelial cells and a variety of tissues. Functional similarities between IL-2 and IL-15 can partially be attributed to receptor subunit sharing. However, IL-2 and IL-15 have been shown to control different aspects of primary T-cell expansion: While IL-15 is critical for initiating $\mathrm{T}$ cell division, IL-2 can limit T cell expansion by reduction of $\gamma$ chain expression and increasing susceptibility to apoptosis (59). Another similarity of IL-15 with IL-2 is its association with CeD: IL-15 has been shown to be a central cytokine in the coeliac lesion of the small intestine (11).

IL-21 is mainly secreted by $T_{h} 17$ and follicular helper $T$ cells. $T_{h} 17$ cells have been connected induction of autoimmunity, and play a role in the clearance of specific types of pathogens that require a massive inflammatory response and are not adequately dealt with by other $\mathrm{CD} 4^{+} \mathrm{T}$ cells (70). IL-21 secreted by follicular helper $\mathrm{T}$ cells is important for the differentiation and function of plasma and memory B cells $(67,71)$. IL-21 has also been shown to be a key cytokine for IELs (72). Both plasma cells and IELs are numerically increased in the coeliac lesion of the small intestine $(73,74)$. In addition, RNA sequencing analysis has recently demonstrated that IL-21, among other markers and cytokines, is transcribed in gluten-specific $\mathrm{T}$ cells from coeliac lesions. A similar phenotype including IL-21 has also been reported in rheumatoid arthritis (64). 
IFN- $\boldsymbol{\gamma}$ is another important cytokine secreted by activated T cells (and NK cells), which is also known as immune interferon or type II interferon. Originally, IFN- $\gamma$ was identified as an antiviral agent has many biological functions: It can stimulate macrophages and increase antigen processing and expression of $\mathrm{MHC}$ molecules among others. As mentioned above, IFN- $\gamma$ secretion is a characteristic feature of proinflammatory $T_{h} 1$ cells, whose response is associated with cell-mediated immunity, mostly effectively to intracellular pathogens $(59,75)$.

IFN- $\gamma$ secretion has been used in Enzyme Linked Immuno-Spot (ELISpot) assays as an alternative read-out to antigen-specific cell staining with tetramers (see below) for gluten-specific T cells $(35,37,76,77)$.

\section{Memory T cells and tissue-homing - further cell surface markers}

The activation of the CD3-TCR complex together with co-stimulatory molecules and cytokines induces downstream signalling pathways, which lead to proliferation of naïve cells and differentiation to distinct types of effector $\mathrm{T}$ cells like regulatory $\mathrm{T}$ cells, T helper cells and cytotoxic T cells. Only a small subset of antigen-experienced $\mathrm{T}$ cells differentiates into memory $\mathrm{T}$ cells in response to antigen encounter. These memory $\mathrm{T}$ cells carry out the main function of the adaptive immunity, as they remember and efficiently respond to reinfection with the antigen (1-3). In order to differentiate naïve from effector/memory $\mathrm{T}$ cells, a variety of cell surface molecules can be used for further classification of T cells: While naïve T cells express the full-length form of CD45, known as CD45RA, on their surface, antigenexperienced memory $\mathrm{T}$ cells express the shorter form CD45RO. Both isoforms of CD45 are involved in TCR signalling (78-80). Memory T cells are further subdivided into three functional subsets, central memory $\mathrm{T}$ cells $\left(\mathrm{T}_{\mathrm{CM}}\right)$, effector memory $\mathrm{T}$ cells $\left(\mathrm{T}_{\mathrm{EM}}\right)(81)$ and the recently identified resident memory $\mathrm{T}$ cells ( $\left.\mathrm{T}_{\mathrm{RM}}\right)(82)$. In contrast to $\mathrm{T}_{\mathrm{CM}}$ and $\mathrm{T}_{\mathrm{EM}}$ cells, $\mathrm{T}_{\mathrm{RM}}$ cells are not present within peripheral blood. They provide immediate response to antigen, because they occupy frontline sites of infection, like mucosal sites and other body surfaces (82).

$\mathrm{T}_{\mathrm{CM}}$ cells, on the other hand, have a high proliferative capacity, but limited effector function compared to $\mathrm{T}_{\mathrm{EM}}$ cells, which possess immediate effector functions. $\mathrm{T}_{\mathrm{CM}}$ cells 
express the lymph node homing receptors C-C chemokine receptor type (CCR) 7 and CD62 ligand (CD62L) allowing them to circulate between peripheral blood and secondary lymphoid organs. $\mathrm{T}_{\mathrm{EM}}$ cells lack both CCR7 and CD62L (81), but express homing receptors to migrate to the effector sites in peripheral tissues where the APCs were primed. For example, cutaneous lymphocyte-associated antigen (CLA) gives $\mathrm{T}_{\mathrm{EM}}$ cells access to the skin (83) or cell surface expression of integrin $\alpha_{4} \beta_{7}$ grants access to the gut (84).

In the present work, several of the described cell surface markers in combination with information about the expression profile of messenger-RNA (mRNA) from T cells, the transcriptome, and cytokine measurements were used to study gluten peptidespecific $\mathrm{CD}^{+} \mathrm{T}_{\mathrm{EM}}$ cells from blood in the setting of CeD.

\subsection{Coeliac disease from an immunological point of view}

\section{HLA association}

In $\mathrm{CeD}$, a strong association with HLA-DQ2 and HLA-DQ8 is observed, a gene complex encoding the MHC proteins in humans and in the case of 'DQ' corresponding to certain variants of the MHC class II. The MHC locus accounts for around $35 \%$ of the genetic variance in the disease (85). The prevalence of $\mathrm{CeD}$ follows a combination of the distribution of HLA variants associated with the disease and the amount of wheat consumption (86). Almost all CeD patients express a variant of HLA-DQ2.5 (DQA1*05, DQB1*02), HLA-DQ8 (DQA1*03, DQB1*03:02) or HLA-DQ2.2 $(D Q A 1 * 02: 01, D Q B 1 * 02: 02)(12,28-30)$. Interestingly, there is also a gene dosage effect of the HLA-DQ allotypes with homozygosity resulting in an increased risk of $\mathrm{CeD}(28,87)$.

The strong association of HLA-DQ2 and HLA-DQ8 with CeD can be explained by the HLA-complexes' preference to present negatively charged peptides, such as deamidated gluten, to T cells (88): The foreign antigens gluten and gluten-like proteins are post-translationally modified by TG2 by a process called deamidation (89). TG2 is one enzyme of a family containing seven additional $\mathrm{Ca}^{2+}$-dependent enzymes that post-translationally modify specific glutaminyl side-chains in proteins by deamidation, transamidation or esterification (90). TG2 is the main autoantigen in 
CeD. Patients display (auto-) antibodies against both gluten, deamidated gluten peptide (DGP) and TG2.

\section{Gluten-specific T cells}

Gluten-specific $\mathrm{CD}^{+} \mathrm{T}$ cells, the key players in $\mathrm{CeD}$ pathogenesis $(11,91)$, get activated when gluten peptides are presented to them via HLA-DQ2 or HLA-DQ8. Gluten-specific $\mathrm{CD}^{+} \mathrm{T}$ cells are only present in the intestine of CeD patients, but not in healthy individuals $(92,93)$. In blood however, low levels of gluten-reactive T cells can also be detected in healthy individuals (94) indicating an important role of immunotolerance in the healthy state. Gluten-specific $\mathrm{CD} 4^{+} \mathrm{T}$ cells in blood display mostly an effector memory phenotype $(37,95)$ and express the gut-homing molecule $\beta 7$ integrin (37) and the surface marker CD38 $(36,40,96,97)$. In our work, we used those previously described cell surface markers to determine the $\mathrm{T}$ cell subsets of interest by flow cytometry.

Gluten-specific $\mathrm{CD}^{+} \mathrm{T}$ cells from both blood and gut produce the pro-inflammatory cytokines IFN- $\gamma$ and IL-21 (98-100). In CeD, IFN- $\gamma$ promotes the death of intestinal epithelial cells (101), while IL-21 seems to be involved in the cross-talk between epithelial and T cells in the gut (102). Another cytokine upregulated both in the lamina propria and the epithelium of the small intestine is IL-15, which has been described as a hallmark cytokine of $\mathrm{CeD}$ : By affecting distinct cell types in the small intestine, IL-15 contributes to CeD pathogenesis (11). Finally, IL-2, which shares the common $\gamma$ chain with IL-15 and IL-21, has been described to increase in blood plasma only a few hours after initiation of gluten challenge. It correlates with symptoms in response to gluten intake and can be used to distinguish $\mathrm{CeD}$ from non-coeliac gluten sensitivity $(38,69)$.

\section{Other cells of the adaptive immune system}

Despite the crucial role of $\mathrm{CD}^{+} \mathrm{T}$ cells in $\mathrm{CeD}$, the importance of $\mathrm{B}$ cells or plasma cells (103-108) and both $\mathrm{CD}^{+} \alpha \beta$ and $\gamma \delta \mathrm{T}$ cells has emerged over the last years: Interestingly, recent evidence has opened up for the concept of B cell help in the form that B cells act as APCs, which help to activate $C D 4^{+} T$ cells $(104,109)$. Regarding $T$ 
cells, Han et al. showed in a publication that $\mathrm{CD} 8^{+} \alpha \beta$ and $\gamma \delta \mathrm{T}$ cells in blood respond to a gluten challenge by an increase in cell numbers (34); a finding, which was confirmed by another group (110). However, these results are still part of an ongoing debate on the specificity of $\mathrm{CD} 8^{+} \mathrm{T}$ cells in $\mathrm{CeD}$ (111). Reports on gluten-specific $\mathrm{CD}^{+} \mathrm{T}$ cells are scarce and all experiments performed in artificial in vitro conditions $(112,113)$. Another critical aspect of reports on $\mathrm{CD} 8^{+} \alpha \beta$ and $\gamma \delta \mathrm{T}$ cells in response to gluten challenge is that the participants in both the US-American and the Spanish study do not appear as well-treated as Scandinavian participants $(114,115)$. This fact may result in diverging findings. Nonetheless, the role of $\mathrm{CD}^{+} \alpha \beta$ and $\gamma \delta \mathrm{T}$ cells in the pathogenesis of $\mathrm{CeD}$ is undoubted, as both types of $\mathrm{CD}^{+} \mathrm{T}$ cells are increased in the inflamed mucosal tissue of the small intestine in untreated CeD (UCD) and CD4 ${ }^{+}$ $\mathrm{T}$ cells alone are not sufficient for tissue destruction in $\operatorname{CeD}(74,111)$.

As mentioned previously, immunotolerance to gluten appears to be an important factor to maintain the healthy state. In this context, the role of regulatory $\mathrm{T}$ cells in the homeostasis and inhibition of pathogenic responses to dietary gluten appears to be very relevant: In small intestinal biopsies from $\mathrm{CeD}$ patients, studies showed an increased expression of the regulatory $\mathrm{T}$ cell marker Foxp3 and increased numbers of $\mathrm{CD}^{+}$regulatory $\mathrm{T}$ cells compared to control subjects $(116,117)$. In blood and biopsies of healthy individuals however, tetramer-binding $\mathrm{CD}^{+} \mathrm{T}$ cells did not display a regulatory $\mathrm{T}$ cell phenotype (118). Another study indeed revealed large numbers of gluten-specific regulatory $\mathrm{T}$ cells exhibiting impaired suppressive function in blood samples from CeD patients after gluten challenge (119). The authors hypothesised that the intrinsic dysfunction of those gluten-specific regular T cells might contribute to the loss of tolerance to gluten (119). Taken together, studies of regulatory $\mathrm{T}$ cells in $\mathrm{CeD}$ have so far unveiled inconsistent results and further studies are needed to clarify their role in CeD pathogenesis (120).

In summary, the pathogenesis of $\mathrm{CeD}$ is driven by deamidated gluten proteins and the catalysing enzyme TG2, which are the (auto-) antigens inducing T- and B-cell activation and subsequent production of (auto-) antibodies. Cytokine-induced 
attraction and activation of intraepithelial lymphocytes presumably lead to the killing of intestinal epithelial cells by $\mathrm{CD} 8^{+} \mathrm{T}$ cells resulting in villous atrophy and a symptomatic disease state (see also figure 1).

\section{Unmet needs}

The most important immunological question still unresolved in regard to $\mathrm{CeD}$ is to understand the discrepancy of $40 \%$ of the European population carrying the risk genes encoding HLA-DQ2 or -DQ8, but less than one tenth of them develop the disease. On the one hand, genome-wide association studies have identified 42 loci in addition to the HLA locus that contribute to CeD development (31). The non-HLA loci account for $\sim 15 \%$ additional disease risk, are mostly common SNPs associated to other autoimmune disorders and localized in the non-coding genome, suggesting that they exert an effect by regulation of gene expression (31). A recent publication on a transgenic mouse model of $\mathrm{CeD}$ in combination with analysis of human sera suggests a role for infection with reovirus in triggering the development of the disease (121). Human studies however indicate a correlation of infection with enterovirus in early childhood in combination with gluten exposure as a risk factor for $\mathrm{CeD}(122,123)$. Together, both certain genetic traits as well as environmental factors are likely to contribute to the development of CeD. Further knowledge about those factors in addition to new and nuanced insights into the immune system will help to understand the development of $\mathrm{CeD}$ and maybe even initiate prevention of the disease. So, despite increasing knowledge about the role of $\mathrm{B}$ and $\mathrm{T}$ cells in $\mathrm{CeD}$, it is still not clear why we may lose tolerance to gluten.

Another important goal is to simplify the diagnosis of $\mathrm{CeD}$. The correct validation of biopsies is challenging (124) and biopsy sampling by esophagogastroduodenoscopy is resource consuming and a burden for patients. However, many experts still insist on a biopsy-based diagnosis, which is reflected in the current guidelines of several gastroenterological societies (125). A diagnosis based on serology is an attractive, but so far only partly achieved goal: In children with high antibody titers, biopsy sampling can be omitted (27). In all other patients including adults, a biopsy-based diagnosis is 
still the gold standard of a diagnostic work-up $(27,126)$, which is agreed on by many experts. Serological tests have nonetheless improved over the recent years and may serve as a future alternative to today's diagnostic algorithm (127). Albeit, this view is still strongly debated in the field.

In addition to standard serological tests, a blood test based on gluten tetramers, a useful tool to study antigen-specific T cells, which will be described in further detail in the methods section of this work, achieve excellent results distinguishing patients from controls and reliably diagnosing $\mathrm{CeD}(40,96,128)$. In this context, it has been shown that gluten-specific T cells can be detected using HLA-DQ:gluten tetramers both with and without gluten challenge $(37,95,96)$. Tetramer staining can also be used to distinguish $\mathrm{CeD}$ patients from patients with non-coeliac gluten sensitivity (35). Finally, the tetramer test was more accurate in identifying $\mathrm{CeD}$ patients than biopsy after a gluten challenge over 14 days (40). So, a tetramer test in blood offers a promising future alternative to standard diagnostic approaches. The availability of more sensitive (blood) tests might also open up for a shortened necessary time period of gluten challenge (33) as increasing evidence suggests that gluten challenge for three days is sufficient for coeliac patients to exhibit a gluten-specific $\mathrm{T}$ cell response in peripheral blood (34-37), which can be measured with an interferon- $\gamma$ release assay (ELISpot) (77), IL-2 assay $(38,69)$ or a tetramer test $(40,95,96)$.

Not only for diagnostics, but also in the setting of clinical trials, better outcome marker is needed to objectify treatment success. The correlation between the so far recommended measures (129), namely patient-reported symptoms, histology and serology is poor (130) and they show a clear time lag (33). In consequence, a fast and robust marker for immune activation after gluten exposure would facilitate the assessment of treatment success in clinical trials. Those trials testing new treatment options are highly demanded as many CeD patients struggle with a GFD. Although compliance to a strict GFD is the key to recovery, it may have a substantial impact on patient functioning and their quality of life (131). Many patients request therefore treatment alternatives to a GFD and several new approaches already exist reaching 
from targeting gluten itself to targeting molecules involved in the pathogenesis of $\mathrm{CeD}$. However, only one of them has reached phase III trials so far (ClinicalTrials.gov Identifier: NCT03569007). Of all possible new treatment options, only Nexvax $2^{\circledR}$ has so far aimed at gluten-specific $\mathrm{T}$ cells, which are crucial for disease development (11, 91). The clinical phase II study of Nexvax $2^{\circledR}$ was however discontinued due to a lack of protection from gluten exposure compared to a placebo (ClinicalTrials.gov Identifier: NCT03644069). Further studies on gluten-specific T cells will offer a better understanding of $\mathrm{CeD}$ pathogenesis, as well as additional treatment options. 


\section{AIMS OF THE THESIS}

The principle aim of this thesis was to characterise gluten-specific $\mathrm{T}$ cells in regards to their kinetics and their transcriptomic profile in the blood after activation by gluten challenge.

More specifically the aims were:

- To study the kinetic profile of gluten-specific $\mathrm{CD} 4^{+} \mathrm{T}$ cells in response to gluten challenge over one and three days and

- To test immunological markers for their potential as surrogate markers for outcome measurements in clinical trials

- To study the phenotype of gluten-specific $\mathrm{CD}^{+} \mathrm{T}$ cells from blood using RNA sequencing and subsequently mass spectrometry, based on the results generated from transcriptome analysis

- To study the kinetic profile and pathogenic relevance of CD8 ${ }^{+} \alpha \beta$ and $\gamma \delta \mathrm{T}$ cells in blood in response to gluten challenge 


\section{SUMMARY OF PAPERS}

\section{Paper I}

We studied HLA-DQ:gluten tetramer-specific $\mathrm{CD} 4^{+} \mathrm{T}$ cells on several time points in blood from $\mathrm{CeD}$ patients after gluten challenge for one or three days.

We found that all participants increased their numbers of gut-homing HLA-DQ:gluten tetramer-positive, effector/memory $\mathrm{CD} 4^{+} \mathrm{T}$ cells (tetramer ${ }^{+} \beta 7^{+} \mathrm{T}_{\mathrm{EM}}$ ) both after challenge over three days and after one single dose of gluten, although the increase was less pronounced in the latter and tetramer ${ }^{+} \beta 7^{+} \mathrm{T}_{\mathrm{EM}}$ cell numbers revealed a typical large inter-individual range. Tetramer ${ }^{+} \beta 7^{+} \mathrm{T}_{\mathrm{EM}}$ cell numbers after three-day gluten challenge were plateauing between days $6-8$. We concluded that this interval is optimal to draw blood samples and study gluten-specific $\mathrm{T}$ cells from blood.

Measurement of IL-2, an auto- and paracrine growth factor on T cells (132) which has been shown to be elevated in blood plasma after ingestion of gluten (133), revealed a significant response to gluten challenge. We did not observe any significant correlation of IL-2 concentration measured four hours after the first dose of gluten in plasma with the number of gluten-specific $\mathrm{T}$ cells, but the number of individuals was limited.

Assessment of the percentage of $\mathrm{CD} 38^{+}$cells among gluten-specific $\mathrm{T}$ cells, however, revealed a uniform increase in all participants. Although one-day challenge induced a less pronounced increase of tetramer ${ }^{+} \beta 7^{+} \mathrm{T}_{\mathrm{EM}}$ cells than 3-day challenge, the surface marker $\mathrm{CD} 38$, which has been observed on $\mathrm{CD}^{+} \mathrm{T}$ cells in the context of $\mathrm{UCD}$ and gluten challenge before $(36,40)$, increased promptly and did not significantly differ between one- and three-day challenges. This finding makes CD38 an attractive surrogate marker for e.g. assessing drug efficacy after gluten challenge in a clinical trial. The assessment of CD38 should be performed on day 8 rather than day 6 after the onset of gluten challenge, since we observed a further increase of CD38 expression after day 6 in individuals with a weaker response.

Taken together, CD38 expression on gluten-specific T cells increased in all participants in a robust manner in contrast to tetramer ${ }^{+} \beta 7^{+} \mathrm{T}_{\mathrm{EM}}$ cells numbers and IL2 in plasma and stands out as a possible alternative to contemporary outcome measures for clinical trials. 


\section{Paper II}

We acquired RNA-seq data from gut-homing, HLA-DQ:gluten tetramers-specific $\mathrm{CD}^{+} \mathrm{T}$ cells in blood six days after onset of a gluten challenge over three days. Despite sparse clinical symptoms, we observed a clear increase in gut-homing glutenspecific effector-memory $\mathrm{T}$ cells on day six. The transcriptome analysis revealed over 3000 differentially expressed protein-coding genes, among them 94 genes coding for cell surface markers.

We selected some immunologically relevant markers available for mass cytometry staining, which were then used in a staining panel to test for correlation of mRNA levels and protein expression on the cell surface. Transcription and protein expression levels correlated well, with few exceptions for the cell surface markers CD47, CD52, CD103 and CD314 (NKG2D). Dimension reduction and visualisation of the data acquired by mass spectrometry using both UMAP and t-SNE, we found that glutenspecific $T$ cells from blood on day 6 form distinct clusters in both visualisation approaches. The observation of distinct clustering is in line with a publication by Christophersen et al. (65). Importantly, with our modified mass cytometry staining panel based on RNA sequencing, we find a similar clustering pattern.

Based on cell surface marker expression, we also confirmed a relevant phenotypical overlap of gluten-specific $\mathrm{T}$ cells from blood induced by gluten challenge with glutenspecific $\mathrm{T}$ cells in the small intestine (65) resembling most likely a peripheral $\mathrm{T}$ helper cell subset $(64,65)$. The phenotypical similarity of gluten-specific $\mathrm{T}$ cells in blood and gut together with the formation of distinct clusters lets us assume that gluten-specific $\mathrm{T}$ cells induced by antigen re-exposure are a valid estimate of an increased number of gluten-specific $\mathrm{T}$ cells in the lamina propria of the small intestine. Gluten-specific $\mathrm{CD}^{+} \mathrm{T}$ cells may therefore serve as an immunological read-out for clinical drug trials. 


\section{Paper III}

In this study, we tested the hypothesis that not only $\mathrm{CD}^{+} \mathrm{T}$ cells, but also $\mathrm{CD}^{+} \alpha \beta$ and $\gamma \delta$ T cells show a response to gluten challenge and specificity to gluten epitopes, an observation first made by Han and colleagues (34). In order to confirm this observation and to understand the T cells' pathogenic involvement in $\mathrm{CeD}, \mathrm{CD}^{+} \alpha \beta$ and $\gamma \delta \mathrm{T}$ cells in blood and IELs of coeliac gut lesions were compared in regard to numbers and clonal relationship before and after different types of gluten challenge. We found that of 20 gluten-challenged CeD patients, around half of them increased in $\left(\mathrm{CD} 38^{+} \mathrm{CD} 103^{+}\right) \gamma \delta$ and $\mathrm{CD}^{+} \alpha \beta \mathrm{T}$ cell numbers, respectively, while the majority surged in gluten-specific $\mathrm{CD}^{+} \mathrm{T}$ cells. In addition, an enhanced frequency of guthoming, activated $\gamma \delta$ and $\mathrm{CD}^{+} \alpha \beta$ T cells in blood corresponded with increased density of IELs after gluten re-exposure.

Comparing different types of gluten challenge, the frequency of gut-homing, activated $\gamma \delta$ and $\mathrm{CD}^{+} \alpha \beta$ T cells in blood on day 6 appeared to be overall lower in the cookie challenge over three days and the muesli bar challenge over 14 days compared to the response after a three-day long bread challenge. The intake of only two slices of bread in participant CD431, who terminated the challenge due to acute gastrointestinal symptoms, induced a robust $\mathrm{T}$ cell response.

From five patients, paired $\gamma \delta$ and $\alpha \beta$ TCR sequences of over 2500 single cells from blood and gut were obtained before and during gluten challenge. Interestingly, sharing between blood and gut $\gamma \delta$ and $\mathrm{CD}^{+} \alpha \beta$ T-cell clonotypes already before onset of gluten challenge was observed. In subjects with a challenge-induced rise in $\gamma \delta$ and/or $\mathrm{CD}^{+} \alpha \beta \mathrm{T}$ cell numbers, no increase in clonotype sharing across compartments nor increased presence of expanded clonotypes were noted.

Altogether, this study reveals that there is $\gamma \delta$ and $\mathrm{CD}^{+} \alpha \beta$ clonotype sharing between blood and the small intestine. This sharing is seen prior to gluten consumption. Based on these results, $\mathrm{CD} 4^{+} \mathrm{T}$ cells can drive expansion of diverse $\gamma \delta$ or $\mathrm{CD} 8^{+} \alpha \beta$ T-cell clonotypes speaking against recognition of gluten peptides by these cells. 


\section{METHODOLOGICAL CONSIDERATIONS}

\subsection{Patient samples}

$\mathrm{CeD}$ patients were recruited for gluten-challenge through media announcements and by invitation after ethical approval by the Regional Committee for Medical and Health Research Ethics South-East Norway (identification number 8025, previously termed 2013/1237). The gluten challenge study was registered on Clinicaltrials.gov (NCT02464150). The immunobiological studies were covered by the regional ethics committee accession (identification number 6544, previously termed 2010/2720). We included patients with biopsy-proven $\mathrm{CeD}$ diagnosed according to guidelines (32, 126).

Information relevant to inclusion was obtained by email or telephone and confirmed by medical records after participants had given written informed consent. Clinical report forms were filled out for each contact with the participants. Self-administered patient-reported outcomes were registered.

Samples were obtained at the Endoscopy Unit, Department of Gastroenterology, Oslo University Hospital - Rikshospitalet. All blood samples were taken by trained staff and analysed either freshly or stored at the Department of Immunology, Oslo University Hospital - Rikshospitalet.

We obtained citrated full blood and serum from treated $\mathrm{CeD}$ patients before, during and after gluten-challenge. Peripheral blood mononuclear cells (PBMCs) were isolated from blood using mononuclear cell preparation tubes containing sodiumcitrate (BD Vacutainer ${ }^{\circledR}$ CPT ${ }^{\mathrm{TM}}$ Mononuclear Cell Preparation Tubes), which had newly been introduced to our laboratory routines after thorough testing in regards of cell yield and survival and which allowed a comparably fast and easy isolation of PBMCs (134).

The PBMCs were processed immediately after isolation; either directly for further analysis in the case of subsequent RNA-sequencing or the cells were frozen, kept in a nitrogen tank at $-160{ }^{\circ} \mathrm{C}$ and thawed at the day of experiment. The processing procedures followed published recommendations on isolation and preservation of PBMCs for analysis of antigen-reactive $\mathrm{T}$ cell responses (135). Immediate processing 
of cells has the advantage that few biasing factors like cellular stress by freeze/thaw cycles are introduced, but immediate cell processing represents a hinder for complex study designs. Reassuringly, a recent study indicated that freezing of cells or tissue does not alter transcriptional profiles (136). This might help to establish new RNAsequencing routines in future, broadening future study designs and the scope of applications in (single-cell) transcriptomics. Analysing previously frozen samples in parts of this work namely allowed me to collect several samples and clinical information about participants before collective analysis. The latter might be important to prevent batch effects and to secure a homogeneous participant population meeting all the inclusion criteria set before the study start. Considering the HLA-type of participants is also a crucial element of working with tetramers, which are described below. The HLA-typing at our facility can take several weeks, so in the present setting, being able to work with frozen samples is a clear advantage.

\subsection{Gluten challenge}

The only treatment for CeD today is a life-long GFD, which results in symptom regress, normalisation of the gut mucosa architecture as well as disease-specific antibody levels. With reintroduction of gluten in the diet however, the mucosal changes reappear and the active disease state is re-established (137). This makes gluten challenge in treated CeD patients an attractive model to study the disease mechanism. In this thesis, all participants were challenged with a newly developed cookie based on gluten-enriched flower, without other allergens like nuts and with a low content of fermentable oligo-, di- and monosaccharides and polyols (FODMAP) (138).

We mainly used gluten-containing cookies, but also the more common bread challenge. Cookies were our first choice for several reasons: Gluten content in bread can vary substantially even when comparing the same brand (115), which we observed to a lesser degree in the present bread challenge (data not shown). Using gluten-enriched cookies, we had a standardized amount of gluten in each cookie helping to compare results. In addition, by using gluten-enriched flour, we were able to reduce the amount of food to be challenged with from several slices of bread to 
only one single cookie per day. One disadvantage with using cookies might be, though that they are not freely available and were exclusively produced for this thesis.

Compared to gluten challenge with bread, the amount of gluten in the cookies is quite condense. This might possibly result in reduced digestion and uptake of gluten and finally a lower $\mathrm{T}$ cell response to gluten challenge.

Gluten challenge with cookies lasted for either three days or only one day and consisted of one single dose of approximately $8 \mathrm{~g}$ of gluten every day, while four slices of bread contained around $10 \mathrm{~g}$ of gluten daily given for three days.

The $\mathrm{T}$ cell kinetics in blood in response to three-day gluten challenge was studied taking blood samples at baseline (before gluten challenge), on day 1 and day 4 - 8 after onset of challenge (figure 3a). Based on the kinetics studied in paper I and in line with previous studies $(37,77)$, the $\mathrm{T}$ cell responses after one- and three-day challenge for transcriptome analysis and for studying the impact of the challenge type on the magnitude of T-cell response were measured on day 6 after onset of challenge (figure $3 b$ and $c)$.

a

Consent
GSRS questionnaire
Blood sample


b

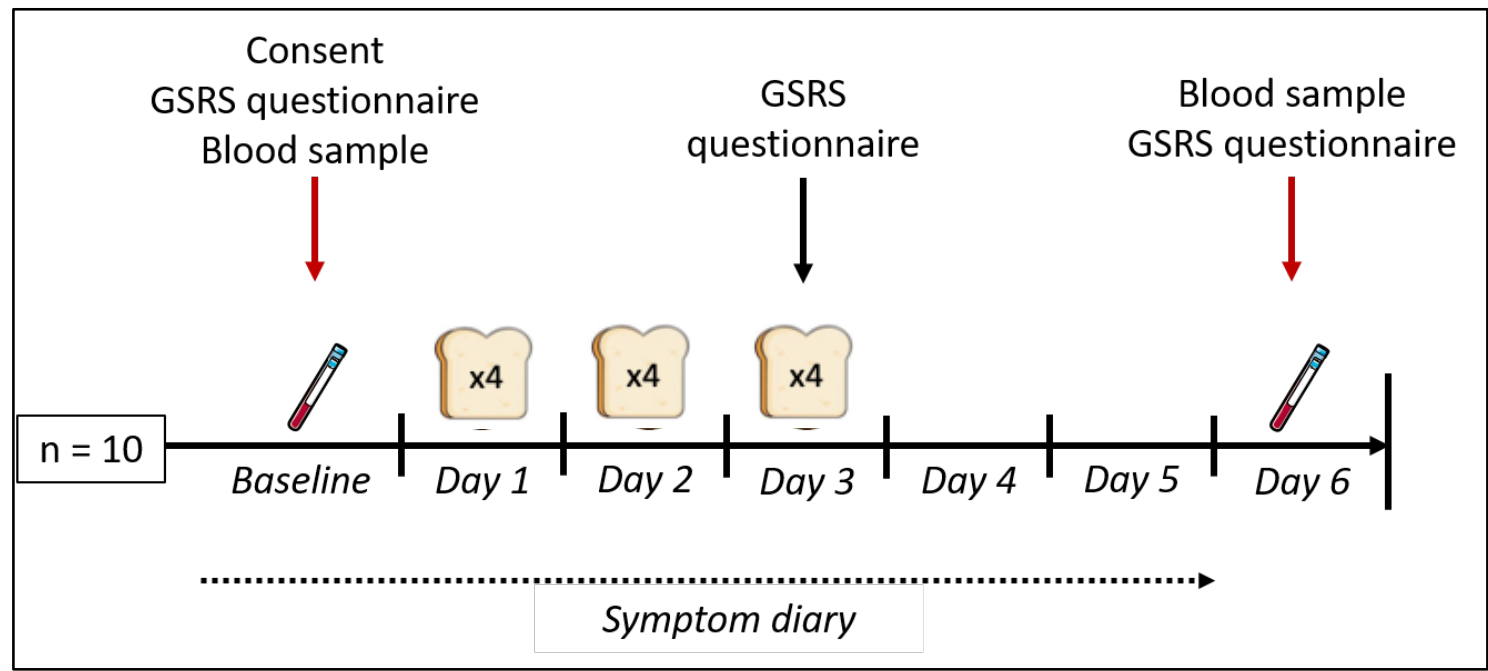

c

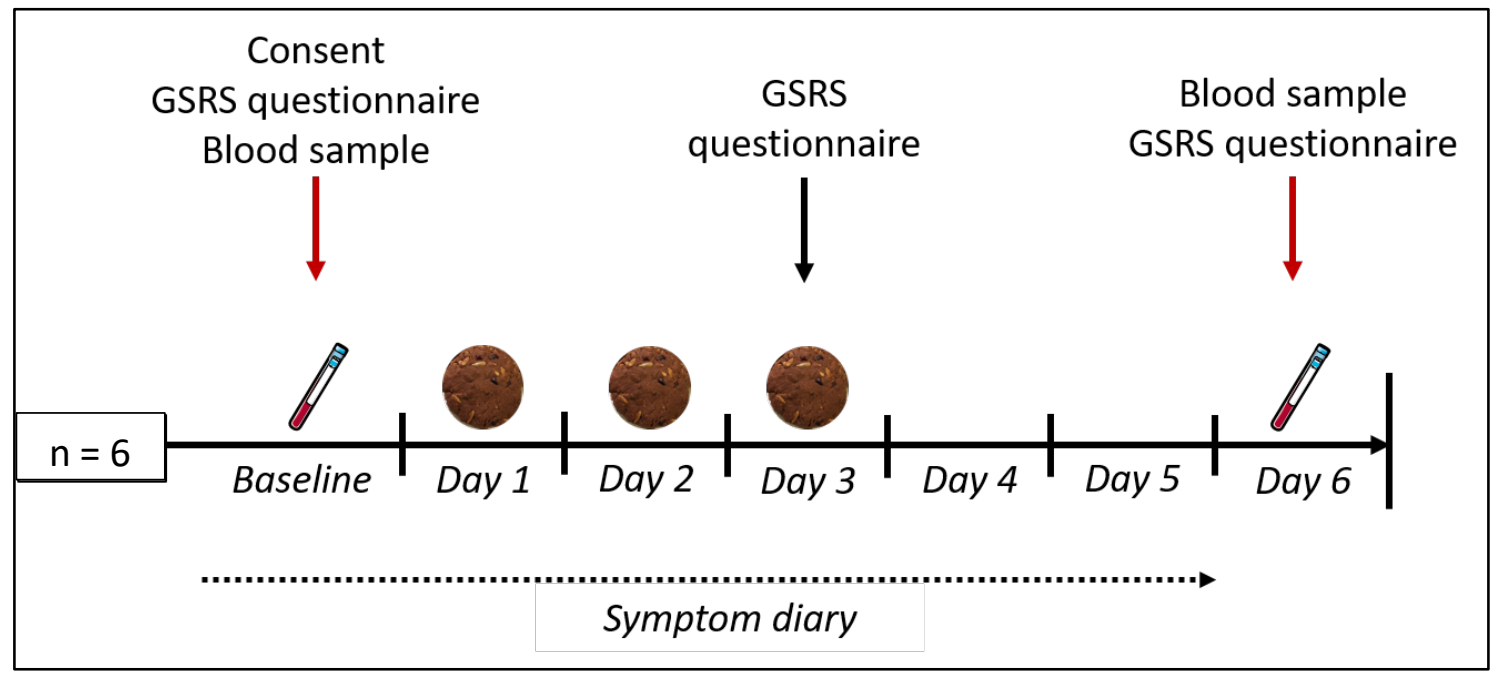

Figure 3. Study timelines of the three- and one-day challenge to study T cell kinetics (a), the three-day challenge to study the transcriptomic profile and $\mathrm{T}$ cell phenotype (b) and the threeday bread challenge to study the impact of the challenge type on T-cell responses (c)

\subsection{HLA-DQ:gluten tetramers and cell enrichment}

In all sub-projects of this thesis, the samples were enriched for gluten-specific $\mathrm{T}$ cells using HLA-DQ:gluten tetramers (figure 4). Tetramers are multimerised peptide-HLA molecules that often consist of more than exactly four attached molecules (139).

Tetramers are a critical tool to identify and isolate cells with high specificity. Yet, the generation of tetramers is laborious and the production of HLA-DQ2 tetramers is complicated by chemical instabilities of the $\alpha$ - and $\beta$-chain (139). Recombinant gluten peptide:HLA-DQ2.5 molecules are produced with peptide being covalently tethered to 
the $\beta$-chain due to stability issues, so new peptide:HLA-DQ2.5 constructs must be prepared for each new gluten peptide of interest.

In this work, PBMCs were stained with HLA-DQ2.5:gluten-tetramers representing a mix of the five gluten epitopes DQ2.5-glia- $\alpha 1$ a (QLQPFPQPELPY), DQ2.5-glia- $\alpha 2$ (PQPELPYPQPQL), DQ2.5-glia- $\omega 1$ (PQQPFPQPEQPFP), DQ2.5-glia- $\omega 2$ (FPQPEQPFPWQP) and DQ2.5-hor3 (PIPEQPQPYPQ) using a protocol described earlier (95): A concentration of $10 \mu \mathrm{g} / \mathrm{ml}$ of biotinylated, soluble tetramer complexed with a streptavidin, R-phycoerythrin (SA-PE) conjugate was used for each sample.

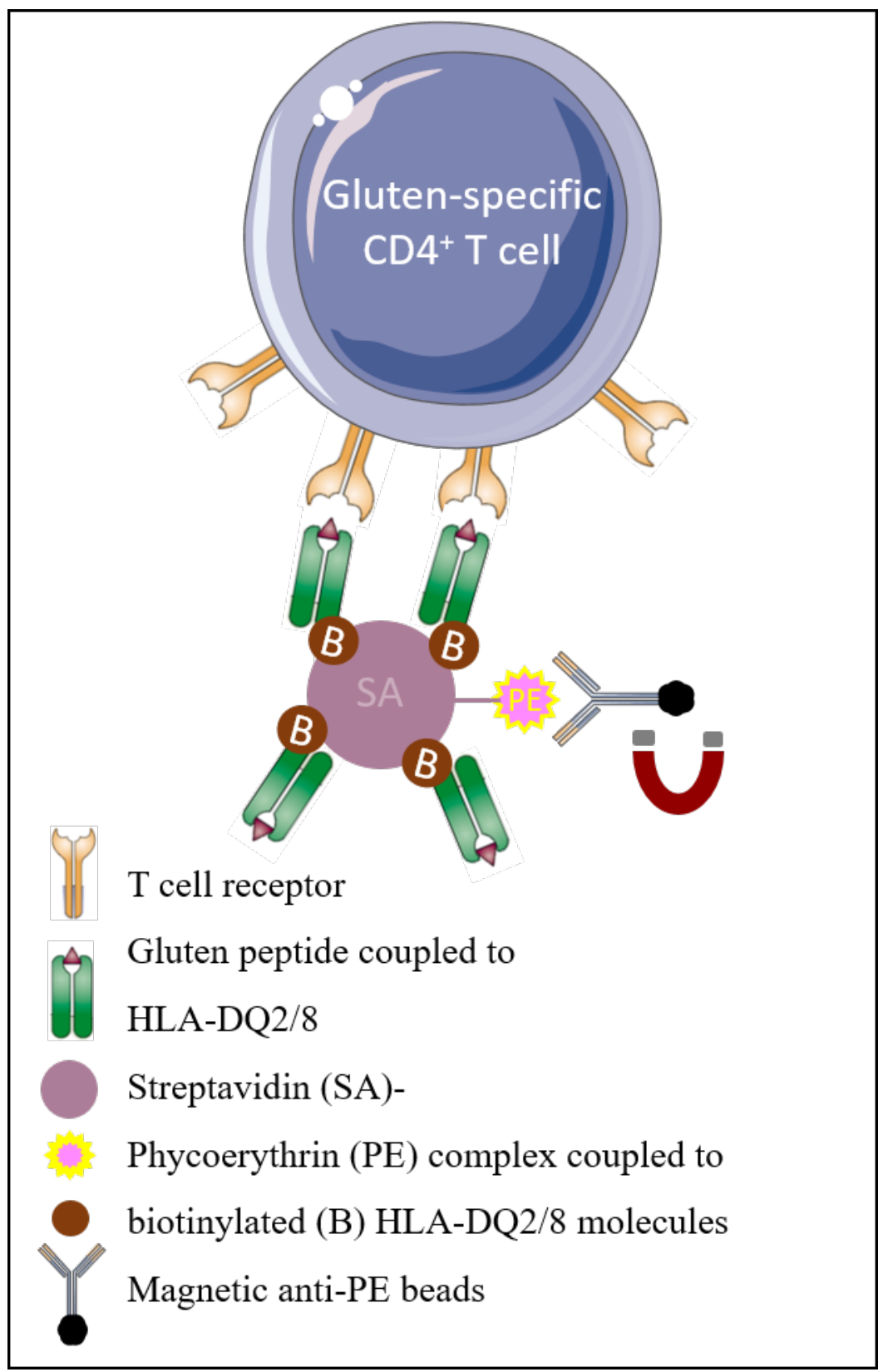

Figure 4. Schematic illustration of a gluten peptide:HLA-DQ2 or -DQ8 construct labelled with magnetic beads against the fluorochrome phycoerythrin (PE) for later magnetic cell enrichment. The figure was made using Servier Medical Art (https://smart.servier.com). 
Before staining, the quality of peptide:HLA-DQ tetramers was assessed in several steps: Protein purity was measured by gel purification after affinity purification (generally yielding $>95 \%$ purity). Size exclusion chromatography was used to confirm absence of protein aggregates. After release of the peptide from the HLADQ $\beta$-chain, MALDI-TOF MS was used to verify the presence of the correct gluten peptide in the construct produced. In addition, tetramer staining of $\mathrm{T}$ cell clones of known specificity was performed to validate tetramer specificity.

Enrichment of antigen-specific $\mathrm{CD} 4^{+} \mathrm{T}$ cells from blood is necessary as the cells occur in a low total frequency, while the amount of blood, which can be drawn from humans is limited. Therefore, enrichment with magnetic microbeads offers the opportunity to largely increase the number of cells of interest (140). In the case of CeD, bead enrichment of around a 100-fold is an important step to detect gluten-specific T cells even in patients on a GFD (95). Cell enrichment was either performed manually or in an automated manner as previously described by Moon et al. (140) and Christophersen et al. (95) or Sarna et al. (40), respectively.

Despite the outstanding properties of tetramers in targeted cell detection, there are also some caveats related to their use and the processing of rare, tetramer-stained cells, which will be elaborated on in the following section.

Tetramers can only detect $\mathrm{T}$ cells that are specific to defined epitopes. Although we used tetramers with the most frequently detected epitopes (13), it possible that $\mathrm{T}$ cells specific for other epitopes are overseen.

Further, tetramers can give unspecific binding - a fact, which turned out to be an obstacle when analysing the blood samples to study T cell kinetics. As a result, several steps in the staining process had to be adjusted, for example going back from automatized to manual cell enrichment.

The trouble-shooting process also resulted in a detailed investigation of earlier studies from our group and the reported tetramer ${ }^{+}$cell numbers in comparison to the methods that were used for cell enrichment (table 1). 
We observed that bead enrichment - in parallel with different challenge vehicles seems to negatively influence the tetramer ${ }^{+} \mathrm{T}$ cell number. This effect was further intensified by the use of automated enrichment compared to manual bead enrichment. Christophersen et al. studied samples from treated and untreated CeD patients (TCD and UCD) and the cell numbers of UCD patients should be comparable to challenged patients on a GFD. Despite that, Christophersen et al. report substantially lower cell numbers than the two previous studies. This effect is likely observed due to the switch in the order of tetramer staining and cell enrichment: In the first two studies, T cells were enriched and then stained with tetramers. Afterwards, cells were stained with tetramers first and enriched after that. A further decrease in cell numbers is observed when Sarna et al. go over to automated bead enrichment and reversed to some extent after we went back to manual bead enrichment during the present work. However, a learning curve of sample processing cannot be excluded to have influenced the observed increase in cell numbers.

\begin{tabular}{|c|c|c|c|c|c|c|}
\hline & $\begin{array}{l}\text { Ráki et al. } \\
2007 \text { (37) }\end{array}$ & $\begin{array}{l}\text { Brottveit et } \\
\text { al. } 2011(35)\end{array}$ & $\begin{array}{l}\text { Christophersen } \\
\text { et al. } 2014(95)\end{array}$ & $\begin{array}{l}\text { Sarna et al. } \\
2018(40)\end{array}$ & $\begin{array}{l}\text { Zühlke / Eggesbø } \\
\text { manuscripts }\end{array}$ & $\begin{array}{l}\text { Zühlke et al. } \\
2019(141)\end{array}$ \\
\hline $\begin{array}{l}\text { Challenge } \\
\text { vehicle }\end{array}$ & White bread & White bread & None & Muesli bar & $\begin{array}{l}\text { Cookie / white } \\
\text { bread }\end{array}$ & Cookie \\
\hline $\begin{array}{l}\text { Cell } \\
\text { population } \\
\text { studied }\end{array}$ & $\begin{array}{l}\mathrm{Tet}^{+} / 10^{6} \\
\mathrm{CD}^{+} \text {on } \mathrm{d} 6\end{array}$ & $\begin{array}{l}\mathrm{Tet}^{+} / 10^{6} \\
\mathrm{CD}^{+} \text {on } \mathrm{d} 6\end{array}$ & $\begin{array}{l}\mathrm{Tet}^{+} / 10^{6} \mathrm{CD}^{+} \\
\text {from UCD and } \\
\text { TCD }\end{array}$ & $\begin{array}{l}\text { Tet }^{+} \beta 7^{+} \mathrm{T}_{\mathrm{EM}} / \\
10^{6} \mathrm{CD}^{+} \text {on } \\
\text { d6 after } \\
\text { challenge }\end{array}$ & $\begin{array}{l}\mathrm{Tet}^{+} \beta 7^{+} \mathrm{T}_{\mathrm{EM}} / 10^{6} \\
\mathrm{CD} 4^{+} \text {on } \mathrm{d} 6 \text { after } \\
\text { challenge }\end{array}$ & $\begin{array}{l}\text { Tet }^{+} \beta 7^{+} \mathrm{T}_{\mathrm{EM}} / \\
10^{6} \mathrm{CD}^{+} \text {on } \\
\mathrm{d} 1, \mathrm{~d} 4-8 \text { after } \\
\text { challenge }\end{array}$ \\
\hline $\begin{array}{l}\text { Epitopes } \\
\text { stained for }\end{array}$ & $\alpha 1, \alpha 2$ & $\alpha 1, \alpha 2$ & $\alpha 1, \alpha 2$ & $\begin{array}{l}\alpha 1, \alpha 2, \omega 1, \\
\omega 2\end{array}$ & $\begin{array}{l}\alpha 1, \alpha 2, \omega 1, \omega 2, \\
\text { hor3 }\end{array}$ & $\begin{array}{l}\alpha 1, \alpha 2, \omega 1, \\
\omega 2, \text { hor3 }\end{array}$ \\
\hline $\begin{array}{l}\text { Enrichment } \\
\text { method }\end{array}$ & $\begin{array}{l}\mathrm{CD}^{+} \\
\text {isolation kit }\end{array}$ & $\begin{array}{l}\mathrm{CD}^{+} \\
\text {isolation kit }\end{array}$ & manual & automated & $\begin{array}{l}\text { automated / } \\
\text { manual }\end{array}$ & manual \\
\hline $\begin{array}{l}\mathrm{Tet}^{+} \mathrm{T} \text { cell } \\
\text { numbers }\end{array}$ & $\begin{array}{l}\text { 200-1000/ } \\
\text { epitope }\end{array}$ & $\begin{array}{l}100-9000 / \\
\text { epitope }\end{array}$ & $\begin{array}{l}\text { TCD: } \sim 8 \\
\text { UCD: } \sim 18 \text { for } \\
\text { all epitopes }\end{array}$ & $\begin{array}{l}3-20 \text { for all } \\
\text { epitopes }\end{array}$ & $\begin{array}{l}\text { 4-53 / 15-1500 } \\
\text { for all epitopes } \\
\text { (cookie / bread) }\end{array}$ & $\begin{array}{l}\text { 7-104 for all } \\
\text { epitopes }\end{array}$ \\
\hline Cut-off & $<150$ cells & $<$ ca. 75 cells & $<2$ cells & $\begin{array}{l}\text { no control } \\
\text { individuals }\end{array}$ & $\begin{array}{l}\text { no control } \\
\text { individuals }\end{array}$ & $\begin{array}{l}\text { no control } \\
\text { individuals }\end{array}$ \\
\hline
\end{tabular}

Table 1. Overview of studies on tetramer ${ }^{+}$cells and reported cell numbers 
Overall, there are two likely causes for the reduction in tetramer ${ }^{+} \mathrm{T}$ cell numbers over time. On one hand, the challenge vehicle might play a role and in an ideal scenario, bread, muesli bar and cookie should be tested for their potency to induce a rise in gluten-specific T cells in CeD patients. This could be performed with a cross-overdesigned intervention with long enough wash-out time where individuals serve as their own controls as it was done by Skodje et al. for a gluten vs. FODMAP intervention (142). Indeed, results from the latest bread challenge with six participants did show a significantly change in tetramer ${ }^{+} \mathrm{T}$ cell numbers compared to cookie challenge (see table 1). The amount of gluten in the bread challenge was determined to be only slightly higher in bread challenge (approximately $10 \mathrm{vs.} 8 \mathrm{~g}$ per challenge day; measured using R5 ELISA Ridascreen $\left.{ }^{\circledR}\right)$.

On the other hand, it is likely that the isolation method of tetramer-stained cells also plays an important role for the achieved cell numbers. For a diagnostic blood test as envisaged by Sarna et al. (96), this might not be of essential importance as cell detection, not cell number, is the main goal. However, in a research setting where rare antigen-specific $\mathrm{T}$ cells are studied regarding $\mathrm{T}$ cell receptor sequences, the transcriptome or other biological features, the cell number is crucial to acquire enough material to work with. Therefore, a parallel testing of enrichment methods would be very helpful to find the method with least loss of tetramer positive cells.

In conclusion, we cannot conclude yet which of the challenge vehicles should preferably be used to obtain the highest T-cell responses in blood. Although our latest findings might support bread challenge over the use of other challenge vehicles, the amount of gluten were higher compared to muesli bar-and cookie challenge. Additionally, the groups of participants were rather small and we did not use a crossover design with the same individuals. We can however conclude that manual enrichment of tetramer ${ }^{+} \mathrm{T}$ cells is the preferred method of cell enrichment to obtain the highest tetramer ${ }^{+} \mathrm{T}$ cell numbers for further analysis.

\subsection{Flow cytometry, cell sorting and mass cytometry}

Flow-cytometry was used to identify and sort gut-homing tetramer-binding $\mathrm{CD}^{+} \mathrm{T}_{\mathrm{EM}}$ cells. Using a mixture of fluorochrome-conjugated antibodies, which are specific for 
cell-surface markers, allows the isolation of those tetramer-binding $\mathrm{T}$ cells with the desired phenotype.

Flow cytometry is a very sensitive method valuable for the detection and sorting of rare cell populations such as gluten-specific $\mathrm{T}$ cells. Yet, the method is sensitive to the overlap of both emission spectra from fluorochromes and gating strategies. For this reason, fluorescence compensation was performed and calculated for each experiment. To prevent unspecific binding, I used a dump channel comprising of Pacific Bluelabelled antibodies for CD15, CD11c, CD19 and CD56 together with LIVE/DEAD marker fixable violet stain. Particularly myeloid cells express immunoglobulin (Ig)- $F_{c}$ gamma receptors, which can bind non-specifically to the $F_{c}$ fragment of antibodies and hence give background staining. In a similar way, dead cells also tend to bind monoclonal antibodies non-specifically. This underlines the importance to exclude the dead cells in flow cytometry analysis. To control for possible background noise from unspecific tetramer binding, staining of tetramer binding $\mathrm{CD}^{-} \mathrm{T}$ cells was assessed to set the gates for isolating tetramer-binding $\mathrm{CD}^{+}{ }^{+}$cells.

Fluorescence-activated cell sorting (FACS) was used to isolate gluten-specific T cells in bulk into Eppendorf tubes. However, cell sorting is a vulnerable process and successful sorting requires several crucial steps like drop-delay calibration, accurate adjustment of tube position for sorting and abruptions due to system clogs caused by cell clumps. Downstream sequencing is one way to confirm successful cell sorting. In the transcriptome data presented in this work, we see many expected features of the sorted cells like the expression of classical cell surface and homing markers that are consistent with earlier publications $(65,85,143-147)$ and unpublished results (Wyrożemski et al.).

However, despite the advantages and wide use of flow cytometry for phenotypical studies of single cells, one drawback of flow cytometry is the limited number of parameters and fluorophores that can be detected without significant emission spectra overlap. Here, mass cytometry offers a powerful alternative. Mass cytometry can be described as a fusion of two experimental platforms: flow cytometry and elemental mass spectrometry. For mass cytometry, antibodies are labelled with isotopically 
purified metal conjugates and quantified by a time-of flight mass spectrometer. This allows detection of many more parameters (currently over 40, but theoretically 100 parameters), as elemental mass spectrometry is able to discriminate isotopes of different atomic weights with high accuracy $(148,149)$.

But neither mass cytometry comes without limitations: It is impossible to recover living cells from mass cytometry, as cells first are fixated in the staining process and later atomized and ionized in the process of analysis. In addition, the throughput of mass cytometry lags behind that of fluorescence-based cytometry due to the dynamics of ion flight in the mass spectrometer. Additionally, the sensitivity of mass reporters makes it more difficult to measure molecular features that are expressed at very low levels. Mass cytometry is also a relatively new method, and commercial reagents are less prevalent that those for fluorescence-based approaches. Moreover, due to the quantity of parameters obtained per single cell, data visualization is a greater challenge compared to flow cytometry, also referred to as the "curse of dimensionality" (148). Finally, however, many limitations of mass cytometry are shared with fluorescence-based flow cytometry: Many small molecule metabolites are difficult to measure because there is no easy approach to maintain small molecules and a binding agent associated with the cell. A key point in both cytometry approaches is controlling for experimental noise between sample runs as minor differences in the number of cells per sample or pipetting errors can potentially introduce technical variance $(148,149)$.

Christophersen et al. have recently advanced the HLA-DQ:gluten staining described above to the use in mass cytometry (65). In their study, they describe a distinct phenotype of gluten-specific T cells based on mass cytometry and RNA-sequencing analysis. This phenotype was also found in other autoimmune conditions like systemic lupus erythematosus, systemic sclerosis (65) and rheumatoid arthritis (64), which indicates that disease-relevant cells in other autoimmune diseases may be similar to the cells recognizing the disease-causing antigen gluten in CeD. 
Being able to study antigen-specific $\mathrm{CD} 4^{+} \mathrm{T}$ cells in $\mathrm{CeD}$ and other conditions using mass cytometry, will be of great relevance for the development of therapeutic drugs targeting disease-causing cells in autoimmune disorders (149).

\subsection{Sequencing methods}

\subsubsection{RNA sequencing and transcriptome analysis}

For RNA sequencing of tetramer ${ }^{+} \beta 7^{+} \mathrm{T}_{\text {EM }}$ cells, the SMART-Seq ${ }^{\circledR}$ Ultra ${ }^{\circledR}$ Low Input RNA Kit for Sequencing was used. This kit offers an additional amplification step before RNA sequencing, which is necessary due to low frequency of gluten-specific T cells in the blood of $\mathrm{CeD}$ patients. The kit has previously been used for bulk sequencing of a limited number of lymphocytes in our group before (65). According to the manufacturer, the SMARTer Kit enables cDNA synthesis directly from 1-1000 intact cells (150). I used the fourth-generation of SMARTer ultra-low kits, which is supposed to be Takara's most sensitive kit for single cells and ultra-low input. The kit outperforms both the SMART-seq2 method and previous generations of SMARTer kits by identifying the greatest number of transcripts according to the manufacturers (150).

The Switching Mechanism at 5' End of RNA Template (SMART) technology (151, 152) applied by this kit provides full-length transcript information and oligo(dT) priming is used to specifically amplify mRNA from high-quality total RNA (RIN > 8) or intact cells. Inclusion of LNA technology in the SMART-Seq oligo is supposed to improve the efficiency of template switching, which allows for identification of high numbers of genes (150).

In comparison to other kits, the SMART-Seq ${ }^{\circledR}$ Ultra ${ }^{\circledR}$ Low Input RNA Kit for Sequencing performs well in many metrics, but shows less correlation with controls than other kits in a publication comparing four types of amplification kits (153). The authors conclude that no single kit met all the challenges of small input material. However, they were encouraged by the fact that excellent data can be recovered with even the 50 pg input total RNA using amplification kits instead of "homemade" protocols (153). 
RNA and cDNA quality were checked at several time points using the Agilent 2100 Bioanalyzer (Agilent Technologies, Santa Clara, California, United States) as recommended by the kit's manufacturer. I only went on with processing of RNA or DNA that met the described quality criteria.

RNA sequencing was performed at the Norwegian Sequencing Centre, which was consulted for advice on sequencing approaches before running the project.

We chose a read length of 75 base pairs and paired-end sequencing as this is the recommended length for RNA sequencing according to Illumina, a globally leading company in sequencing technology (154). The read length refers to the number of base pairs, which is sequenced from a DNA fragment. The overlapping regions between reads are used to assemble and align the reads to a reference genome after sequencing. In this way, the full cDNA sequence can be reconstructed. The read length corresponds directly to the amount of sequencing reagents - and thereby costs - used on a Next Generation Sequencing instrument, such as the Illumina NextSeq500 platform chosen in the present work. Long reads allow for more sequence overlap and are useful for de novo assembly of the genome. For other applications, such as expression profiling, shorter reads are more cost-effective. Paired-end sequencing refers to the process, in which a DNA fragment is read from both ends, the $3^{\prime}$ and the 5 ' end of the DNA strand. This method produces twice the number of sequencing reads and enables more accurate read alignment and detection of structural rearrangements. Due to these advantages, most researchers use the paired-end approach today according to Illumina. However, depending on the research question, resources can in many cases be saved by using shorter read length and single-end reads (155).

The Illumina NextSeq500 platform was chosen in this project due to a short run time and it's feasibility for small-medium sized high priority projects according to the Norwegian Sequencing Centre.

The resulting raw sequencing data were processed by a bioinformatician in the group. Briefly, RNA-seq reads were mapped to the human reference genome GRCh38.p7 
containing alternative loci with gene annotations curated by Ensembl release 86 using Salmon (156). The quasi-mapping index in Salmon was built using a default k-mer length of 31 . Read counts of transcripts were aggregated to gene level.

Further data processing was performed using $\mathrm{R}$ with the Bioconductor and the Tidyverse collection of packages. Estimated gene counts were loaded into R using Tximport. Differential gene expression analysis and log fold-change estimation were computed using DESeq2 (157) with a design formula considering the sample donor. In order to visualize the $\log 2$ fold change, heat maps were generated using ggplot2. According to the present EU General Data Protection Regulation (158), the raw sequencing data were processed on a secure computing platform, the TSD (Tjeneste for Sensitive Data) facilities. The TSD is developed and operated by the TSD service group and owned by the University of Oslo.

\subsubsection{T-cell receptor sequencing and repertoire analysis}

Single $\mathrm{CD} 8^{+} \alpha \beta$ or $\gamma \delta \mathrm{T}$ cells were sorted in 96 -well plates and stored at $-80{ }^{\circ} \mathrm{C}$ to ensure cell lysis prior to cDNA synthesis. cDNA synthesis was performed using SuperScript II and the plates were then stored at $-20^{\circ} \mathrm{C}$. Three rounds of nested multiplex PCR followed, where the third PCR reaction incorporated plate and well barcodes and Illumina Paired-End primers. PCR was performed with multiplexed primers covering all TRGV and TRDV genes. The primers for the TRDV and TRDC regions were adapted from Han et al. (34) and the primers for the TRGV and TRGC regions from Guo et al. (159). In addition, the primers were modified to fit the format described in Han et al. and be compatible with Illumina sequencing. The modified primers are compatible with simultaneous TCR $\alpha$ and TCR $\beta$ sequencing, using the protocol of Risnes et al. (160).

Since the constant genes for the $\alpha \beta$ and $\gamma \delta$ TCR are different, the two libraries were combined and sequenced in the same Illumina Miseq sequencing run. Sequencing was performed at the Norwegian Sequencing Centre. The obtained reads from the Illumina sequencing were pre-processed using tools from the pRESTO toolkit (161). Then, the TCR sequences were submitted to the IMGT/HighV-Quest online tool (162). This tool allowed for determination of the V, D, and J genes and alleles as well as the 
nucleotide sequences of the CDR3 junctions. The resulting output files were then imported into an in-house Java programme and subjected to further filtration to identify clonotypes. This process is described in further detail in Risnes et al. (160).

\subsection{Interleukin-2 (IL-2) assay}

IL-2 is one important cytokine with an immediate response in blood after gluten challenge (38). We aimed to measure IL-2 in plasma samples from participants in the kinetics study and used the V-PLEX platform by MesoScale Diagnostics (MSD, Maryland, USA).

V-PLEX immunoassays work with electro-chemi-luminescence: Electro-chemiluminescent labels generate light when they get stimulated by electricity in the appropriate chemical environment. They provide a light signal, which is used to measure the biomedical molecules of interest. The operating principle according to the manufacturer is as follows (163): High binding carbon electrodes in the bottom of the microplates provide easy attachment of biological reagents. Electro-chemiluminescent labels, called SULFO-TAG, are conjugated to detection antibodies and allow for ultra-sensitive detection. Finally, electricity is applied to the plate electrodes by an MSD instrument, the MSD QuickPlex SQ 120 in our case, and lead to light emission by the SULFO-TAG labels. The intensity of light emission is then measured to quantify the analyte IL-2, in the plasma samples (figure 4).

According to MSD, using electro-chemi-luminescence assays has the advantages of being highly sensitive while at the same time having a broad dynamic range, low background and being easy to use with high flexibility due to stable, non-radioactive labels and conveniently conjugated biological molecules (163). There are few reported disadvantages of this method, mainly referring to the Ruthenium compound used as luminophore in the assay, as the hydrophobicity of the layer environment or leakage resulting in electrode instability or measurement difficulties due to relatively broad emission spectra $(164,165)$. MSD offers an assay with even higher sensitivity of IL-2 detection with a price about tenfold higher than the conventional IL-2 V-PLEX. We considered to use this assay (which is so far only offered to be run as a service by 
MSD in the US). However, based on results by Goel et al. (38) reporting a detection rate of $81 \%$ of IL-2 with S-PLEX in challenged CeD patients four hours after ingestion of gluten compared to $71 \%$ using V-PLEX, we decided in favour of the more reasonable assay with comparable sensitivity. This decision turned out to be the right choice as the protocol was convenient and the assay performed well with consistent values in repeated measurements.

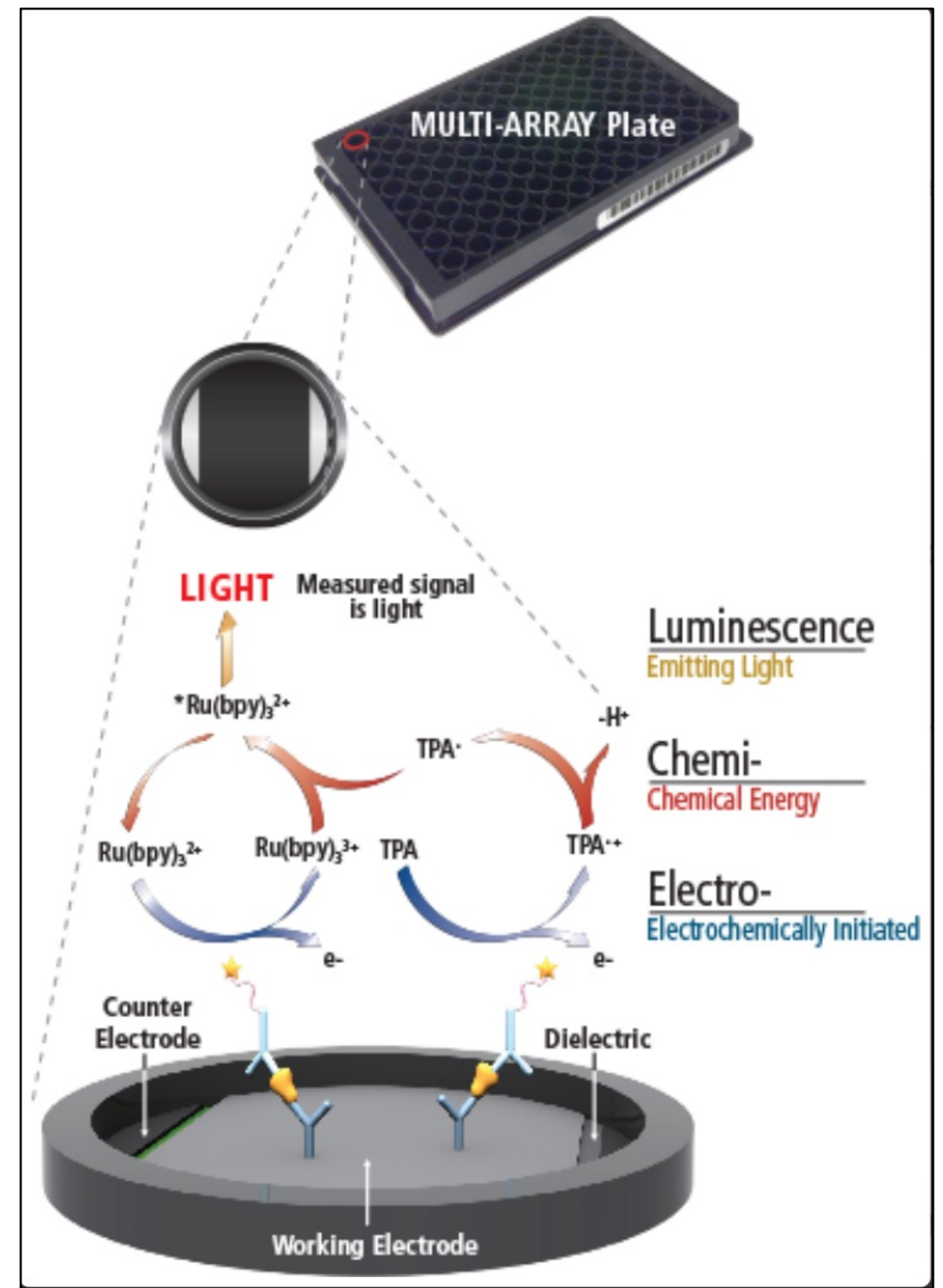

Figure 4. Overview over the electro-chemi-luminescence assay used for IL-2 measurements (illustration taken from (163) according to MSD's terms and conditions stated on the website https://www.mesoscale.com/en/our_company/legal_terms_and_policies/terms _and_conditions by 02.08.2020) 


\subsection{Patient reported outcomes}

As already mentioned before, PROs are a useful tool to study the symptom level of patients before and after an intervention given their ability to detect a clinically meaningful change with a certain sensitivity, accuracy and reliability (47).

Of the above described variety of PROs for CeD, we chose to apply measures for patient reported outcomes that have successfully been used in previous studies by our group $(40,142,166)$ : The Gastrointestinal Symptom Rating Scale modified for use in patients with irritable bowel syndrome (GSRS-IBS) (167) was used as a validated patient reported outcome scheme, although it is not validated for CeD. However, it has previously been shown that CeD and IBS symptoms overlap $(166,168)$. In addition, we wished to compare our current data with previously obtained data $(40,142,166)$. Symptoms were assessed at baseline, day 3 of challenge and at the last visit (day 6 or 8). However, the GSRS-IBS questionnaire covers a period of the last seven days, which might have led to some blur of symptoms as for example the symptoms reported on day 3 include both a baseline period and challenge interval. Hence, we also applied a visual analogue scale for selected gastrointestinal symptoms (pain, bloating, flatulence, nausea, stool consistency and overall symptoms). The visual analogue scale is a widely used, easily understandable tool to assess symptoms. Over a period of two to three days before gluten challenge until the day before the last blood sample symptoms were assessed. This diary-type of questionnaire is likely to be more accurate regarding the report of symptoms as participants were asked to fill in the form every evening resulting in short recall time.

Together, both measures for patient reported outcomes give nuanced insights in the gastrointestinal symptoms experienced during gluten challenge, but lack nongastrointestinal categories like for example fatigue or memory fog (131).

\subsection{Statistical analysis}

I used the GraphPad Prism 8 Software (GraphPad Software, San Diego, California, USA) for statistical analysis and visualisation of cell frequencies.

Non-parametric tests have been used in the present work to calculate statistical significance and correlation as they are designed to work with very small samples or 
data with a lot of variance (169), such as the number of tetramer ${ }^{+} \beta 7^{+} \mathrm{T}_{\mathrm{EM}}$ cells or the IL-2 concentration in blood plasma. However, non-parametric tests are less powerful than parametric statistics and do not exploit all the information about the sample distribution (169).

The Wilcoxon signed rank test is the nonparametric equivalent of the parametric paired t-test (169) and was used to calculate statistical significance of repeated measures of the tetramer ${ }^{+} \beta 7^{+} \mathrm{T}_{\mathrm{EM}}$ cell number and $\mathrm{CD} 38^{+}$percentage of cells on baseline and day 6 , respectively the IL-2 concentration on baseline and after four hours.

Friedman's test is a non-parametric test suitable for experiments with repeated measures to determine if a particular factor has an effect (169). This test was used to test for statistical significance of tetramer ${ }^{+} \beta 7^{+} \mathrm{T}_{\mathrm{EM}}$ cells and $\mathrm{CD} 38^{+}$percentage of cells between baseline and day 8 .

Spearman's rank order correlation, also known as Spearman's rho, is based on data ranks, not on the data itself and thus resistant to outliers. This is a very important characteristic of this test as outliers can significantly alter the outcome of the Pearson correlation coefficient, the parametric equivalent of Spearman's rho (169).

Spearman's rho was used to look for correlations of tetramer ${ }^{+} \beta 7^{+} \mathrm{T}_{\mathrm{EM}}$ cell numbers with the IL-2 concentration, $\mathrm{CD} 38^{+}$percentage or symptoms after gluten challenge. The small sample size of the present work due to a demanding protocol might have blurred some existing correlations, which have been reported earlier (38).

The significance level was set to $\mathrm{p}<0.05$ and adjusted for multiple testing in the case of Friedman's test. Missing values were excluded list wise. For RNA sequencing analysis, we used a narrower significance threshold of 0.05 after adjusting for multiple testing. 


\section{Ethical Considerations}

For this project, biological material from coeliac disease patients was used. To work with biological material from animals or humans requires particular reflections about ethical aspects and precautions to ensure personal rights and privacy according to the Declaration of Helsinki (170).

In general, it is important to inform study participants about the whereabouts of the donated biological material, advantages or disadvantages participants may experience and about the possibility to withdraw their consent at any time and without any reason.

In this work, I challenged $\mathrm{CeD}$ patients with gluten, the nutrition component they have to avoid in order to achieve freedom from symptoms. A GFD is still the only known treatment for coeliac disease. However, I asked participants to undergo a short "disease relapse" to get hold in the cells of scientific interest: gluten-specific T cells. The Regional Committee for Medical and Health Research Ethics South-East Norway Ethical granted approval for this study (see above).

The most important prerequisite for the gluten challenge is that participants voluntarily wish to donate biological material to research. The challenge procedure can only be justified by taking several means of precaution for both the participants and us as researchers: A study nurse or I provided detailed explanation about the project, the time line and possible side effects of gluten challenge. The participants were checked for good health and medical care was supplied whenever necessary before, during and after gluten challenge. Project leader and senior physician Knut Lundin and I as a medical doctor observed and followed up the participants in case of any blood values outside the normal range. We ensured close contact to the health care system during and after study participation. It was a conscious decision not to include gastroscopy in the study protocol to balance carefully invasiveness and outcome benefit. 
A strong motivation to complete challenge was also an important requirement to ensure acquisition of material won under similar conditions. The participants' motivation arose often from the hope of new treatment options for CeD. Here, we were ethically obliged to explain the concept of basic research not having a clear goal. Nonetheless, new medical treatments can evolve from this after a long study process in- and outside the lab. We communicated that our main goal is to gain knowledge about immunological phenomena that will then help us to apply and translate our findings into the clinical setting.

To ensure privacy, all participants were de-identified and sensitive research data was stored safely on platforms with restricted access according to the latest EU regulations regarding data protection (General Data Protection Regulation, GDPR).

Taken together, the individual participant did not directly profit from the study, but the community of $\mathrm{CeD}$ patients will benefit due to increased knowledge about the disease. We were able to suggest optimisations for the gluten challenge protocol and showed that only one single dose of gluten gives a measurable immune response. In addition, we showed that CD38 is a consistent marker in response to gluten challenge, which may help to objectify clinical drug trials or potentially even improve diagnostics. We studied the kinetics of gluten-specific $\mathrm{T}$ cells and the surface marker CD38, which will help to design further studies on those crucial cells for CeD. We also demonstrate that gluten-specific $\mathrm{T}$ cells differentially express many proteincoding genes, some of which may serve as new treatment options. However, adverse effects of potential treatment options must be weighed carefully against the existing treatment, a strict GFD that barely goes along with any physiological side effects. The insights gained through this work were acquired with as little harm as possible for the participants: They underwent a short gluten challenge with blood sampling and reported only mild to moderate symptoms in response to this study design. 


\section{Discussion}

\subsection{One- versus three-day gluten challenge}

It was Willem-Karel Dicke who performed ground-breaking studies on the GFD as treatment for CeD in the early 1940ies (171). However, the medical community hesitated to diagnose $\mathrm{CeD}$ until it was proven that gluten was indeed the cause of the mucosal atrophy in the small intestine. Thus, not only a complete remission on a GFD was considered necessary for the diagnosis, but it had to be followed by the normalization of the lesion documented by - at that time recently introduced gastroscopy, and finally by its recurrence on a gluten-containing diet (172). In a first consensus paper published in Acta Paediatrica in 1970, CeD was defined as a permanent condition of gluten intolerance with mucosal flattening, which reversed on a GFD and relapsed on re-introduction of gluten (173). In today's clinical setting, it is still debated on how long a gluten challenge should last in patients with unsure diagnosis or those who already have commenced a GFD before proper diagnosis, although diagnostic methods have evolved and there is no more need to proof the relapse on re-introduction of gluten (126). A reason for the ongoing debate on the duration of a gluten challenge might be the time gap between re-introduction of gluten and histologically detectable in the mucosa of the small intestine (174). From a scientific point of view, the main benefit of gluten challenge is the stimulation of a specific cell response to antigen to subsequently acquire enough cells of interest to study without exposing patients to intolerable discomfort. We know that substantial amounts of gluten-specific $\mathrm{T}$ cells can be achieved with a gluten challenge over three days $(35,37,98)$. In addition, recent studies have shown that an increase of IL-2 concentration in plasma can be detected after one single dose of gluten $(38,69)$. Based on this, we hypothesized that a single dose of gluten would be enough to induce a detectable response of gluten-specific $\mathrm{T}$ cells in blood.

In the present work, we observed an increase of gluten-specific $\mathrm{T}$ cells in all six participants after one single dose of gluten, but the response was less pronounced compared to challenge over three days. However, the symptoms after one dose peaked almost exclusively on the day of challenge, while the symptoms after 3-day challenge 
were more spread. In addition, the surface expression of CD38 on gluten-specific T cells did not differ between 1- and 3-day challenge, indicating that one single dose of gluten is sufficient to induce a detectable increase of CD38 expression on the cells. In summary, we have shown that gluten challenge consisting of only one single dose is sufficient to induce detectable responses on gluten-specific T cells, which may be of future diagnostic value, provided that diagnostics will move away from being biopsybased to advantage of being $\mathrm{T}$ cell-based, either in the form of a tetramer test or by using IL-2 concentration in plasma, which I will elaborate on in the next section. In regard of the scientific use of a single gluten challenge, the number of glutenspecific $\mathrm{T}$ cells induced was not convincing to further pursue this very short challenge. However, given the setting of a therapeutic drug trial, a single gluten challenge may be of value based on its benign symptom profile and feasibility.

\subsection{IL-2 concentration in plasma after gluten exposure}

As described above, IL-2 is mainly secreted by activated T cells following antigenic stimulation, which leads to clonal expansion $(59,67)$. Recently, two studies have underlined the value of cytokine measurements in blood plasma after a single dose of gluten; among them IL-2 with the most pronounced results both in regard of symptoms and possibility to differentiate $\mathrm{CeD}$ from non-coeliac gluten sensitivity (NCGS) $(38,69)$.

In this work, we tested if IL-2 measured 4 hours after gluten challenge could serve as a surrogate marker for immune cell activation. We observed a highly significant increase of IL-2 in blood plasma, which was comparable to the previously mentioned studies $(38,69)$. Yet, in line with the gluten-specific $\mathrm{T}$ cell response, we found large inter-individual differences both in fold increase and absolute levels of IL-2. We could also reproduce the previously reported correlation of IL-2 increase and symptoms after gluten challenge $(38,40)$, but failed to reproduce the correlation of glutenspecific $\mathrm{T}$ cell number at baseline and the increase of IL-2 levels in response to challenge (38). The latter observation might be interpreted as a type II error, the failure to reject a false null hypothesis, which may have occurred due to undersampling in our study. 
Taken together, the assessment of the physiologically relevant T-cell growth factor IL$2(59,67)$ in plasma reflects both the diagnosis of $\mathrm{CeD}$ as well as it correlates with symptom intensity after only one single dose of gluten. However, the obvious potential of IL-2 as a diagnostic marker is slightly tempered by its large variation between individuals.

\subsection{Kinetics of gluten-specific $\mathrm{CD}^{+} \mathrm{T}$ cells in response to gluten challenge}

Related to the work with antigen-reactive $\mathrm{T}$ cells and tetramers, there are several limitations to be considered. Firstly, the availability of tetramers is limited to only a few research groups in addition to ours $(34,175-177)$. Secondly, access to flow cytometry / FACS machines and expertise in their usage is required for the work with tetramers. Thirdly, the time window for sample processing is relatively short in regards of maintaining cell viability, preventing contamination with granulocytes and subsequent functional impairment of $\mathrm{T}$ cells $(135,178,179)$. And finally, given the rare frequency of gluten-specific T cells in blood and the limited amount of blood that can be drawn without physiological impairments (180), the material to work with is very restricted.

In our hands, however, tetramers have been an extremely useful tool to study glutenspecific T cells and have been used by us and others to detect gluten-specific T cells in gut and blood of CeD patients for over 15 years $(34-36,40,65,95,96,98,118,139$, 160, 181). Yet, the kinetics of gluten-specific T cells has not been studied thoroughly before, and study protocols were mainly based on the observation by Anderson et al. that IFN- $\gamma$ secretion measured by ELISpot was highest on day 6 or 8 after a gluten challenge over three days (77). The use of ELISpot is an alternative to tetramers (37, 77), but an indirect measurement, which does not allow the study of individual glutenspecific $\mathrm{T}$ cells and their features.

Motivated to specify the optimal time window for sampling blood and study glutenspecific T cells, we initiated a study to describe the kinetics of gluten-specific T cells after gluten challenge. We found that the optimal time window for blood sample taking is 6-8 days to gain the highest number of gluten-specific T cells after a gluten challenge over three days, which is in accordance with the results from Anderson et al. 
(77) and a study by Han et al. (34). We also observed the previously reported phenomenon of large inter-individual differences in cell numbers $(35,37,40,95)$. However, a new finding is the observation that the number of gluten-specific $\mathrm{T}$ cells does not show a clear peak in all individuals, but rather plateaued between day 6 and 8.

\subsection{CD38 expression in response to gluten challenge}

The cell surface receptor CD38 is an ADP ribosyl cyclase that converts NAD to cyclic ADP ribose and not only stands in lateral associations to the TCR/CD3 complex, but also to the BCR and CD16 in T, B, and NK cells $(182,183)$. High cell surface levels of CD38 go along with a reduced proliferative capacity of $\mathrm{T}$ cells, while the cells displayed an improved potential to produce IL-2 and IFN- $\gamma(97)$. In CeD, CD38 has been identified as a consistent marker on activated gut-homing gluten-specific $\mathrm{T}$ cells $(36,40,96,141)$.

In the present work, we find CD38 among the highest upregulated transcripts in the transcriptome data set. We also observed the induction of CD38 expression on the cell surface of gluten-specific $\beta 7^{+} \mathrm{T}_{\mathrm{EM}} \mathrm{CD} 4^{+} \mathrm{T}$ cells in all study participants. It was strikingly uniform in contrast to high quantitative variability in the numbers of glutenspecific T cells and levels of IL-2. A similar uniform response of CD38 expression has been shown previously on day 6 under ongoing gluten challenge for 14 days (40). After day 6 after the onset of gluten challenge, the expression of CD38 further increases until day 8 in individuals with a weaker response to gluten challenge and offers the opportunity to differentiate between slow responders and non-responders to gluten challenge. Given the fast and robust upregulation of CD38 after gluten exposure in contrast to the long latency of serologic and mucosal conversion $(33,129$, 141), the measurement of the percentage of $\mathrm{CD} 38^{+}$cells among gluten-specific $\mathrm{T}$ cells is an attractive surrogate marker for assessing drug efficacy after gluten challenge. The assessment should be performed on day 8 rather than day 6 after the onset of a gluten challenge. 


\subsection{Kinetics of $\mathrm{CD8}^{+} \alpha \beta$ and $\gamma \delta \mathrm{T}$ cells in response to gluten challenge}

Another aspect elucidated by Han et al. besides the TCR repertoire of the $\mathrm{CD}^{+} \alpha \beta$ and $\gamma \delta \mathrm{T}$ cells in the blood on day 6 and the outlined kinetics of gluten-specific $\mathrm{CD}^{+}$ $\mathrm{T}$ cells is the significant increase in gut-homing, activated $\mathrm{CD} 8^{+} \alpha \beta$ and $\gamma \delta$ T cells in the blood following gluten challenge (34). We saw this phenomenon only in a subset of CeD patients. As such, our results are more in line with López-Palacios and colleagues, who also observed an increase in $\mathrm{CD}^{+} \alpha \beta$ and $\gamma \delta \mathrm{T}$ cells in some, but not all CeD patients (110). Importantly, in all the three gluten challenges performed in paper III, we observed a $\mathrm{CD} 8^{+} \alpha \beta$ T-cell response in all patients that displayed a $\gamma \delta \mathrm{T}$ cell response. In addition, all patients that exhibited a CD8+ $\alpha \beta$ and/or $\gamma \delta$ T-cell response also had a gluten-specific $\mathrm{CD} 4^{+} \mathrm{T}$-cell response.

In the bread challenge, the percentage of patients with a $\gamma \delta$ and/or $\mathrm{CD} 8^{+} \alpha \beta$ T-cell response was higher compared to the other challenges. This was especially interesting in the case of CD431, who had to stop gluten challenge after only two slices of bread due to severe nausea, but still had a detectable T-cell response on day 6. This patient also had the highest number of gluten-specific $\mathrm{CD}^{+} \mathrm{T}$ cells at baseline. This supports the notion that a high level of circulating gluten-specific $\mathrm{CD} 4^{+} \mathrm{T}$ cells might fire off more easily in the gluten recall response, and lead to more acute gastrointestinal symptoms (184).

Taken together, these results give rise to the hypothesis that there is a hierarchy of Tcell responses during gluten exposure, which starts off with gluten-specific $\mathrm{CD} 4^{+} \mathrm{T}$ cells. Thus, it is possible that the $\mathrm{CD} 8^{+} \alpha \beta$ and $\gamma \delta$ T-cell responses are induced by the inflammatory environment that gluten-specific $\mathrm{CD}^{+} \mathrm{T}$ cells generate in the gut.

\subsection{Transcriptome analysis of gluten-specific $\mathbf{T}$ cells}

We performed RNA sequencing of gluten-specific $\mathrm{T}$ cells using a bulk sequencing kit for small cell numbers (SMART-Seq ${ }^{\circledR}$ Ultra $^{\circledR}$ Low Input RNA Kit for Sequencing) since the total numbers of sorted cells ranged from a few hundred to a few thousand cells per participant, a number comparable to previous results (40). Bulk sequencing appeared to be an appropriate method although the signal resolution is lower compared to single cell sequencing. That is because this sequencing approach has 
already been established for gluten-specific T cells from the small intestine in our group (65), which on one hand offered the opportunity to compare gut and blood $\mathrm{T}$ cells using the same sequencing method. On the other hand, single cell resolution did not appear as a necessity at the time of project planning as the main aim was to compare the transcriptome of two cell populations, which later was complemented by mass spectrometry and the comparison of the same cell populations.

Specifically, we compared gut-homing effector/memory $\mathrm{T}$ cells with specificity to gluten tetramers with gut-homing effector/memory $\mathrm{T}$ cells without specificity to gluten tetramers. Transcriptome analysis of the RNA sequencing data revealed over 3000 significant $(\mathrm{p}<0.05)$ differentially expressed protein-coding genes. Among those over 3000 genes, we identified 94 genes coding for cell surface markers. Obviously, those 94 genes represent only a small portion of all differentially expressed genes, which offer the possibility to identify relevant metabolic or signalling pathways in addition to several potential drug targets. The transcriptome data generated by us should therefore be examined thoroughly in future projects of the group.

\subsection{Mass cytometry analysis of gluten-specific T cells}

The identification of 94 differentially expressed genes coding for cell surface markers gave us the opportunity to study the correlation of mRNA expression of the genes and protein expression on the cell surface. We chose mass cytometry because of the larger number of markers that can be incorporated in the staining panel without significant overlap of emission spectra and the associated necessity for compensation compared to flow cytometry. We show that RNA sequencing data on genes coding for CD markers correlate well with protein expression on the cell surface of gut-homing, gluten-specific effector/memory T cells after gluten challenge. However, the four cell surface markers CD47, CD52, CD103 and CD314 were an exception from otherwise good correlation. Those markers have in common that elaborate regulatory mechanisms of internalisation (CD103 and CD314), proteolytic cleavage (CD52) or secretion as extracellular vesicles (CD47) have been described for them (185-188). Consequently, the markers' cell surface expression might not be as stable as the level of mRNA transcribed in gluten-specific T cells. 
In addition, the missing correlation for these markers could be the result of partly different patient cohorts in RNA-seq and mass spectrometry analysis, slightly diverging gating strategies and antibodies used for cell analysis/sorting and staining, respectively. For example, the lower expression of CD103 on tetramer ${ }^{+} \mathrm{T}$ cells in mass cytometry is a result of a small, $\mathrm{CD} 103^{+}$subgroup, which may have been excluded from cell sorting before RNA-seq. Taken together, many possible reasons for the missing correlation of CD47, CD52, CD103 and CD314 exist, but importantly, we observed a robust correlation of protein expression and RNA levels for the large majority of cell surface markers.

\subsection{Gluten-specific $\mathrm{T}$ cells as a new read-out for clinical drug trials}

Gluten-specific T cells in blood after gluten challenge are strikingly (but not completely) overlapping with their intestinal counterparts (65). We were able to confirm that the expression of cell surface markers on gluten-specific T cells from blood after gluten challenge is comparable to the expression of markers on glutenspecific $\mathrm{T}$ cells from the small intestine resembling a peripheral $\mathrm{T}$ helper cell subset $(64,65)$.

The phenotypical similarity of gluten-specific T cells in blood and gut in addition to formation of distinct cell clusters substantiates the notion that gluten-specific $\mathrm{T}$ cells induced by antigen re-exposure are a valid estimate of an increased number of glutenspecific T cells in the lamina propria of the small intestine. Consequently, glutenspecific $\mathrm{T}$ cells from blood may serve for the search for new potential drug targets and as read-outs for clinical drug studies.

Taken together, both the measurement of $\mathrm{CD} 38^{+}$cells among gluten-specific $\mathrm{T}$ cells, but also gluten-specific T cells from blood as such are an attractive and objective readout for assessing drug efficacy after gluten challenge. In line with that, the use of gluten-specific $\mathrm{CD}^{+} \mathrm{T}$ cells as an immunological read-out for clinical drug trials has recently been suggested by a working group (129). 


\subsection{Implications for coeliac disease and beyond - future perspectives}

Gluten-specific $\mathrm{CD}^{+} \mathrm{T}$ cells are the crucial players in $\mathrm{CeD}$ pathogenesis. In the present work, we have combined tetramer-staining with bulk RNA sequencing of gluten-specific $\mathrm{CD}^{+} \mathrm{T}$ to study the kinetic profile of gluten-specific $\mathrm{T}$ cells and to identify a potential drug target based on transcriptome analysis of gluten-specific $\mathrm{T}$ cells from blood after gluten challenge.

We demonstrate that all participants increased their numbers of gut-homing glutenspecific $\mathrm{T}_{\mathrm{EM}}$ cells both after challenge over three days and after one single dose of gluten. The increase was less pronounced after one single dose of gluten. Cell numbers after three-day gluten challenge plateaued between days 6-8 and we concluded that this interval is optimal to draw blood samples and study gluten-specific $\mathrm{T}$ cells from blood. The cell surface marker CD38 increased promptly and did not significantly differ between one- and three-day challenges. This finding makes CD38 an attractive surrogate marker for e.g. assessing drug efficacy after gluten challenge in a clinical trial. These insights into the kinetics of gluten-specific T cells and CD38 will help to design further necessary studies both on biological and therapeutic aspects of those crucial players in CeD.

Moreover, we performed transcriptome analysis on gut-homing gluten-specific $\mathrm{T}$ cells and found over 3000 differentially expressed protein-coding genes. Examining the correlation of some immunologically relevant cell surface markers among the differentially expressed genes, we found a good correlation of mRNA and protein expression level. In addition, we were able to confirm distinct clustering of glutenspecific $\mathrm{T}$ cells. These insights may provide the basis for the use of gluten-specific $\mathrm{T}$ cells as an objective read-out for clinical trials and potentially the identification of new drug targets on gluten-specific $\mathrm{T}$ cells (figure 5). 


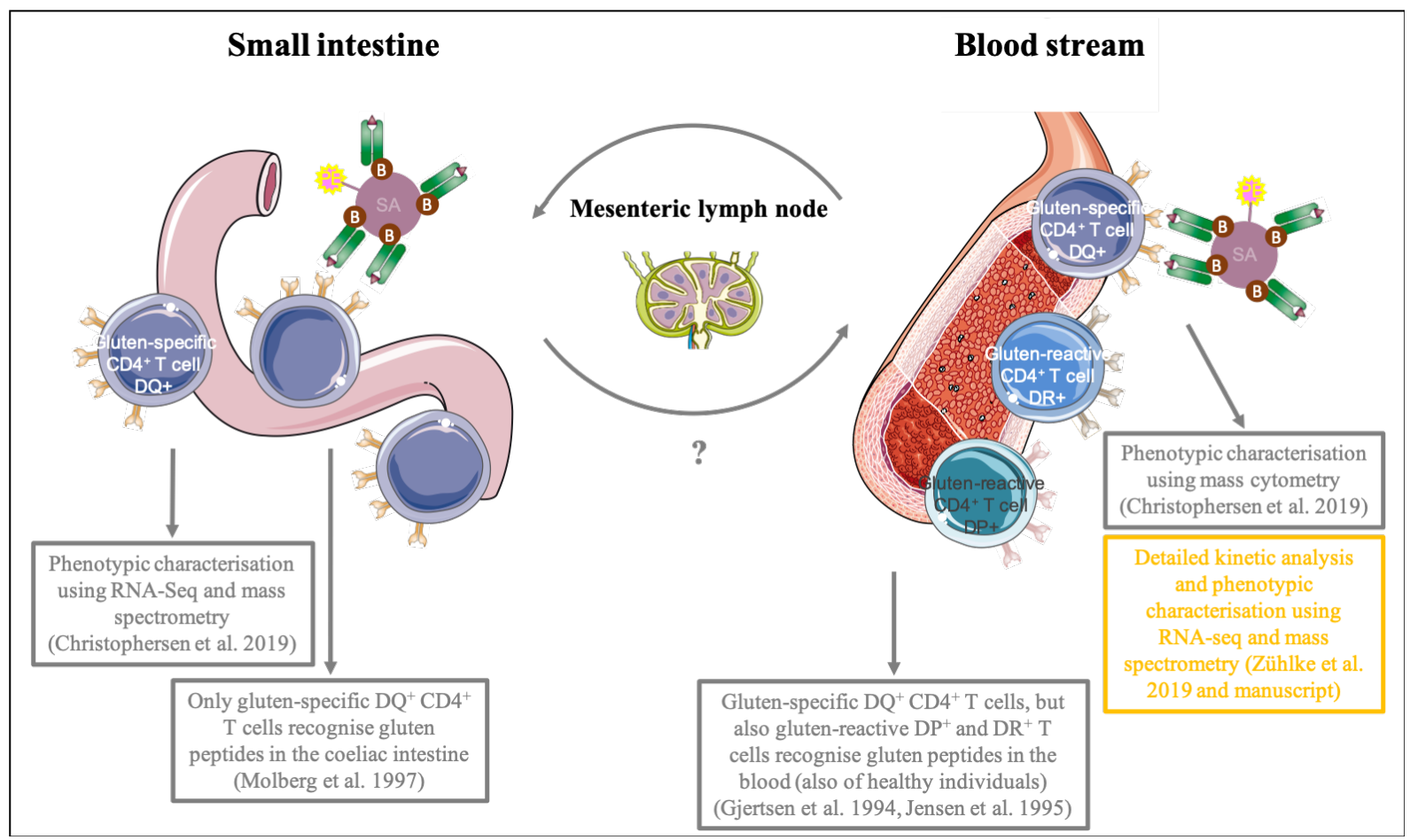

Figure 5. Concept of gluten-specific $\mathbf{T}$ cells in blood and gut - An overview over established knowledge (grey boxes) and how this work contributes to new insights (yellow box). The figure was made using Servier Medical Art (https://smart.servier.com). 


\section{REFERENCES}

1. Janeway CAT, P.; Walport, M.; Shlomchik, M. Immunobiology. 7th edition ed2008.

2. Alberts BJ, A.; Lewis, J.; Raff, M.; Roberts, K.; Walter, P. Molecular Biology of the Cell. 4th ed2002.

3. Lüllmann-Rauch R. Taschenlehrbuch Histologie. 3rd ed2009.

4. Ribatti D, Crivellato E, Vacca A. The contribution of Bruce Glick to the definition of the role played by the bursa of Fabricius in the development of the B cell lineage. Clinical and experimental immunology. 2006;145(1):1-4.

5. Zepp F. Principles of vaccine design - Lessons from nature. Vaccine. 2010;28:C14-C24.

6. Davidson A, Diamond B. Autoimmune Diseases. New England Journal of Medicine. 2001;345(5):340-50.

7. Petersen J, Ciacchi L, Tran MT, Loh KL, Kooy-Winkelaar Y, Croft NP, et al. T cell receptor cross-reactivity between gliadin and bacterial peptides in celiac disease. Nature Structural \& Molecular Biology. 2020;27(1):49-61.

8. Ahsan H. Selfie: Autoimmunity, boon or bane. J Immunoassay Immunochem. 2017;38(3):235-46.

9. Kim YJ. Autoimmune Diseases - A Rising Epidemic. Dartmouth Undergraduate Journal of Science. 2011.

10. Lindfors K, Ciacci C, Kurppa K, Lundin KEA, Makharia GK, Mearin ML, et al. Coeliac disease. Nat Rev Dis Primers. 2019;5(1):3.

11. Abadie V, Jabri B. IL-15: a central regulator of celiac disease immunopathology. Immunol Rev. 2014;260(1):221-34.

12. Sollid LM, Jabri B. Triggers and drivers of autoimmunity: lessons from coeliac disease. Nat Rev Immunol. 2013;13(4):294-302.

13. Sollid LM, Qiao SW, Anderson RP, Gianfrani C, Koning F. Nomenclature and listing of celiac disease relevant gluten T-cell epitopes restricted by HLA-DQ molecules. Immunogenetics. 2012;64(6):455-60.

14. Balakireva AV, Zamyatnin AA. Properties of Gluten Intolerance: Gluten Structure, Evolution, Pathogenicity and Detoxification Capabilities. Nutrients. 2016;8(10).

15. Garsed K, Scott BB. Can oats be taken in a gluten-free diet? A systematic review. Scand J Gastroenterol. 2007;42(2):171-8.

16. Catassi C, Anderson RP, Hill ID, Koletzko S, Lionetti E, Mouane N, et al. World perspective on celiac disease. J Pediatr Gastroenterol Nutr. 2012;55(5):494-9.

17. Fasano A, Catassi C. Clinical practice. Celiac disease. N Engl J Med. 2012;367(25):2419-26.

18. Choung RS, Khaleghi S, Cartee AK, Marietta EV, Larson JJ, King KS, et al. Community-Based Study of Celiac Disease Autoimmunity Progression in Adults. Gastroenterology. 2020;158(1):151-9.e3.

19. Tortora R, Zingone F, Rispo A, Bucci C, Capone P, Imperatore N, et al. Coeliac disease in the elderly in a tertiary centre. Scand J Gastroenterol.

2016;51(10):1179-83. 
20. Catassi C, Kryszak D, Bhatti B, Sturgeon C, Helzlsouer K, Clipp SL, et al. Natural history of celiac disease autoimmunity in a USA cohort followed since 1974. Annals of Medicine. 2010;42(7):530-8.

21. Itzlinger A, Branchi F, Elli L, Schumann M. Gluten-Free Diet in Celiac DiseaseForever and for All? Nutrients. 2018;10(11).

22. Sollid LM, Lundin KE. Diagnosis and treatment of celiac disease. Mucosal Immunol. 2009;2(1):3-7.

23. Al-Toma A, Volta U, Auricchio R, Castillejo G, Sanders DS, Cellier C, et al. European Society for the Study of Coeliac Disease (ESsCD) guideline for coeliac disease and other gluten-related disorders. United European Gastroenterol J. 2019;7(5):583-613.

24. Schumann M, Lebenheim L. [Celiac disease]. Dtsch Med Wochenschr. 2016;141(20):1474-7.

25. Leffler DA, Schuppan D. Update on serologic testing in celiac disease. Am J Gastroenterol. 2010;105(12):2520-4.

26. Dickson BC, Streutker C, Chetty R. Coeliac disease: An update for pathologists. Journal of clinical pathology. 2006;59:1008-16.

27. Husby S, Koletzko S, Korponay-Szabo I, Kurppa K, Mearin ML, RibesKoninckx C, et al. European Society Paediatric Gastroenterology, Hepatology and Nutrition Guidelines for Diagnosing Coeliac Disease 2019. J Pediatr Gastroenterol Nutr. 2019.

28. Karell K, Louka AS, Moodie SJ, Ascher H, Clot F, Greco L, et al. HLA types in celiac disease patients not carrying the DQA1*05-DQB1*02 (DQ2) heterodimer: results from the European Genetics Cluster on Celiac Disease. Hum Immunol. 2003;64(4):469-77.

29. Lundin KE, Scott H, Fausa O, Thorsby E, Sollid LM. T cells from the small intestinal mucosa of a DR4, DQ7/DR4, DQ8 celiac disease patient preferentially recognize gliadin when presented by DQ8. Hum Immunol. 1994;41(4):285-91.

30. Sollid LM, Markussen G, Ek J, Gjerde H, Vartdal F, Thorsby E. Evidence for a primary association of celiac disease to a particular HLA-DQ alpha/beta heterodimer. J Exp Med. 1989;169(1):345-50.

31. Withoff S, Li Y, Jonkers I, Wijmenga C. Understanding Celiac Disease by Genomics. Trends Genet. 2016;32(5):295-308.

32. Ludvigsson JF, Bai JC, Biagi F, Card TR, Ciacci C, Ciclitira PJ, et al. Diagnosis and management of adult coeliac disease: guidelines from the British Society of Gastroenterology. Gut. 2014;63(8):1210-28.

33. Leffler D, Schuppan D, Pallav K, Najarian R, Goldsmith JD, Hansen J, et al. Kinetics of the histological, serological and symptomatic responses to gluten challenge in adults with coeliac disease. Gut. 2013;62(7):996-1004.

34. Han A, Newell EW, Glanville J, Fernandez-Becker N, Khosla C, Chien YH, et al. Dietary gluten triggers concomitant activation of CD4+ and CD8+ alphabeta T cells and gammadelta T cells in celiac disease. Proc Natl Acad Sci U S A. 2013;110(32):13073-8.

35. Brottveit M, Raki M, Bergseng E, Fallang LE, Simonsen B, Lovik A, et al. Assessing possible celiac disease by an HLA-DQ2-gliadin Tetramer Test. Am J Gastroenterol. 2011;106(7):1318-24. 
36. du Pre MF, van Berkel LA, Raki M, van Leeuwen MA, de Ruiter LF, Broere F, et al. CD62L(neg)CD38(+) expression on circulating CD4(+) T cells identifies mucosally differentiated cells in protein fed mice and in human celiac disease patients and controls. Am J Gastroenterol. 2011;106(6):1147-59.

37. Raki M, Fallang LE, Brottveit M, Bergseng E, Quarsten H, Lundin KE, et al. Tetramer visualization of gut-homing gluten-specific $\mathrm{T}$ cells in the peripheral blood of celiac disease patients. Proc Natl Acad Sci U S A. 2007;104(8):2831-6.

38. Goel GT-D, J.A.; Qiao, S-W.; Russell, A.K.; Toufic Mayassi, Cezary Ciszewski, Vikas K. Sarna, Suyue Wang, Kaela E. Goldstein, John L. Dzuris, Leslie J. Williams, Ramnik J. Xavier, Knut E.A. Lundin, Bana Jabri, Ludvig M. Sollid, Robert P. Anderson. Cytokine release and gastrointestinal symptoms after gluten challenge in celiac disease. Science Advances. 2019;5(8).

39. Tye-Din JA, Skodje GI, Sarna VK, Dzuris JL, Russell AK, Goel G, et al. Cytokine release after gluten ingestion differentiates coeliac disease from selfreported gluten sensitivity. United European Gastroenterol J. 2020;8(1):108-18.

40. Sarna VK, Skodje GI, Reims HM, Risnes LF, Dahal-Koirala S, Sollid LM, et al. HLA-DQ:gluten tetramer test in blood gives better detection of coeliac patients than biopsy after 14-day gluten challenge. Gut. 2018;67(9):1606-13.

41. Food and Agriculture Organization of the United Nations WHO. Codex Alimentarius - Standard for Foods for Special Dietary Use for Persons Intolerant to Gluten. 2008.

42. Collin P, Thorell L, Kaukinen K, Maki M. The safe threshold for gluten contamination in gluten-free products. Can trace amounts be accepted in the treatment of coeliac disease? Aliment Pharmacol Ther. 2004;19(12):1277-83.

43. Caja S, Mäki M, Kaukinen K, Lindfors K. Antibodies in celiac disease: implications beyond diagnostics. Cellular And Molecular Immunology. 2011;8:103.

44. Ciacci C, Cirillo M, Cavallaro R, Mazzacca G. Long-term follow-up of celiac adults on gluten-free diet: prevalence and correlates of intestinal damage. Digestion. 2002;66(3):178-85.

45. Pekki H, Kaukinen K, Ilus T, Maki M, Huhtala H, Laurila K, et al. Long-term follow-up in adults with coeliac disease: Predictors and effect on health outcomes. Dig Liver Dis. 2018;50(11):1189-94.

46. Sharkey LM, Corbett G, Currie E, Lee J, Sweeney N, Woodward JM. Optimising delivery of care in coeliac disease - comparison of the benefits of repeat biopsy and serological follow-up. Aliment Pharmacol Ther. 2013;38(10):1278-91.

47. Canestaro WJ, Edwards TC, Patrick DL. Systematic review: patient-reported outcome measures in coeliac disease for regulatory submissions. Aliment Pharmacol Ther. 2016;44(4):313-31.

48. Leffler DA, Dennis M, Edwards George J, Jamma S, Cook EF, Schuppan D, et al. A validated disease-specific symptom index for adults with celiac disease. Clin Gastroenterol Hepatol. 2009;7(12):1328-34, 34 e1-3.

49. Eberl $\mathrm{MH}, \mathrm{A}$. Gamma Delta $(\gamma \delta) \mathrm{T}$ Cells [Available from: https:/www.immunology.org/public-information/bitesizedimmunology/cells/gamma-delta- $\% \mathrm{CE} \% \mathrm{~B} 3 \% \mathrm{CE} \% \mathrm{~B} 4-\mathrm{t}-\mathrm{cells}$. 
50. Chien Y-h, Meyer C, Bonneville M. $\gamma \delta$ T Cells: First Line of Defense and Beyond. Annual Review of Immunology. 2014;32(1):121-55.

51. Stark MA, Huo Y, Burcin TL, Morris MA, Olson TS, Ley K. Phagocytosis of apoptotic neutrophils regulates granulopoiesis via IL-23 and IL-17. Immunity. 2005;22(3):285-94.

52. Shiromizu CM, Jancic CC. $\gamma \delta$ T Lymphocytes: An Effector Cell in Autoimmunity and Infection. Frontiers in immunology. 2018;9:2389-.

53. Le Nours J, Gherardin NA, Ramarathinam SH, Awad W, Wiede F, Gully BS, et al. A class of $\gamma \delta \mathrm{T}$ cell receptors recognize the underside of the antigenpresenting molecule MR1. Science. 2019;366(6472):1522-7.

54. Anderson MS, Su MA. Aire and T cell development. Curr Opin Immunol. 2011;23(2):198-206.

55. Akika E, Megumi N, Yasushi AS, Kenji S. Identification of food-derived peptides in human blood after ingestion of corn and wheat gluten hydrolysates. Journal of Food Bioactives. 2018;2(2).

56. Bretscher P, Cohn M. A Theory of Self-Nonself Discrimination. Paralysis and induction involve the recognition of one and two determinants on an antigen, respectively. 1970;169(3950):1042-9.

57. Bernard A, Lamy L, Alberti I. THE TWO-SIGNAL MODEL OF T-CELL ACTIVATION AFTER 30 YEARS. Transplantation. 2002;73(1).

58. Chen L, Flies DB. Molecular mechanisms of T cell co-stimulation and coinhibition. Nat Rev Immunol. 2013;13(4):227-42.

59. Cameron MaK, DJ. Cytokines, Chemokines and Their Receptors. Madame Curie Bioscience Database [Internet]. Austin (TX): Landes Bioscience; 20002013.

60. Corthay A. A Three-cell Model for Activation of Naïve T Helper Cells. Scandinavian Journal of Immunology. 2006;64(2):93-6.

61. Mosmann TR, Cherwinski H, Bond MW, Giedlin MA, Coffman RL. Two types of murine helper T cell clone. I. Definition according to profiles of lymphokine activities and secreted proteins. J Immunol. 1986;136(7):2348-57.

62. Saravia J, Chapman NM, Chi H. Helper T cell differentiation. Cell Mol Immunol. 2019;16(7):634-43.

63. Luckheeram RV, Zhou R, Verma AD, Xia B. CD4(+)T cells: differentiation and functions. Clin Dev Immunol. 2012;2012:925135.

64. Rao DA, Gurish MF, Marshall JL, Slowikowski K, Fonseka CY, Liu Y, et al. Pathologically expanded peripheral T helper cell subset drives B cells in rheumatoid arthritis. Nature. 2017;542(7639):110-4.

65. Christophersen A, Lund EG, Snir O, Solà E, Kanduri C, Dahal-Koirala S, et al. Distinct phenotype of CD4+ T cells driving celiac disease identified in multiple autoimmune conditions. Nature Medicine. 2019.

66. Jameson SC, Masopust D. Understanding Subset Diversity in T Cell Memory. Immunity. 2018;48(2):214-26.

67. Spolski R, Li P, Leonard WJ. Biology and regulation of IL-2: from molecular mechanisms to human therapy. Nature Reviews Immunology. 2018;18(10):64859. 
68. Abbas AK, Trotta E, D RS, Marson A, Bluestone JA. Revisiting IL-2: Biology and therapeutic prospects. Sci Immunol. 2018;3(25).

69. Tye-Din JA, Skodje GI, Sarna VK, Dzuris JL, Russell AK, Goel G, et al. Cytokine release after gluten ingestion differentiates coeliac disease from selfreported gluten sensitivity. United European Gastroenterology Journal. 2019:2050640619874173.

70. Korn T, Bettelli E, Oukka M, Kuchroo VK. IL-17 and Th17 Cells. Annual Review of Immunology. 2009;27(1):485-517.

71. Moens LT, Stuart. Cytokine-Mediated Regulation of Plasma Cell Generation: IL-21 Takes Center Stage. Frontiers in Immunology. 2014;5(65).

72. Kooy-Winkelaar YMC, Bouwer D, Janssen GMC, Thompson A, Brugman MH, Schmitz F, et al. CD4 T-cell cytokines synergize to induce proliferation of malignant and nonmalignant innate intraepithelial lymphocytes. Proceedings of the National Academy of Sciences. 2017;114(6):E980-E9.

73. Di Niro R, Mesin L, Zheng N-Y, Stamnaes J, Morrissey M, Lee J-H, et al. High abundance of plasma cells secreting transglutaminase $2-$ specific IgA autoantibodies with limited somatic hypermutation in celiac disease intestinal lesions. Nature Medicine. 2012;18(3):441-5.

74. Abadie V, Discepolo V, Jabri B. Intraepithelial lymphocytes in celiac disease immunopathology. Semin Immunopathol. 2012;34(4):551-66.

75. Schroder K, Hertzog PJ, Ravasi T, Hume DA. Interferon- $\gamma$ : an overview of signals, mechanisms and functions. Journal of Leukocyte Biology. 2004;75(2):163-89.

76. Anderson RP, van Heel DA, Tye-Din JA, Barnardo M, Salio M, Jewell DP, et al. T cells in peripheral blood after gluten challenge in coeliac disease. Gut. 2005;54(9):1217-23.

77. Anderson RP, Degano P, Godkin AJ, Jewell DP, Hill AV. In vivo antigen challenge in celiac disease identifies a single transglutaminase-modified peptide as the dominant A-gliadin T-cell epitope. Nat Med. 2000;6(3):337-42.

78. Altin JG, Sloan EK. The role of CD45 and CD45-associated molecules in T cell activation. Immunol Cell Biol. 1997;75(5):430-45.

79. Schwinzer R, Siefken R, Franklin RA, Saloga J, Wonigeit K, Gelfand EW. Human CD45RA+ and CD45R0+ T cells exhibit similar CD3/T cell receptormediated transmembrane signaling capacities but differ in response to costimulatory signals. European Journal of Immunology. 1994;24(6):1391-5.

80. Michie CA, McLean A, Alcock C, Beverley PC. Lifespan of human lymphocyte subsets defined by CD45 isoforms. Nature. 1992;360(6401):264-5.

81. Sallusto F, Lenig D, Forster R, Lipp M, Lanzavecchia A. Two subsets of memory T lymphocytes with distinct homing potentials and effector functions. Nature. 1999;401(6754):708-12.

82. Schenkel Jason M, Masopust D. Tissue-Resident Memory T Cells. Immunity. 2014;41(6):886-97.

83. Fuhlbrigge RC, Kieffer JD, Armerding D, Kupper TS. Cutaneous lymphocyte antigen is a specialized form of PSGL-1 expressed on skin-homing T cells. Nature. 1997;389(6654):978-81. 
84. Bargatze RF, Jutila MA, Butcher EC. Distinct roles of L-selectin and integrins alpha 4 beta 7 and LFA-1 in lymphocyte homing to Peyer's patch-HEV in situ: the multistep model confirmed and refined. Immunity. 1995;3(1):99-108.

85. Hunt KA, Zhernakova A, Turner G, Heap GA, Franke L, Bruinenberg M, et al. Newly identified genetic risk variants for celiac disease related to the immune response. Nat Genet. 2008;40(4):395-402.

86. Abadie V, Sollid LM, Barreiro LB, Jabri B. Integration of Genetic and Immunological Insights into a Model of Celiac Disease Pathogenesis. Annual Review of Immunology. 2011;29(1):493-525.

87. Ploski R, Ek J, Thorsby E, Sollid LM. On the HLA-DQ $(\alpha 1 * 0501, \beta 1 * 0201)-$ associated susceptibility in celiac disease: a possible gene dosage effect of DQB1*0201. Tissue Antigens. 1993;41(4):173-7.

88. Tollefsen S, Arentz-Hansen H, Fleckenstein B, Molberg O, Raki M, Kwok WW, et al. HLA-DQ2 and -DQ8 signatures of gluten T cell epitopes in celiac disease. J Clin Invest. 2006;116(8):2226-36.

89. Molberg Ø, McAdam SN, Körner R, Quarsten H, Kristiansen C, Madsen L, et al. Tissue transglutaminase selectively modifies gliadin peptides that are recognized by gut-derived T cells in celiac disease. Nature Medicine. 1998;4(6):713-7.

90. Lorand L, Graham RM. Transglutaminases: crosslinking enzymes with pleiotropic functions. Nat Rev Mol Cell Biol. 2003;4(2):140-56.

91. Sollid LM, Iversen R, Steinsbo O, Qiao SW, Bergseng E, Dorum S, et al. Small bowel, celiac disease and adaptive immunity. Dig Dis. 2015;33(2):115-21.

92. Molberg O, Kett K, Scott H, Thorsby E, Sollid LM, Lundin KE. Gliadin specific, HLA DQ2-restricted T cells are commonly found in small intestinal biopsies from coeliac disease patients, but not from controls. Scand J Immunol. 1997;46(3):103-9.

93. Lundin KE, Scott H, Hansen T, Paulsen G, Halstensen TS, Fausa O, et al. Gliadin-specific, HLA-DQ $(\alpha 1 * 0501, \beta 1 * 0201)$ restricted T cells isolated from the small intestinal mucosa of celiac disease patients. J Exp Med. 1993;178(1):187-96.

94. Jensen K, Sollid LM, Scott H, Paulsen G, Kett K, Thorsby E, et al. GliadinSpecific T Cell Responses in Peripheral Blood of Healthy Individuals Involve T Cells Restricted by the Coeliac Disease Associated DQ2 Heterodimer. Scandinavian Journal of Immunology. 1995;42(1):166-70.

95. Christophersen A, Raki M, Bergseng E, Lundin KE, Jahnsen J, Sollid LM, et al. Tetramer-visualized gluten-specific CD4+ T cells in blood as a potential diagnostic marker for coeliac disease without oral gluten challenge. United European Gastroenterol J. 2014;2(4):268-78.

96. Sarna VK, Lundin KEA, Morkrid L, Qiao SW, Sollid LM, Christophersen A. HLA-DQ-Gluten Tetramer Blood Test Accurately Identifies Patients With and Without Celiac Disease in Absence of Gluten Consumption. Gastroenterology. 2018;154(4):886-96 e6.

97. Sandoval-Montes C, Santos-Argumedo L. CD38 is expressed selectively during the activation of a subset of mature $T$ cells with reduced proliferation but improved potential to produce cytokines. J Leukoc Biol. 2005;77(4):513-21. 
98. Bodd M, Raki M, Tollefsen S, Fallang LE, Bergseng E, Lundin KE, et al. HLADQ2-restricted gluten-reactive T cells produce IL-21 but not IL-17 or IL-22. Mucosal Immunol. 2010;3(6):594-601.

99. Nilsen EM, Jahnsen FL, Lundin KE, Johansen FE, Fausa O, Sollid LM, et al. Gluten induces an intestinal cytokine response strongly dominated by interferon gamma in patients with celiac disease. Gastroenterology. 1998;115(3):551-63.

100. Nilsen EM, Lundin KE, Krajci P, Scott H, Sollid LM, Brandtzaeg P. Gluten specific, HLA-DQ restricted T cells from coeliac mucosa produce cytokines with Th1 or Th0 profile dominated by interferon gamma. Gut. 1995;37(6):766.

101. Przemioslo RT, Lundin KE, Sollid LM, Nelufer J, Ciclitira PJ. Histological changes in small bowel mucosa induced by gliadin sensitive T lymphocytes can be blocked by anti-interferon gamma antibody. Gut. 1995;36(6):874-9.

102. Caruso R, Fina D, Peluso I, Stolfi C, Fantini MC, Gioia V, et al. A functional role for interleukin-21 in promoting the synthesis of the T-cell chemoattractant, MIP-3alpha, by gut epithelial cells. Gastroenterology. 2007;132(1):166-75.

103. Iversen R, Roy B, Stamnaes J, Hoydahl LS, Hnida K, Neumann RS, et al. Efficient $\mathrm{T}$ cell-B cell collaboration guides autoantibody epitope bias and onset of celiac disease. Proc Natl Acad Sci U S A. 2019;116(30):15134-9.

104. Hoydahl LS, Richter L, Frick R, Snir O, Gunnarsen KS, Landsverk OJ, et al. Plasma Cells are the Most Abundant Gluten Peptide MHC-expressing Cells in Inflamed Intestinal Tissues From Patients With Celiac Disease. Gastroenterology. 2018.

105. Hietikko M, Koskinen O, Kurppa K, Laurila K, Saavalainen P, Salmi T, et al. Small-intestinal TG2-specific plasma cells at different stages of coeliac disease. BMC Immunol. 2018;19(1):36.

106. Snir O, Chen X, Gidoni M, du Pre MF, Zhao Y, Steinsbo O, et al. Stereotyped antibody responses target posttranslationally modified gluten in celiac disease. JCI Insight. 2017;2(17).

107. Snir O, Mesin L, Gidoni M, Lundin KE, Yaari G, Sollid LM. Analysis of celiac disease autoreactive gut plasma cells and their corresponding memory compartment in peripheral blood using high-throughput sequencing. J Immunol. 2015;194(12):5703-12.

108. Iversen R, Fleur du Pre M, Di Niro R, Sollid LM. Igs as Substrates for Transglutaminase 2: Implications for Autoantibody Production in Celiac Disease. J Immunol. 2015;195(11):5159-68.

109. du Pre MF, Sollid LM. T-cell and B-cell immunity in celiac disease. Best Pract Res Clin Gastroenterol. 2015;29(3):413-23.

110. Lopez-Palacios N, Pascual V, Castano M, Bodas A, Fernandez-Prieto M, Espino-Paisan L, et al. Evaluation of T cells in blood after a short gluten challenge for coeliac disease diagnosis. Dig Liver Dis. 2018.

111. Jabri B, Sollid LM. T Cells in Celiac Disease. J Immunol. 2017;198(8):3005-14.

112. Gianfrani C, Troncone R, Mugione P, Cosentini E, De Pascale M, Faruolo C, et al. Celiac Disease Association with CD8+ T Cell Responses: Identification of a Novel Gliadin-Derived HLA-A2-Restricted Epitope. The Journal of Immunology. 2003;170(5):2719-26. 
113. Picascia S, Sidney J, Camarca A, Mazzarella G, Giardullo N, Greco L, et al. Gliadin-Specific CD8+ T Cell Responses Restricted by HLA Class I A*0101 and B*0801 Molecules in Celiac Disease Patients. The Journal of Immunology. 2017;198(5):1838-45.

114. Johansson K, Norstrom F, Nordyke K, Myleus A. Celiac Dietary Adherence Test simplifies Determining Adherence to a Gluten-free Diet in Swedish Adolescents. J Pediatr Gastroenterol Nutr. 2019;69(5):575-80.

115. Lovik A, Skodje G, Bratlie J, Brottveit M, Lundin KE. Diet adherence and gluten exposure in coeliac disease and self-reported non-coeliac gluten sensitivity. Clin Nutr. 2017;36(1):275-80.

116. Vorobjova T, Uibo O, Heilman K, Rägo T, Honkanen J, Vaarala O, et al. Increased FOXP3 expression in small-bowel mucosa of children with coeliac disease and type I diabetes mellitus. Scand J Gastroenterol. 2009;44(4):422-30.

117. Hmida NB, Ben Ahmed M, Moussa A, Rejeb MB, Said Y, Kourda N, et al. Impaired control of effector $\mathrm{T}$ cells by regulatory $\mathrm{T}$ cells: a clue to loss of oral tolerance and autoimmunity in celiac disease? Am J Gastroenterol. 2012;107(4):604-11.

118. Christophersen A, Risnes LF, Bergseng E, Lundin KE, Sollid LM, Qiao SW. Healthy HLA-DQ2.5+ Subjects Lack Regulatory and Memory T Cells Specific for Immunodominant Gluten Epitopes of Celiac Disease. J Immunol. 2016;196(6):2819-26.

119. Cook L, Munier CML, Seddiki N, van Bockel D, Ontiveros N, Hardy MY, et al. Circulating gluten-specific FOXP3+CD39+ regulatory T cells have impaired suppressive function in patients with celiac disease. Journal of Allergy and Clinical Immunology. 2017;140(6):1592-603.e8.

120. Tye-Din JA, Galipeau HJ, Agardh D. Celiac Disease: A Review of Current Concepts in Pathogenesis, Prevention, and Novel Therapies. Frontiers in Pediatrics. 2018;6(350).

121. Bouziat R, Hinterleitner R, Brown JJ, Stencel-Baerenwald JE, Ikizler M, Mayassi $\mathrm{T}$, et al. Reovirus infection triggers inflammatory responses to dietary antigens and development of celiac disease. Science. 2017;356(6333):44-50.

122. Kahrs CR, Chuda K, Tapia G, Stene LC, Marild K, Rasmussen T, et al. Enterovirus as trigger of coeliac disease: nested case-control study within prospective birth cohort. Bmj. 2019;364:1231.

123. Lindfors K, Lin J, Lee HS, Hyoty H, Nykter M, Kurppa K, et al. Metagenomics of the faecal virome indicate a cumulative effect of enterovirus and gluten amount on the risk of coeliac disease autoimmunity in genetically at risk children: the TEDDY study. Gut. 2019.

124. Taavela J, Koskinen O, Huhtala H, Lahdeaho ML, Popp A, Laurila K, et al. Validation of morphometric analyses of small-intestinal biopsy readouts in celiac disease. PLoS One. 2013;8(10):e76163.

125. Lebwohl B, Sanders DS, Green PHR. Coeliac disease. The Lancet. 2018;391(10115):70-81. 
126. Al-Toma A, Volta U, Auricchio R, Castillejo G, Sanders DS, Cellier C, et al. European Society for the Study of Coeliac Disease (ESsCD) guideline for coeliac disease and other gluten-related disorders. United European Gastroenterology Journal. 2019;0(0):2050640619844125.

127. Holmes G, Ciacci C. The serological diagnosis of coeliac disease - a step forward. Gastroenterol Hepatol Bed Bench. 2018;11(3):209-15.

128. Fuchs V, Kurppa K, Huhtala H, Laurila K, Maki M, Collin P, et al. Serologybased criteria for adult coeliac disease have excellent accuracy across the range of pre-test probabilities. Aliment Pharmacol Ther. 2019;49(3):277-84.

129. Ludvigsson JF, Ciacci C, Green PH, Kaukinen K, Korponay-Szabo IR, Kurppa $\mathrm{K}$, et al. Outcome measures in coeliac disease trials: the Tampere recommendations. Gut. 2018;67(8):1410-24.

130. Mahadev S, Murray JA, Wu T-T, Chandan VS, Torbenson MS, Kelly CP, et al. Factors associated with villus atrophy in symptomatic coeliac disease patients on a gluten-free diet. Alimentary Pharmacology \& Therapeutics. 2017;45(8):108493.

131. Leffler DA, Acaster S, Gallop K, Dennis M, Kelly CP, Adelman DC. A Novel Patient-Derived Conceptual Model of the Impact of Celiac Disease in Adults: Implications for Patient-Reported Outcome and Health-Related Quality-of-Life Instrument Development. Value Health. 2017;20(4):637-43.

132. Boyman O, Sprent J. The role of interleukin-2 during homeostasis and activation of the immune system. Nat Rev Immunol. 2012;12(3):180-90.

133. Tye-Din JAD, J; Russell, A; Wang, S; Goldstein, K; Williams, L; Anderson, R. An acute cytokine signature elicited by a bolus gluten challenge identifies patients following a gluten-free diet (GFD) with celiac disease (CeD) from those without. 17th International Celiac Disease Symposium; 08.-10.09.2017; New Delhi, India2017. p. 20.

134. Nilsson C, Aboud S, Karlén K, Hejdeman B, Urassa W, Biberfeld G. Optimal Blood Mononuclear Cell Isolation Procedures for Gamma Interferon EnzymeLinked Immunospot Testing of Healthy Swedish and Tanzanian Subjects. Clinical and Vaccine Immunology. 2008;15(4):585.

135. Mallone R, Mannering SI, Brooks-Worrell BM, Durinovic-Belló I, Cilio CM, Wong FS, et al. Isolation and preservation of peripheral blood mononuclear cells for analysis of islet antigen-reactive $\mathrm{T}$ cell responses: position statement of the T-Cell Workshop Committee of the Immunology of Diabetes Society. Clinical \& Experimental Immunology. 2011;163(1):33-49.

136. Guillaumet-Adkins A, Rodríguez-Esteban G, Mereu E, Mendez-Lago M, Jaitin DA, Villanueva A, et al. Single-cell transcriptome conservation in cryopreserved cells and tissues. Genome Biology. 2017;18(1):45.

137. Sollid LM, Jabri B. Triggers and drivers of autoimmunity: lessons from coeliac disease. NatRevImmunol. 2013;13(4):294-302.

138. Gibson PR, Shepherd SJ. Evidence-based dietary management of functional gastrointestinal symptoms: The FODMAP approach. J Gastroenterol Hepatol. 2010;25(2):252-8. 
139. Quarsten H, McAdam SN, Jensen T, Arentz-Hansen H, Molberg O, Lundin KE, et al. Staining of celiac disease-relevant T cells by peptide-DQ2 multimers. J Immunol. 2001;167(9):4861-8.

140. Moon JJ, Chu HH, Pepper M, McSorley SJ, Jameson SC, Kedl Ross M, et al. Naive CD4+ T Cell Frequency Varies for Different Epitopes and Predicts Repertoire Diversity and Response Magnitude. Immunity. 2007;27(2):203-13.

141. Zühlke S, Risnes LF, Dahal-Koirala S, Christophersen A, Sollid LM, Lundin KE. CD38 expression on gluten-specific T cells is a robust marker of gluten reexposure in coeliac disease. United European Gastroenterol J. 2019;7(10):133744.

142. Skodje GI, Sarna VK, Minelle IH, Rolfsen KL, Muir JG, Gibson PR, et al. Fructan, Rather Than Gluten, Induces Symptoms in Patients With Self-Reported Non-Celiac Gluten Sensitivity. Gastroenterology. 2018;154(3):529-39 e2.

143. Garner C, Ahn R, Ding YC, Steele L, Stoven S, Green PH, et al. Genome-wide association study of celiac disease in North America confirms FRMD4B as new celiac locus. PLoS One. 2014;9(7):e101428.

144. Trynka G, Hunt KA, Bockett NA, Romanos J, Mistry V, Szperl A, et al. Dense genotyping identifies and localizes multiple common and rare variant association signals in celiac disease. Nat Genet. 2011;43(12):1193-201.

145. Dubois PC, Trynka G, Franke L, Hunt KA, Romanos J, Curtotti A, et al. Multiple common variants for celiac disease influencing immune gene expression. Nat Genet. 2010;42(4):295-302.

146. Garner CP, Murray JA, Ding YC, Tien Z, van Heel DA, Neuhausen SL. Replication of celiac disease UK genome-wide association study results in a US population. Hum Mol Genet. 2009;18(21):4219-25.

147. van Heel DA, Franke L, Hunt KA, Gwilliam R, Zhernakova A, Inouye M, et al. A genome-wide association study for celiac disease identifies risk variants in the region harboring IL2 and IL21. Nat Genet. 2007;39(7):827-9.

148. Spitzer MH, Nolan GP. Mass Cytometry: Single Cells, Many Features. Cell. 2016;165(4):780-91.

149. Christophersen A. Peptide-MHC class I and class II tetramers: From flow to mass cytometry. HLA. 2020;95(3):169-78.

150. USA TB. SMART-Seq ${ }^{\circledR}$ v4 Ultra ${ }^{\circledR}$ Low Input RNA Kit for Sequencing User Manual2017. Available from:

https:/www.takarabio.com/assets/documents/User\%20Manual/SMARTer\%20U niversal\%20Low $\% 20$ Input $\% 20$ RNA $\% 20$ Kit $\% 20$ for $\% 20$ Sequencing $\% 20$ User $\% 2$ 0Manual_010919.pdf.

151. Picelli S, Faridani OR, Bjorklund AK, Winberg G, Sagasser S, Sandberg R. Fulllength RNA-seq from single cells using Smart-seq2. Nat Protoc. 2014;9(1):17181.

152. Ramskold D, Luo S, Wang YC, Li R, Deng Q, Faridani OR, et al. Full-length mRNA-Seq from single-cell levels of RNA and individual circulating tumor cells. Nat Biotechnol. 2012;30(8):777-82. 
153. Shanker S, Paulson A, Edenberg HJ, Peak A, Perera A, Alekseyev YO, et al. Evaluation of commercially available RNA amplification kits for RNA sequencing using very low input amounts of total RNA. J Biomol Tech. 2015;26(1):4-18.

154. van Dijk EL, Auger H, Jaszczyszyn Y, Thermes C. Ten years of next-generation sequencing technology. Trends in Genetics. 2014;30(9):418-26.

155. Chhangawala S, Rudy G, Mason CE, Rosenfeld JA. The impact of read length on quantification of differentially expressed genes and splice junction detection. Genome biology. 2015;16(1):131-.

156. Patro R, Duggal G, Love MI, Irizarry RA, Kingsford C. Salmon provides fast and bias-aware quantification of transcript expression. Nature Methods. 2017; 14:417.

157. Love MI, Huber W, Anders S. Moderated estimation of fold change and dispersion for RNA-seq data with DESeq2. Genome Biology. 2014;15(12):550.

158. website EC. [Available from: https://ec.europa.eu/commission/priorities/justiceand-fundamental-rights/data-protection/2018-reform-eu-data-protectionrules/eu-data-protection-rules_en.

159. Guo XZ, Dash P, Calverley M, Tomchuck S, Dallas MH, Thomas PG. Rapid cloning, expression, and functional characterization of paired alphabeta and gammadelta T-cell receptor chains from single-cell analysis. Mol Ther Methods Clin Dev. 2016;3:15054.

160. Risnes LF, Christophersen A, Dahal-Koirala S, Neumann RS, Sandve GK, Sarna VK, et al. Disease-driving CD4+ T cell clonotypes persist for decades in celiac disease. J Clin Invest. 2018;128(6):2642-50.

161. Vander Heiden JA, Yaari G, Uduman M, Stern JN, O'Connor KC, Hafler DA, et al. pRESTO: a toolkit for processing high-throughput sequencing raw reads of lymphocyte receptor repertoires. Bioinformatics. 2014;30(13):1930-2.

162. Alamyar E, Duroux P, Lefranc MP, Giudicelli V. IMGT((R)) tools for the nucleotide analysis of immunoglobulin (IG) and T cell receptor (TR) V-(D)-J repertoires, polymorphisms, and IG mutations: IMGT/V-QUEST and IMGT/HighV-QUEST for NGS. Methods Mol Biol. 2012;882:569-604.

163. Diagnostics M. [Available from:

https://www.mesoscale.com/en/technical_resources/our_technology/ecl.

164. Chen XM, Su BY, Song XH, Chen QA, Chen X, Wang XR. Recent advances in electrochemiluminescent enzyme biosensors. Trac-Trend Anal Chem. 2011;30(5):665-76.

165. Richter MM. Electrochemiluminescence (ECL). Chem Rev. 2004;104(6):300336.

166. Brottveit M, Vandvik PO, Wojniusz S, Lovik A, Lundin KE, Boye B. Absence of somatization in non-coeliac gluten sensitivity. Scand J Gastroenterol. 2012;47(7):770-7.

167. Wiklund IK, Fullerton S, Hawkey CJ, Jones RH, Longstreth GF, Mayer EA, et al. An irritable bowel syndrome-specific symptom questionnaire: development and validation. Scand J Gastroenterol. 2003;38(9):947-54. 
168. Verdu EF, Armstrong D, Murray JA. Between celiac disease and irritable bowel syndrome: the "no man's land" of gluten sensitivity. Am J Gastroenterol. 2009;104(6):1587-94.

169. Scheff SW. Chapter 8 - Nonparametric Statistics. In: Scheff SW, editor. Fundamental Statistical Principles for the Neurobiologist: Academic Press; 2016. p. 157-82.

170. WMA Declaration of Helsinki - Ethical Priciples For Medical Research Involving Human Subjects, (2013).

171. van Berge-Henegouwen GP, Mulder CJ. Pioneer in the gluten free diet: WillemKarel Dicke 1905-1962, over 50 years of gluten free diet. Gut. 1993;34(11):1473-5.

172. Guandalini S. Historical Perspective of Celiac Disease. Fasano A, Troncone R, Branski D, editors. Pediatr Adolesc Med. Basel: Karger; 2008.

173. Ludvigsson JF, Leffler DA, Bai JC, Biagi F, Fasano A, Green PH, et al. The Oslo definitions for coeliac disease and related terms. Gut. 2013;62(1):43-52.

174. Bruins MJ. The clinical response to gluten challenge: a review of the literature. Nutrients. 2013;5(11):4614-41.

175. Ooi JD, Petersen J, Tan YH, Huynh M, Willett ZJ, Ramarathinam SH, et al. Dominant protection from HLA-linked autoimmunity by antigen-specific regulatory T cells. Nature. 2017;545(7653):243-7.

176. Petersen J, van Bergen J, Loh KL, Kooy-Winkelaar Y, Beringer DX, Thompson A, et al. Determinants of gliadin-specific T cell selection in celiac disease. $\mathrm{J}$ Immunol. 2015;194(12):6112-22.

177. Scally SW, Petersen J, Law SC, Dudek NL, Nel HJ, Loh KL, et al. A molecular basis for the association of the HLA-DRB1 locus, citrullination, and rheumatoid arthritis. J Exp Med. 2013;210(12):2569-82.

178. McKenna KC, Beatty KM, Vicetti Miguel R, Bilonick RA. Delayed processing of blood increases the frequency of activated CD11b+CD15+ granulocytes which inhibit T cell function. Journal of Immunological Methods. 2009;341(1):68-75.

179. Bull M, Lee D, Stucky J, Chiu Y-L, Rubin A, Horton H, et al. Defining blood processing parameters for optimal detection of cryopreserved antigen-specific responses for HIV vaccine trials. Journal of Immunological Methods. 2007;322(1):57-69.

180. Bonanno FG. Hemorrhagic shock: The "physiology approach". J Emerg Trauma Shock. 2012;5(4):285-95.

181. Dahal-Koirala S, Risnes LF, Christophersen A, Sarna VK, Lundin KE, Sollid LM, et al. TCR sequencing of single cells reactive to DQ2.5-glia-alpha2 and DQ2.5-glia-omega2 reveals clonal expansion and epitope-specific V-gene usage. Mucosal Immunol. 2016;9(3):587-96.

182. Malavasi F, Deaglio S, Funaro A, Ferrero E, Horenstein AL, Ortolan E, et al. Evolution and Function of the ADP Ribosyl Cyclase/CD38 Gene Family in Physiology and Pathology. Physiological Reviews. 2008;88(3):841-86.

183. Funaro A, De Monte LB, Dianzani U, Forni M, Malavasi F. Human CD38 is associated to distinct molecules which mediate transmembrane signaling in different lineages. Eur J Immunol. 1993;23(10):2407-11. 
184. Goel G, Tye-Din JA, Qiao S-W, Russell AK, Mayassi T, Ciszewski C, et al. Cytokine release and gastrointestinal symptoms after gluten challenge in celiac disease. Sci Adv. 2019;5(8):eaaw7756-eaaw.

185. Swain S, Roe MM, Sebrell TA, Sidar B, Dankoff J, VanAusdol R, et al. CD103 ( $\alpha$ E Integrin) Undergoes Endosomal Trafficking in Human Dendritic Cells, but Does Not Mediate Epithelial Adhesion. Front Immunol. 2018;9:2989.

186. Molfetta R, Quatrini L, Zitti B, Capuano C, Galandrini R, Santoni A, et al. Regulation of NKG2D Expression and Signaling by Endocytosis. Trends Immunol. 2016;37(11):790-802.

187. Toh BH, Kyaw T, Tipping P, Bobik A. Immune regulation by CD52-expressing CD4 T cells. Cell Mol Immunol. 2013;10(5):379-82.

188. Kaur S, Singh SP, Elkahloun AG, Wu W, Abu-Asab MS, Roberts DD. CD47dependent immunomodulatory and angiogenic activities of extracellular vesicles produced by T cells. Matrix Biol. 2014;37:49-59.

189. Risnes LF, Christophersen A, Dahal-Koirala S, Neumann RS, Sandve GK, Sarna VK, et al. Disease-driving CD4+ T cell clonotypes persist for decades in celiac disease. The Journal of Clinical Investigation. 2018;128(6). 

I 



\title{
CD38 expression on gluten-specific $T$ cells is a robust marker of gluten re-exposure in coeliac disease
}

\author{
Stephanie Zühlke ${ }^{1} \odot$, Louise Fremgaard Risnes ${ }^{1}$, Shiva Dahal-Koirala ${ }^{1}$, \\ Asbjørn Christophersen ${ }^{1}$, Ludvig M Sollid ${ }^{1, \star}$ and Knut EA Lundin ${ }^{1,2, \star}$
}

\begin{abstract}
Background: Increasing efforts are being put into new treatment options for coeliac disease (CeD), a chronic disorder of the small intestine induced by gluten. Interleukin-2 (IL-2) and gluten-specific CD $4+$ T cells increase in the blood after four hours and six days, respectively, following a gluten challenge in $\mathrm{CeD}$ patients. These responses are unique to $\mathrm{CeD}$ and are not seen in controls. We aimed to evaluate different markers reflecting a recall response to gluten exposure that may be used to monitor therapy.

Methods: CeD patients on a gluten-free diet underwent a one- $(n=6)$ or three-day $(n=7)$ oral gluten challenges. We collected blood samples at several time points between baseline and day 8, and monitored gluten-specific CD $4+T$ cells for their frequency and CD38 expression using HLA-DQ:gluten tetramers. We assessed the IL-2 concentration in plasma four hours after the first gluten intake.

Results: The frequency of gut-homing, tetramer-binding, CD4 + effector memory $T$ (tetramer $+\beta 7+T_{E M}$ ) cells and the IL-2 concentration measured shortly after the first dose of gluten increased significantly after the one- and three-day gluten challenges, but large interindividual differences were exhibited. The frequency of tetramer $+\beta 7+T_{E M}$ plateaued between days 6 and 8 and was lower after the one-day challenge. We observed a consistent increase in CD38 expression on tetramer $+\beta 7+T_{E M}$ cells and did not find a significant difference between the one- and three-day challenges.

Conclusions: The optimal time points for monitoring therapy response in $\mathrm{CeD}$ after a three-day oral gluten challenge is four hours for plasma IL-2 or six to eight days for the frequency of tetramer $+\beta 7+T_{E M}$ cells, but both these parameters involved large interindividual differences. In contrast, CD38 expression on tetramer $+\beta 7+T_{E M}$ cells increased uniformly and irrespectively of the length of gluten challenge, suggesting that this parameter is more suited for monitoring drug efficacy in clinical trials for CeD.
\end{abstract}

Keywords

Coeliac disease, gluten, kinetics, tetramers, T cells, CD4, CD38, interleukin, IL-2, activation marker

Received: 4 June 2019; accepted: 6 August 2019

\section{Introduction}

Coeliac disease (CeD) is a human leucocyte antigen (HLA)-associated autoimmune enteropathy driven by an immune response upon consumption of foodstuff containing gluten proteins from wheat, rye or barley. ${ }^{1}$ Gluten-specific CD4 + T cells preferentially recognise deamidated gluten epitopes that are selectively presented by the disease-associated HLA-DQ2 (DQ2.5/ DQ2.2) or HLA-DQ8 molecules. Gluten-specific $\mathrm{CD} 4+\mathrm{T}$ cells orchestrate immune responses that lead to the formation of small intestinal lesions, to the production of antibodies to transglutaminase 2 (TG2) and anti-deamidated gluten peptides (DGP) as well as to expansion of gluten-specific CD4+T-cell clones. ${ }^{2,3}$

\footnotetext{
${ }^{1}$ K.G. Jebsen Coeliac Disease Research Centre, Department of Immunology, University of Oslo, Oslo, Norway

${ }^{2}$ Department of Gastroenterology, Oslo University Hospital Rikshospitalet, Oslo, Norway

*These authors contributed equally to this work.

Corresponding author:

Stephanie Zühlke, Department of Immunology, Oslo University Hospital Rikshospitalet, Sognsvannsveien 20, N-0372 0slo, Norway.

Email: stephanie.zuhlke@medisin.uio.no
} 
A growing interest in the development of new therapies for $\mathrm{CeD}$ has created a need for robust surrogate markers to assess biological effect of treatment in addition to the mandatory monitoring of patient-reported outcomes. ${ }^{4-6}$ Many of those surrogate markers constitute a challenge, as their values display large interindividual variation, thus necessitating large sample sizes of study groups to assess treatment efficacy. ${ }^{7-10}$ Surrogate markers that reflect activation of gluten-specific CD4+T cells would have particular promise, given the central role of these cells in the disease pathogenesis. ${ }^{11}$ Glutenspecific CD4 + T cells can be detected in an interferon- $\gamma$ secretion assay (ELISPOT) and by flow cytometry in the blood of treated CeD patients on day 6 after the onset of a three-day gluten challenge using HLADQ: gluten tetramers. ${ }^{10,12,13}$ These responses are exclusively seen in CeD patients. ${ }^{8,13,14}$ Some results from kinetic analysis of interferon $\gamma$-secreting $\mathrm{T}$ cells using ELISPOT $^{10}$ and sequential measurements of HLADQ:gluten tetramer-positive $T$ cells ${ }^{15}$ have been reported. However, day-by-day kinetic analysis of HLA-DQ:gluten tetramer-positive $\mathrm{T}$ cells in blood after gluten challenge has not been performed. Since gluten-specific $\mathrm{T}$ cells may be used for diagnostic and therapeutic purposes, ${ }^{7,8,16}$ a more detailed understanding of their kinetics and cell biology is needed.

T cells expressing high levels of CD38 have been shown to exhibit an improved potential to produce the cytokines interleukin-2 (IL-2) and interferon- $\gamma$, despite a reduced proliferative capacity. ${ }^{17} \mathrm{CD} 38$ is a multifunctional enzyme playing a role in cellular and tissue nicotinamide adenine dinucleotide homeostasis and in the generation of second messengers involved in intracellular calcium signalling. ${ }^{18}$ In T cells, CD38 ligation leads to cellular signalling that involves pathways also downstream of TCR-CD3 ligation, ${ }^{19,20}$ thus suggesting a role of $\mathrm{CD} 38$ during antigen-induced activation of T cells. ${ }^{21} \mathrm{Du}$ Pré et al. were the first to describe CD38 + gluten-specific $\mathrm{T}$ cells in blood from CeD patients. ${ }^{22}$ Subsequently, CD 38 has been identified as a consistent marker on activated gut-homing glutenspecific $\mathrm{T}$ cells in $\mathrm{CeD}$, which could have diagnostic relevance. $^{7,8}$

Recent studies provide insights on fast-rising cytokine levels within few hours after a gluten challenge in treated CeD patients. ${ }^{8,9}$ Here, IL-2 in particular stands out as the cytokine with the most robust increase. ${ }^{9}$ IL-2 is to a large extent produced by $\mathrm{T}$ cells themselves, but also natural killer (NK) cells, NK T cells, dendritic cells and mast cells. It acts in an auto- and paracrine manner and exerts crucial functions during immune homeostasis. ${ }^{23}$

In this study, we assessed the potential of IL-2 and CD38 as surrogate markers for gluten re-exposure compared to the increase of gluten-specific $\mathbf{T}$ cells in the blood in response to an antigen challenge. In addition, we examined the kinetics of gluten-specific CD4+ T-cell frequency after a gluten challenge over three days in a detailed manner and assessed patient-reported outcome measures (PROM).

\section{Methods}

\section{Patient recruitment and inclusion}

Participants were recruited by direct invitation and announcements on hospital employee websites, a public health website, the K.G. Jebsen Coeliac Disease Research Centre website and social media.

All study participants had a biopsy-confirmed CeD diagnosis according to guidelines. ${ }^{24}$ Compliance was evaluated by anti-TG2 immunoglobulin $\mathrm{A}(\mathrm{IgA})$ and anti-DGP immunoglobulin G (IgG) levels below the upper limit of normal and led otherwise to exclusion. A complete list of inclusion and exclusion criteria is given in Table 1. All participants gave informed written consent, and blood samples were drawn at Oslo University Hospital. The study was approved by the regional ethics committee $(2013 / 1237)$ and was published on ClinicalTrials.gov (NCT02464150).

Table 1. Inclusion and exclusion criteria.

\begin{tabular}{|c|c|}
\hline Inclusion criteria & Exclusion criteria \\
\hline Between 18 and 80 years of age & Anti-TG2 IgA and anti-DGP IgG levels above upper limit of normal \\
\hline Given written informed consent for participation & $\begin{array}{l}\text { Woman in fertile age not taking adequate contraceptive measures, } \\
\text { pregnant or breastfeeding }\end{array}$ \\
\hline $\begin{array}{l}\text { Coeliac disease verified by positive biopsy before start of } \\
\text { gluten-free diet }\end{array}$ & Use of immune-suppressive medication for the last three months \\
\hline Following a gluten-free diet for at least six months & $\begin{array}{l}\text { Chronic (other gastrointestinal or systemic disease) or severe acute } \\
\text { infection }\end{array}$ \\
\hline HLA-DQ2.5 genotype & Anaemia \\
\hline
\end{tabular}

HLA: human leucocyte antigen; IgA: immunoglobulin A; DGP: deamidated gluten peptides; IgG: immunoglobulin G. 
Sixteen subjects were invited to participate in either a one-day gluten challenge study or a three-day gluten challenge study protocol. One patient in the three-day challenge group dropped out after the first day of challenge. Due to technical issues, samples from one patient in the one-day challenge group could not be analysed. Samples from the three-day challenge had to be analysed several times by flow cytometry, which resulted in a lack of one sample at baseline and one on day 7 . Together, 13 (12 female) patients were included in the analysis (Supplemental Figure S1).

\section{Gluten challenge protocol}

All participants ingested one $46 \mathrm{~g}$ cookie daily for either one or three days and gave a baseline blood sample. Individuals participating in the three-day challenge protocol gave additional blood samples on day 1 (four hours after challenge) and on days 4-8. Individuals participating in the one-day challenge protocol gave additional samples on day 1 (four hours after challenge) and on day 6 (Supplemental Figure S2).

The cookies contained $10 \mathrm{~g}$ of gluten-enriched flour ( $8 \mathrm{~g}$ of gluten protein) and were free of most common allergens (Table 2). The cookies were baked at the Department of Nutrition at the University of Oslo (Oslo, Norway). The gluten content in the cookies was confirmed by enzyme-linked immunosorbent assay (ELISA; RIDASCREEN ${ }^{\text {G }}$ Gliadin; R-Biopharm AG, Darmstadt, Germany) and nano liquid chromatography tandem mass spectrometry (data not shown). Apart from the gluten-containing cookies, the participants continued their regular gluten-free diet.

\section{PROM}

Symptoms were scored using a visual analogue scale (VAS; Supplemental Figure S3) for gastrointestinal

Table 2. List of ingredients in a $46 \mathrm{~g}$ cookie.

\begin{tabular}{lc}
\hline Ingredients & $46 \mathrm{~g}$ cookie \\
\hline Gluten flour & $10.4 \mathrm{~g}$ \\
Milk and soya-free margarine & $10.0 \mathrm{~g}$ \\
Dark chocolate & $8.0 \mathrm{~g}$ \\
Swede syrup & $5.2 \mathrm{~g}$ \\
Maple syrup & $5.2 \mathrm{~g}$ \\
Cranberries & $3.6 \mathrm{~g}$ \\
Coconut flour & $3.2 \mathrm{~g}$ \\
Raisins & $2.4 \mathrm{~g}$ \\
Vanilla sugar & $0.6 \mathrm{~g}$ \\
Salt & $0.15 \mathrm{~g}$ \\
\hline
\end{tabular}

symptoms over a period of two to three days before gluten challenge until the day before the last blood sample. Scores were obtained for pain, bloating, flatulence, nausea, stool consistency and overall symptoms. In addition, the Gastrointestinal Symptom Rating Scale modified for patients with irritable bowel syndrome (GSRS-IBS) ${ }^{25}$ was measured before gluten challenge, on day 3 and at the time point of the last blood sample drawing (day 6 or day 8).

\section{Antibody tests, HLA typing and cytokine analysis}

Measurements of IgA-anti-TG2 (normal $<4 \mathrm{IU} / \mathrm{mL}$; QUANTA Lite R h-tTG IgA ELISA) and IgG-antiDGP IgG (normal $<20 \quad \mathrm{IU} / \mathrm{mL}$; QUANTA Lite Gliadin IgG II; both INOVA Diagnostics, San Diego, CA) were performed in serum at baseline and on day 6 after the start of challenge (Supplemental Table S1). All included participants were typed for $H L A-D Q A I$ and $H L A-D Q B I$ alleles (full genomic HLA typing, LABType SSO; ONE LAMBDA, Los Angeles, CA).

Plasma samples for cytokine measurements $(n=13)$ were collected at baseline and four hours after the onset of challenge (day 1). Samples were kept frozen at $-80^{\circ} \mathrm{C}$ and were later analysed in duplicate with a V-PLEX assay for IL-2 at a 1:1 dilution according to the manufacturer's instructions on a MSD QuickPlex SQ 120 (Meso Scale Diagnostics, Rockville, MD). The values presented are the means of the duplicates.

\section{Peripheral blood mononuclear cell isolation, tetramer staining and surface marker staining}

Immediately after drawing between $40 \mathrm{~mL}$ (days 1-8) and $100 \mathrm{~mL}$ of blood at baseline, peripheral blood mononuclear cells (PBMC) were isolated from cell preparation tubes (BD Vacutainer ${ }^{8} \mathrm{CPT}^{\mathrm{TM}}$ Mononuclear Cell Preparation Tubes; BD Biosciences, San Jose, CA). PBMC collected for the three-day challenge protocol were frozen and kept in a liquid-nitrogen tank until cell staining and analysis. PBMC collected for the oneday challenge protocol were processed immediately. Samples were incubated with an equal mixture of HLA-DQ2.5:gluten tetramers, ${ }^{26}$ representing the epitopes DQ2.5-glia- $\alpha 1 \mathrm{a}, \mathrm{DQ} 2.5$-glia- $\alpha 2$, DQ2.5-glia- $\omega 1$, DQ2.5-glia- $\omega 2$ and DQ2.5-hor $3(10 \mu \mathrm{g} / \mathrm{mL}$ of each tetramer). HLA-DQ:gluten tetramer-binding cells underwent manual (for frozen samples) or automated (for fresh samples) bead enrichment, as described previously, ${ }^{7,27}$ and were stained with the following antibody mixture: CD38-FITC, CD45RA-PE-Cy7 and LIFE/DEAD Fixable Dead Cell Violet Stain (eBioscience, Thermo Fisher Scientific, Waltham, MA); CD4-APC-H7, CD62L-PerCP/Cy5.5, Integrin $\beta$ 7-APC, CD11c-Pacific Blue (PB; BD Biosciences), CD14-PB, CD19-PB, 
CD56-PB and CD3-Brilliant Violet 605 (BioLegend, San Diego, CA); or CD3-Superbright 605 (eBioscience, Thermo Fisher Scientific). CD4 + T cells were analysed by flow cytometry for CD3 + CD4 + CD11c-CD14 CD19-CD56-CD45RA-CD62L-integrin $\beta 7+$ HLADQ:gluten tetramer $+\left(\right.$ tetramer $\left.+\beta 7+T_{E M}\right)$ cells. Flow cytometry was performed using either BD LSRFortessa $^{\mathrm{TM}}$ or BD FACSAria ${ }^{\mathrm{TM}}$ IIu (BD Biosciences). The gating strategy is shown in Supplementary Figure S4. The number of tetramer+ $\beta 7+\mathrm{T}_{\mathrm{EM}}$ was normalised to $10^{6} \mathrm{CD} 4+$ cells estimated from a pre-enriched sample.

\section{Data analysis}

Flow cytometry data were analysed with FlowJo v10.5 (FlowJo, LLC, Ashland, OR). GraphPad Prism v8 (GraphPad Software, San Diego, CA) was used assess significant differences and correlations. The Wilcoxon signed-rank test was used to compare groups. The significance level was set at $p<0.05$ and was adjusted for multiple testing where applicable. Missing values were excluded list-wise.

\section{Results}

\section{Patient characteristics}

All included participants $(n=13)$ were HLA-DQ2.5positive and seronegative (IgA-anti-TG2 and IgG-anti-DGP) at inclusion. None of them showed parameters of blood indicating anaemia or other relevant diseases. Participants had been on a gluten-free diet for a median of 11 years (range 3-29 years). The median age of the patients was 37 years (range 19-75 years) at inclusion (Table 3).

\section{PROM}

After ingesting gluten-containing cookies, the participants reported their gastrointestinal symptoms daily in a symptom diary in the form of a VAS. For the three-day challenge, the median VAS score peaked on days $1-2$ or days $6-7$ (pain: $22 / 100 \mathrm{~mm}$ on day 1 ; nausea: $4 / 100 \mathrm{~mm}$ on day 1 ; satisfaction with defecation: $18 / 100 \mathrm{~mm}$ on day 2 ; bloating: $16 / 100 \mathrm{~mm}$ on day 6 ; flatulence: $24 / 100 \mathrm{~mm}$ on day 7 ). The highest total symptom score was reported on day 2 (20/ $100 \mathrm{~mm}$; Supplemental Figure S5(a)). The median GSRS-IBS score increased to a maximum of $30 / 91$ points on day 3 and remained stable until day 8 . Pain increased marginally from 5 to 6 points (minimum 2 points) and bloating from 6 to 9 points (minimum 4 points). Diarrhoea peaked on day 3 (10 points; minimum 4 points) and constipation increased from a minimum of 2 to 3 points until day 8, while satiety remained at a minimum score of 2 points (Supplemental Figure S5(b)).

For the one-day gluten challenge, symptoms occurred almost exclusively on the day of challenge (pain: 16/100 mm; bloating: $3 / 100 \mathrm{~mm}$; nausea: $48 / 100 \mathrm{~mm}$ ). Flatulence symptoms decreased over time $(16 / 100 \mathrm{~mm}$ at baseline), while satisfaction with defecation increased $(17 / 100 \mathrm{~mm}$ at baseline). The score for total complaints peaked on day $1(27 / 100 \mathrm{~mm}$; Supplemental Figure S5(c)). The median GSRS score increased slightly to a maximum score of $28 / 91$ points on day 3. Pain, constipation (both 5 points) and diarrhoea ( 8 points) peaked on day 3 . Bloating decreased from 9 to 6 points, while satiety remained unchanged at 3 points (Supplemental Figure S5(d)). An overview over all individual symptoms is given in Supplemental Table S1.

\section{T-cell kinetics in response to gluten challenge}

Analysis of sequential blood samples after the threeday gluten challenge revealed an increased number of tetramer $+\beta 7+\mathrm{T}_{\mathrm{EM}}$ cells from day 5 to day 8 , with a plateau forming in most individuals, while the total number of CD4+T cells was steady over the course of the experiment (Supplemental Figure S6). The median tetramer $+\beta 7+\mathrm{T}_{\mathrm{EM}}$ cell number increased from 7 at baseline to 71 tetramer $+\beta 7+\mathrm{T}_{\mathrm{EM}}$ cells/ million $\mathrm{CD}^{+} \mathrm{T}$ cells on day 8 . We found a significant increase in cell numbers between days 4 and 7 ( 5 vs. 65 tetramer $+\beta 7+\mathrm{T}_{\mathrm{EM}}$ cells/million $\mathrm{CD} 4+\mathrm{T}$ cells; $p<0.05$ ) and observed large interindividual differences in cell numbers (Figure 1(a)). For subjects undergoing a one-day challenge, tetramer $+\beta 7+\mathrm{T}_{\mathrm{EM}}$ cells from all participants increased to a lower extent compared to subjects receiving a three-day challenge (a median of 3-19 tetramer $+\beta 7+\mathrm{T}_{\mathrm{EM}}$ cells $/ 10^{6}$ CD4 + T cells from baseline to day $6 ; p<0.05$; Figure 1(b)).

\section{IL-2 concentration in plasma}

We aimed to test if early immune cell activation reflected by $\mathrm{IL}-2$ release serves as a more uniform marker than the tetramer $+\beta 7+\mathrm{T}_{\mathrm{EM}}$ cell numbers. After four hours, the IL-2 concentration in plasma increased in all participants in response to a single dose of gluten $(p<0.001$; Figure 1(c)). However, we observed a large interindividual variation, ranging from a 2 - to more than a 150 -fold increase in IL-2 concentrations in plasma. We did not find a significant correlation of the IL-2 concentration at four hours after the first gluten exposure with tetramer $+\beta 7+\mathrm{T}_{\mathrm{EM}}$ cell numbers (shown for day 8 ; 


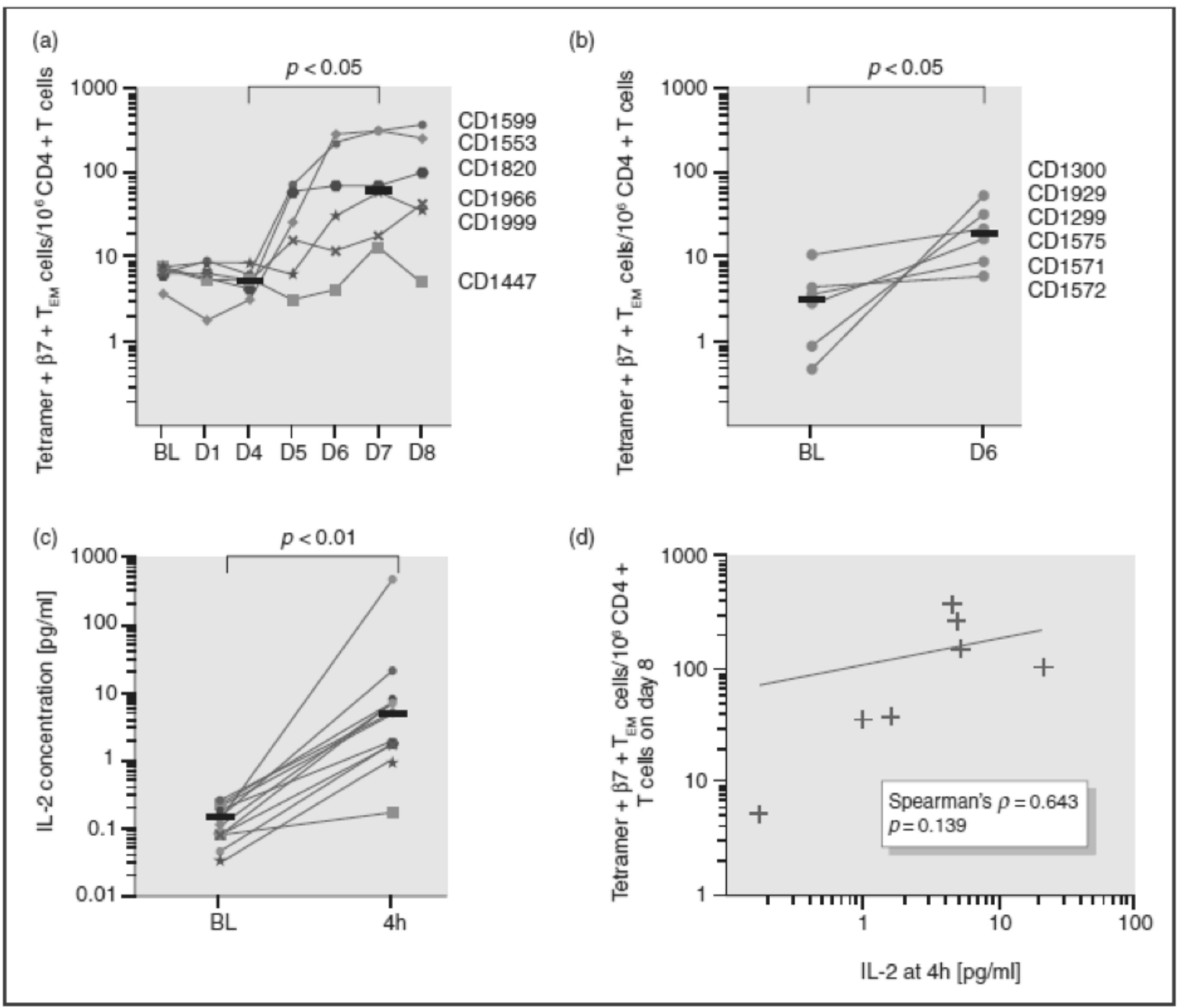

Figure 1. T-cell kinetics and interleukin-2 (IL-2) concentration in plasma. (a) Tetramer $+\beta 7+\mathrm{T}_{\mathrm{EM}} / 10^{6} \mathrm{CD} 4+\mathrm{T}$-cell numbers over time plateauing between days 6 and 8 and (b) tetramer $+\beta 7+T_{E M} / 10^{6} \mathrm{CD} 4+T$-cell numbers at baseline and on day 6 after the one-day gluten challenge. (c) IL-2 concentration in plasma before and four hours after the first gluten exposure. Horizontal lines represent median values. (d) No significant correlation of tetramer $+\beta 7+T_{E M}$ cells on day 8 with IL-2 concentration four hours after the first gluten exposure. Horizontal lines represent median values. Coloured symbols represent individuals in the three-day challenge group. Circles represent individuals in the one-day challenge group.

Figure 1(d)) but with total symptoms (VAS) on day 1 $(p<0.05)$. Further, the correlation between IL-2 fold change and baseline numbers of tetramer $+\beta 7+\mathrm{T}_{\mathrm{EM}}$ cells was not significant.

\section{CD38 expression in response to gluten challenge}

The activation status of tetramer $+\beta 7+T_{\mathrm{EM}}$ cells was assessed by the percentage of cell surface expression of CD38 on tetramer $+\beta 7+\mathrm{T}_{\mathrm{EM}}$ cells. In contrast to the large interindividual variation of both tetramer + cell numbers and the IL-2 response after gluten challenge, CD38 expression increased after the three-day challenge in a consistent manner from a median of $2.0 \%$ at baseline to a maximum of $93.6 \%$ on day 6 , with continuous elevation until day $8(p<0.05$, baseline vs. days 6-8; Figure 2(a)). Even the individual with the weakest tetramer $+\beta 7+\mathrm{T}_{\mathrm{EM}}$ cell response (CD1447) revealed a clear increase in CD38 expression. For the one-day challenge, a median of $83.0 \%$ of the tetramer $+\beta 7+\mathrm{T}_{\mathrm{EM}}$ cells expressed CD38+compared to $6.5 \%$ at baseline $(p<0.05$; Figure 2(b)). There was no significant difference in the percentage of CD $38+$ cells after the one-day challenge compared to the three-day challenge.

\section{Discussion}

In this study, we assessed the suitability of T-cellrelated parameters for monitoring the efficacy of intervention as part of oral gluten challenge in treated CeD patients. Specifically, we assessed the 


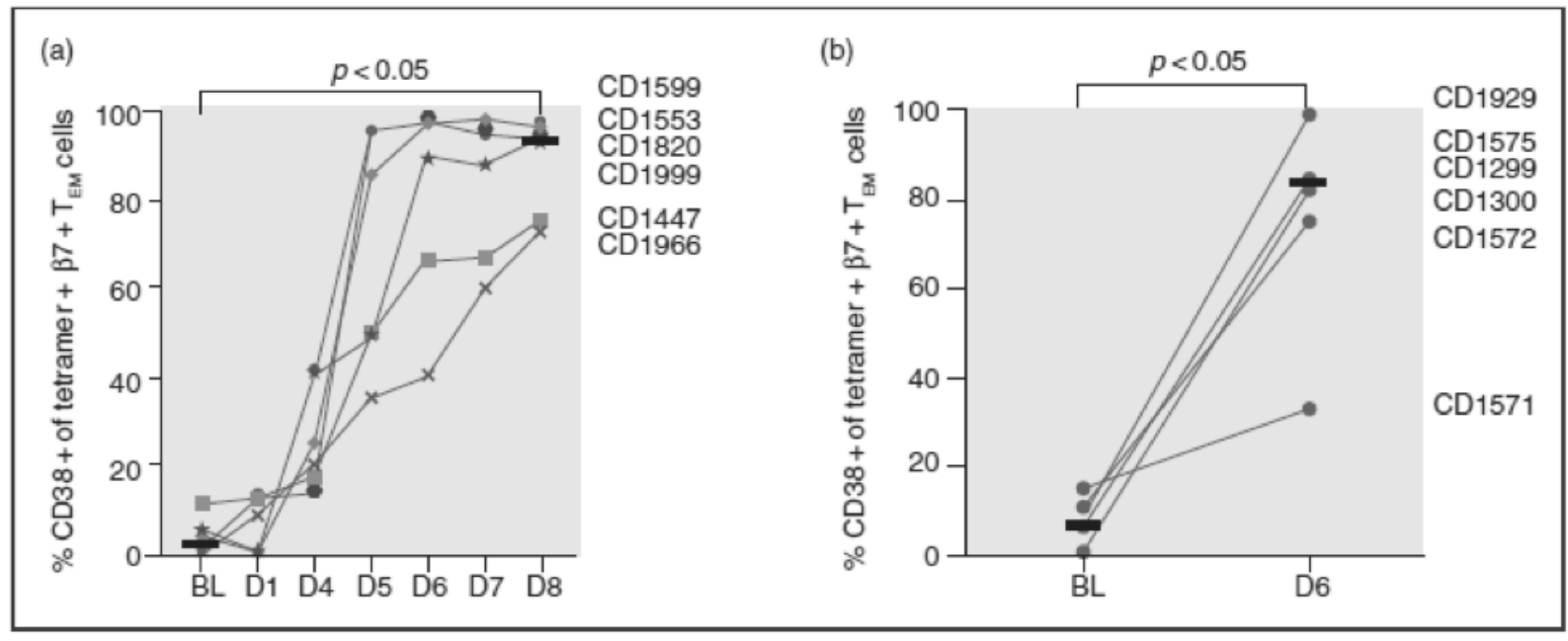

Figure 2. $C D 38$ expression on tetramer $+\beta 7+T_{E M}$ in response to gluten challenge. Percentage $C D 38+$ of all tetramer $+\beta 7+T_{E M}$ after (a) the three-day challenge and (b) the one-day challenge. Horizontal lines represent median values.

numbers of gluten-specific $\mathrm{T}$ cells in peripheral blood, the percentage of these cells expressing the activation marker CD38, as well as the concentration of $\mathrm{IL}-2$ in plasma. We also determined the kinetics of appearance of gluten-specific $T$ cells in blood and investigated the effect of challenge with a single dose of gluten. The findings on oral challenge-induced surrogate markers were complemented with PROM recordings.

We monitored symptoms in response to gluten challenge using the GSRS-IBS questionnaire and a VAS for five different gastrointestinal symptoms. ${ }^{8}$ Symptoms reported in the GSRS questionnaire increased mildly after gluten exposure. Symptoms reported on the VAS peaked on days 1-2 and days 6-7 after gluten challenge over three days. The symptoms after the one-day challenge almost exclusively peaked on the day of challenge. Based on previous documentation of PROM after gluten challenge, ${ }^{8,28}$ we expected symptom peaks during challenge. The strong symptom response after the one-day challenge might also be explained by psychological or physical responses to the single intervention due to a lack of blinding ${ }^{29}$ in this study or due to a longer observation period after the three-day challenge.

In accordance with earlier studies, ${ }^{8,12,13,27}$ we found that an oral gluten challenge induces a significant increase in the number of gluten-specific $\beta 7+\mathrm{T}_{\mathrm{EM}}$ $\mathrm{CD} 4+\mathrm{T}$ cells in the blood. However, there is wide interindividual variation in terms of both fold increase and absolute numbers of cells at plateau. The increase in gluten-specific $\mathrm{T}$ cells was less pronounced after one single dose of gluten compared to challenge over three days. We further tested if plasma IL-2 measured at four hours after gluten challenge could serve as a surrogate marker for immune cell activation, and we found a highly significant increase in IL-2. Yet, there were large interindividual differences in both fold increase and absolute levels of the cytokine. We did not find a statistically significant correlation of IL-2 concentration and tetramer $+\beta 7+\mathrm{T}_{\mathrm{EM}}$ cell numbers and hence failed to reproduce the newly reported finding that the tetramer $+\beta 7+\mathrm{T}_{\mathrm{EM}}$ cell frequency at baseline correlates with the fold change of IL-2 concentration. ${ }^{30}$ This finding may relate to the small sample size of this study due to a demanding protocol. However, we could reproduce the previously reported correlation of IL-2 increase and symptoms after gluten challenge. ${ }^{8}$

In contrast to high quantitative variability in numbers of gluten-specific T cells and levels of IL-2, the induction of $\mathrm{CD} 38$ expression by gluten-specific $\beta 7+\mathrm{T}_{\mathrm{EM}} \mathrm{CD} 4+\mathrm{T}$ cells was strikingly uniform. A similar uniform response of CD38 expression has been shown previously on day 6 under ongoing gluten challenge for 14 days. ${ }^{8}$ Here, we demonstrate that after day 6 , the expression of CD38 further increases until day 8 in individuals with a weaker response to gluten challenge. In the case of participant CD1571, assessment of CD38 expression on day 8 would likely have given a better indication if this patient was a slow responder (as CD1447 and CD1966) or a non-responder to gluten challenge. Thus, measurement of the percentage of CD38 + cells among gluten-specific T cells is an attractive surrogate marker for assessing drug efficacy after gluten challenge, and the assessment should be performed on day 8 rather than day 6 after the onset of gluten challenge. 
Table 3. Characteristics of included participants.

\begin{tabular}{|c|c|c|c|c|c|c|c|c|c|}
\hline Individual & Sex & $\begin{array}{l}\text { Age at } \\
\text { inclusion }\end{array}$ & HLA-DQ & $\begin{array}{l}\text { IgA-anti-TG2 } \\
\mathrm{BL}[\mathrm{AU}]\end{array}$ & $\begin{array}{l}\text { IgA-anti-TG2 } \\
\text { D6 [AU] }\end{array}$ & $\begin{array}{l}\text { IgG-anti-DGP } \\
\mathrm{BL}[\mathrm{AU}]\end{array}$ & $\begin{array}{l}\text { lgG-anti-DGP } \\
\text { D6 [AU] }\end{array}$ & $\begin{array}{l}\text { Anaemia } \\
\text { status }\end{array}$ & $\begin{array}{l}\text { Years } \\
\text { of GFD }\end{array}$ \\
\hline CD1929 & $F$ & 31 & 2.5 & 1.3 & $<1.0$ & $<5.0$ & $<5.0$ & Normal & 6 \\
\hline CD1300 & $F$ & 63 & 2.5 & $<1.0$ & $<1.0$ & $<5.0$ & $<5.0$ & Normal & 29 \\
\hline CD1299 & $F$ & 24 & 2.5 & $<1.0$ & $<1.0$ & $<5.0$ & $<5.0$ & Normal & 12 \\
\hline CD1572 & $F$ & 38 & 2.5 & $<1.0$ & 1.1 & 6 & 6 & Normal & 8 \\
\hline CD1571 & $F$ & 55 & 2.5 & $<1.0$ & $<1.0$ & 8 & 8 & Normal & 6 \\
\hline CD1575 & $F$ & 57 & 2.5 & $<1.0$ & $<1.0$ & $<5.0$ & $<5.0$ & Normal & 14 \\
\hline CD1553 & $F$ & 22 & 2.5 & $<1.0$ & 2.6 & $<5.0$ & 6 & Normal & 3 \\
\hline CD1447 & $F$ & 29 & 2.5 & $<1.0$ & 1.9 & $<5.0$ & 14 & Normal & 11 \\
\hline CD1573 & M & 75 & 2.5 & $<1.0$ & $<1.0$ & $<5.0$ & $<5.0$ & Normal & 12 \\
\hline CD1582 & $F$ & 56 & 2.5 & $<1.0$ & $<1.0$ & $<5.0$ & $<5.0$ & Normal & 4 \\
\hline CD1599 & $F$ & 45 & 2.5 & $<1.0$ & $<1.0$ & $<5.0$ & $<5.0$ & Normal & 4 \\
\hline CD1966 & $F$ & 31 & 2.5 & $<1.0$ & $<1.0$ & $<5.0$ & $<5.0$ & Normal & 25 \\
\hline CD1999 & $F$ & 19 & 2.5 & $<1.0$ & $<1.0$ & $<5.0$ & $<5.0$ & Normal & 18 \\
\hline Median & & 37 & & & & & & & 11 \\
\hline
\end{tabular}

Reference values: IgA-anti-TG2 $<4$; IgG-anti-DGP $<20$.

GFD: gluten-free diet; F: female; M: male; IgA-anti-TG2: immunoglobulin A-anti-transglutaminase 2; IgG-anti-DGP: immunoglobulin G-anti-deamidated gluten peptide; BL: baseline; D6, day 6 after onset of gluten challenge.

In conclusion, the frequency of gluten-specific $T$ cells plateaus between days 6 and 8 after gluten challenge over three days, indicating the appropriate time window for collecting gluten-specific T cells in future studies. The IL-2 concentration in plasma increased in all participants but with a large interindividual range, while the CD38 expression on gluten-specific T cells incremented in a robust manner. A single gluten challenge was sufficient to induce a response of glutenspecific $\mathrm{T}$ cells and was not inferior to the three-day challenge regarding CD38 expression. This study promotes a role for assessment of CD38 expression as a consistent alternative to contemporary outcome measures for upcoming clinical trials.

\section{Acknowledgements}

We thank Bjørg Simonsen, Marie K. Johannesen, Stine R. Lund, Carina Hinrichs, Marte Hulbaklien Bakke and Khaledeh Samimi for technical assistance, and Siv Furholm for administrative assistance. We are thankful to Kjersti Langballe Rolfsen for testing and baking the gluten-containing cookies and muesli bars, and the Proteomics Core Facility at Oslo University Hospital Rikshospitalet for analysis of the cookies. We also thank Shuo-Wang Qiao for productive input and discussions in the start of the kinetics project. Finally, we thank Jens Pahnke and his lab for kindly providing access to the MSD QuickPlex SQ 120 and for useful advice.

\section{Declaration of conflicting interests}

The authors declare that there is no conflict of interest.

\section{Funding}

This work was funded by the K.G. Jebsen Coeliac Disease Research Centre. No funding source had any role in the design, conduct or reporting of this study.

\section{Ethics approval}

The study was approved by the Norwegian regional ethics committee $(2013 / 1237)$ and was published on ClinicalT rials.gov (NCT02464150).

\section{Informed consent}

Written, informed consent was obtained from each patient included in the study. The study protocol conforms to the ethical guidelines of the 1975 Declaration of Helsinki as reflected in a priori approval by the Norwegian regional ethics committee.

\section{ORCID iD}

Stephanie Zühlke (D) https://orcid.org/0000-0003-1012-7526

\section{Supplemental material}

Supplemental material for this article is available online.

\section{References}

1. Jabri B and Sollid LM. T cells in celiac disease. $J$ Immunol 2017; 198: 3005-3014.

2. Sollid LM, Iversen R, Steinsbo O, et al. Small bowel, celiac disease and adaptive immunity. Dig Dis 2015; 33: 115-121. 
3. Du Pre MF and Sollid LM. T-cell and B-cell immunity in celiac disease. Best Pract Res Clin Gastroenterol 2015; 29 : 413-423.

4. Al-Toma A, Volta U, Auricchio R, et al. European Society for the Study of Coeliac Disease (ESsCD) guideline for coeliac disease and other gluten-related disorders. United Eur Gastroenterol J 2019; 7: 583-613.

5. Lindfors K, Ciacci C, Kurppa K, et al. Coeliac disease. Nat Rev Dis Primers 2019; 5: 3.

6. Ludvigsson JF, Ciacci C, Green PH, et al. Outcome measures in coeliac disease trials: the Tampere recommendations. Gut 2018; 67: 1410-1424.

7. Sarna VK, Lundin KEA, Morkrid L, et al. HLA-DQgluten tetramer blood test accurately identifies patients with and without celiac disease in absence of gluten consumption. Gastroenterology 2018; 154: 886-996.e6.

8. Sarna VK, Skodje GI, Reims HM, et al. HLA-DQ:gluten tetramer test in blood gives better detection of coeliac patients than biopsy after 14-day gluten challenge. Gut 2018; 67: 1606-1613.

9. Goel G, Tye-Din J, Qiao S-W, et al. Cytokine release and gastrointestinal symptoms after gluten challenge in celiac disease. Science Advances 2019; 5: eaaw7756. DOI: 10.1126/sciadv.aaw7756.

10. Anderson RP, Degano P, Godkin AJ, et al. In vivo antigen challenge in celiac disease identifies a single transglutaminase-modified peptide as the dominant A-gliadin T-cell epitope. Nat Med 2000; 6: 337-342.

11. Sollid LM and Jabri B. Triggers and drivers of autoimmunity: lessons from coeliac disease. Nat Rev Immunol 2013; 13: 294-302.

12. Brottveit M, Raki M, Bergseng E, et al. Assessing possible celiac disease by an HLA-DQ2-gliadin Tetramer Test. Am J Gastroenterol 2011; 106: 1318-1324.

13. Raki M, Fallang LE, Brottveit M, et al. Tetramer visualization of gut-homing gluten-specific $\mathrm{T}$ cells in the peripheral blood of celiac disease patients. Proc Natl Acad Sci U S A 2007; 104: 2831-2836.

14. Christophersen A, Risnes LF, Bergseng E, et al. Healthy HLA-DQ2.5 + subjects lack regulatory and memory $\mathrm{T}$ cells specific for immunodominant gluten epitopes of celiac disease. J Immunol 2016; 196: 2819-2826.

15. Han A, Newell EW, Glanville J, et al. Dietary gluten triggers concomitant activation of $\mathrm{CD} 4+$ and $\mathrm{CD} 8+$ alphabeta $\mathrm{T}$ cells and gammadelta $\mathrm{T}$ cells in celiac disease. Proc Natl Acad Sci U S A 2013; 110: 13073-13078.

16. Hardy MY and Tye-Din JA. T cells in coeliac disease: a rational target for diagnosis and therapy. Nat Rev Gastroenterol Hepatol 2018; 15: 583-584.

17. Sandoval-Montes C and Santos-Argumedo L. CD38 is expressed selectively during the activation of a subset of mature $\mathrm{T}$ cells with reduced proliferation but improved potential to produce cytokines. J Leukoc Biol 2005; 77: $513-521$.

18. Shubinsky $G$ and Schlesinger M. The CD 38 lymphocyte differentiation marker: new insight into its ectoenzymatic activity and its role as a signal transducer. Immunity 1997; 7: 315-324.

19. Zubiaur M, Izquierdo M, Terhorst C, et al. CD38 ligation results in activation of the Raf-1/mitogen-activated protein kinase and the CD3-zeta/zeta-associated protein70 signaling pathways in Jurkat $\mathrm{T}$ lymphocytes. J Immunol 1997; 159: 193-205.

20. Funaro A, De Monte LB, Dianzani U, et al. Human CD38 is associated to distinct molecules which mediate transmembrane signaling in different lineages. Eur $J$ Immunol 1993; 23: 2407-2411.

21. Munoz P, Mittelbrunn M, de la Fuente H, et al. Antigeninduced clustering of surface CD38 and recruitment of intracellular CD38 to the immunologic synapse. Blood 2008; 111: 3653-3664.

22. Du Pre MF, van Berkel LA, Raki M, et al. CD62L(neg)CD38 $(+)$ expression on circulating CD4(+) T cells identifies mucosally differentiated cells in protein fed mice and in human celiac disease patients and controls. Am J Gastroenterol 2011; 106: 1147-1159.

23. Boyman $\mathrm{O}$ and Sprent $\backslash \mathbf{J}$. The role of interleukin-2 during homeostasis and activation of the immune system. Nat Rev Immunol 2012; 12: 180-190.

24. Ludvigsson JF, Bai JC, Biagi F, et al. Diagnosis and management of adult coeliac disease: guidelines from the British Society of Gastroenterology. Gut 2014; 63: $1210-1228$

25. Wiklund IK, Fullerton S, Hawkey CJ, et al. An irritable bowel syndrome-specific symptom questionnaire: development and validation. Scand J Gastroenterol 2003; 38: 947-954.

26. Quarsten H, McAdam SN, Jensen T, et al. Staining of celiac disease-relevant $\mathrm{T}$ cells by peptide-DQ2 multimers. J Immunol 2001; 167: 4861-4868.

27. Christophersen A, Raki M, Bergseng E, et al. Tetramervisualized gluten-specific CD4 $+\mathrm{T}$ cells in blood as a potential diagnostic marker for coeliac disease without oral gluten challenge. United Eur Gastroenterol J 2014; 2: 268-278.

28. Brottveit M, Vandvik PO, Wojniusz S, et al. Absence of somatization in non-coeliac gluten sensitivity. Scand $J$ Gastroenterol 2012; 47: 770-777.

29. Schulz KF and Grimes DA. Blinding in randomised trials: hiding who got what. Lancet 2002; 359: 696-700.

30. Goel G, Tye-Din JA, Qiao S-W, et al. Cytokine release and gastrointestinal symptoms after gluten challenge in celiac disease. Sci Adv 2019; 5. 


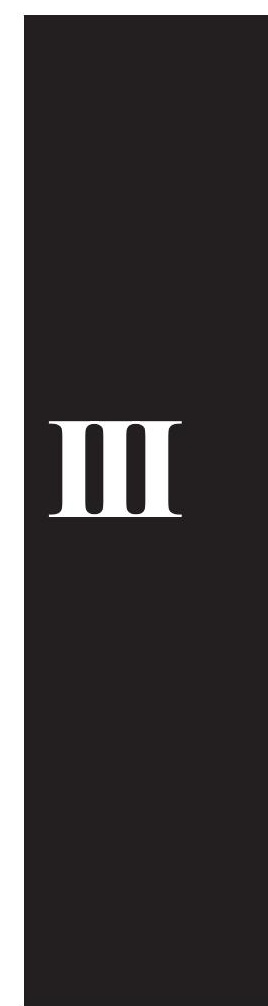



Title: Circulating CD103 $+\gamma \delta$ and CD8 + T cells are clonally shared with tissue-resident intraepithelial lymphocytes in celiac disease

Authors: Linn M. Eggesbø ${ }^{1, *}$, Louise F. Risnes ${ }^{1,2, *}$, Stephanie Zühlke ${ }^{1,2}$, Shiva DahalKoirala $^{1}$, Ralf S. Neumann ${ }^{1}$, Knut E. A. Lundin ${ }^{1,3}$, Asbjørn Christophersen ${ }^{1}$, Ludvig M. Sollid ${ }^{1,2}$

\section{Affiliations:}

${ }^{1}$ K. G. Jebsen Centre for Coeliac Disease Research, University of Oslo, 0424 Oslo, Norway ${ }^{2}$ Department of Immunology, University of Oslo and Oslo University HospitalRikshospitalet, 0372 Oslo, Norway ${ }^{3}$ Department of Gastroenterology, Oslo University Hospital-Rikshospitalet, 0372 Oslo, Norway

*The authors contributed equally to this work

\section{Abstract}

Gut intraepithelial $\gamma \delta$ and CD8 $+\alpha \beta$ T lymphocytes have been connected to celiac disease $(\mathrm{CeD})$ pathogenesis. In treated $\mathrm{CeD}$ it was demonstrated that activated $(\mathrm{CD} 38+)$, gut-homing $(\mathrm{CD} 103+) \gamma \delta$ and CD8 $+\alpha \beta \mathrm{T}$ cells increase in blood upon oral gluten challenge. To confirm this observation and to understand the pathogenic involvement of these T cells, we examined the clonal relationship between cells of blood and gut during gluten exposure. Of 20 glutenchallenged CeD patients, 8 and 10 had increase in $(\mathrm{CD} 38+\mathrm{CD} 103+) \gamma \delta$ and $\mathrm{CD} 8+\alpha \beta \mathrm{T}$ cells, respectively, while 16 had increase in gluten-specific CD4+ T cells. We obtained $\gamma \delta$ and $\alpha \beta$ TCR sequences of $>2500$ single cells from blood and gut of 5 patients, before and during challenge. We observed extensive sharing between blood and gut $\gamma \delta$ and CD8 $+\alpha \beta$ T-cell clonotypes even prior to gluten challenge. In subjects with challenge-induced surge of $\gamma \delta$ and/or CD8+ $\alpha \beta$ T cells, as larger populations of cells analyzed, we observed more expanded clonotypes and clonal sharing, yet no discernible TCR similarities between expanded and/or shared clonotypes.

Thus, CD4+ T cells can drive expansion of clonally diverse $\gamma \delta$ or CD8 $+\alpha \beta$ T-cell clonotypes that may not be not directed against specific antigens. 


\section{Introduction}

Celiac disease $(\mathrm{CeD})$ is a common disorder where gluten consumption causes chronic inflammation in the small intestine. The only available treatment for the disease is a glutenfree diet (GFD) which generally leads to normalization of the gut mucosal pathology ${ }^{1}$. The disease has strong association with certain HLA-class II allotypes, specifically HLA-DQ2.5, HLA-DQ2.2 and HLA-DQ8 ${ }^{2}$. CD4+ T cells of CeD patients selectively recognize deamidated gluten peptides in context of these disease-associated HLA-DQ molecules, strongly speaking to a central role of $\mathrm{T}$ cells in the pathogenesis. These gluten-specific CD4+ T cells, detectable by HLA-DQ2.5:gluten tetramers, are found at high frequency in the celiac lesion of the small intestine and at much lower frequency in peripheral blood ${ }^{3-6}$. Several studies have reported a transient surge of gluten-specific CD4+ T cells peaking at day 5-8 in blood after CeD patients in remission are exposed to gluten ${ }^{7-10}$. One of these studies also demonstrated that concomitant with this increase of CD4+ T cells, there is an increase of gut-homing (CD103+), activated (CD38+) $\gamma \delta$ and CD8 $+\alpha \beta$ T cells in the blood during gluten challenge10. Singlecell TCR repertoire analysis of both $\gamma \delta$ and CD8 $+\alpha \beta$ T cells occurring in blood on day 6 after gluten challenge, revealed clonal expansion and highly focused repertoire. These results led the authors to suggest an involvement of an antigen-driven induction of certain $\gamma \delta$ and CD $8+$ $\alpha \beta$ T-cell clonotypes. Relevant to this, it was reported that gut CD8+ $\alpha \beta \mathrm{T}$ cells in CeD, mainly localized in the lamina propria though, recognize gluten peptides in the context of HLA class I molecules ${ }^{11,12}$. Alternative to TCR mediated activation and expansion of intraepithelial lymphocytes (IELs), it has been demonstrated that in the IL-15 rich environment of the $\mathrm{CeD}$ gut, $\mathrm{T}$ cells via their expression of $\mathrm{NK}$ cell receptors can get activated and also expand by recognition of stress induced molecules on enterocytes ${ }^{13-15}$. To further understand the role of IELs in $\mathrm{CeD}$, we wanted to examine the occurrence of $\mathrm{CD} 38+\mathrm{CD} 103+\gamma \delta$ and $\mathrm{CD} 8+\alpha \beta$ blood T cells on day 6 of gluten challenge, as well as to compare the TCR repertoires of gut-homing $\gamma \delta$ and CD8 $8 \beta$ T cells in blood with that of tissue-resident $\mathrm{T}$ cells in the small intestine. In such a gluten challenge setting, one could expect that the activated and gut-homing $\mathrm{T}$ cells that increase on day 6 in blood should seed the lesion and make up the majority of newly detected IELs following challenge. Likewise, one could expect that these activated blood T cells mirror either all the IELs in the lesion, or, if responding to a distinct antigen, only a subset of these IELs. A way to investigate these matters is to determine the clonality and diversity of the TCR repertoire. A more focused and 
expanded TCR repertoire at peak response on day 6 or in tissue after challenge might possibly indicate a TCR-dependent induction supporting the findings by Han et $\mathrm{al}^{10}$.

To this end we analyzed eight samples from treated CeD patients that were recruited to a 14day oral gluten challenge study ${ }^{16}$, as well as samples from another $12 \mathrm{CeD}$ patients that were challenged for three days. For the single-cell paired TCR sequencing of $\gamma \delta$ and CD $8+\alpha \beta$ T cells in blood and gut, we analyzed cells from five patients that underwent the 14-day gluten challenge. In blood on day 6 almost all patients had increase in HLA-DQ2.5:gluten tetramer+ integrin $\beta 7+$ effector-memory CD4+ T cells and fewer had increased in CD38+CD103+ $\gamma \delta \mathrm{T}$ cell and CD38+CD103+CD8+ $\alpha \beta$ T cells. All of the subject who had increase $\mathrm{CD} 38+\mathrm{CD} 103+\gamma \delta \mathrm{T}$ cells, also had an increase in CD38+CD103+CD8 $+\alpha \beta \mathrm{T}$ cells. Thus, there was a correlated and hierarchical pattern of the responses. We further observed that circulating CD103 $+\gamma \delta$ and CD8 + T cells were clonally shared with the IELs in CeD, and this was so even prior to the gluten challenge. Diverse clonotypes were present among the $\mathrm{CD} 103+\gamma \delta$ and CD8 $+\mathrm{T}$ cells in patients who had surge of cells in blood on day 6 . Thus, gluten-specific CD4+ T cells appears to drive expansion of diverse $\gamma \delta$ or CD8 $+\alpha \beta$ T-cell clonotypes in $\mathrm{CeD}$.

\section{Results}

Increased frequency of gut-homing, activated $\gamma \delta$ and CD $8+\alpha \beta$ T cells in blood corresponds with increased density of IELs after gluten re-exposure

From the gluten challenge reported by Sarna et $\mathrm{al}^{16}$, we obtained IEL samples from eight patients. In order to estimate the absolute number and the distribution of $\gamma \delta$ and $\mathrm{CD} 8+\alpha \beta$ IELs, we compared the relative number of $\gamma \delta$ and CD8 $+\alpha \beta$ IELs of total CD3+ IELs as measured by flow cytometry with the total number of IELs per 100 intestinal epithelial cells (IECs) as assessed by histological examination of parallel biopsies (Table 1). Based on this, the increase of IELs in response to gluten seemed to be predominantly due to the CD8+ $\alpha \beta$ IELs, and not by the $\gamma \delta$ IEL subset. In contrast to a clear increase in blood on day 6 of $\mathrm{CD} 103+\mathrm{CD} 38+\gamma \delta$ and $\mathrm{CD} 8+\alpha \beta \mathrm{T}$ cells as was reported by Han $\mathrm{al}^{10}$, we could only detect a distinct increase of these T-cell populations on day 6 in a subset of patients (Fig 1a, b). The increase of CD103 $+\mathrm{CD} 38+\mathrm{CD} 8+\alpha \beta \mathrm{T}$ cells in blood corresponded with the increase of CD8 $+\alpha \beta$ IELs on day 14. Interestingly, both of the patients CD1340 and CD1342, who had the highest IEL count on day 14 , had a clear gut-homing CD8 $\alpha \beta$ T-cell response in blood on day 6. However, only CD1340 exhibited a $\gamma \delta$ T-cell response in blood. The CD8 $\alpha \beta$ and $\gamma \delta$ Tcell responses also appeared to be connected to the gluten-specific CD4+ T-cell response 
measured by HLA-DQ2.5:gluten tetramers, as all subjects with increase in CD8 $\alpha \beta$ and/or $\gamma \delta$ $\mathrm{T}$ cells also had increase in tetramer $+\mathrm{CD} 4+\mathrm{T}$ cells. Representative flow plots for patients CD1340 and CD1342 can be found in Fig S1. Of note, all patients that exhibited a $\gamma \delta$ T-cell response in blood also displayed a CD8 $+\alpha \beta$ T-cell response but not vice versa. We also investigated the expression of CD103 and CD38 on $\gamma \delta$ and CD $8+\alpha \beta$ IELs. As expected, virtually all IELs were CD103+. Interestingly, all $\gamma \delta$ IELs were CD38+ throughout the entire challenge period in contrast to CD8+ $\alpha \beta$ IELs, where the CD38 expression increased with the ingestion of gluten (Fig 1c, d).

\section{Gut-homing $\gamma \delta$ and CD8+ $\alpha \beta$ T cells in blood share TCR features with IELs}

We performed single-cell paired TCR sequencing of $\gamma \delta$ and CD8 $+\alpha \beta$ T cells in blood and IEL samples from four of these eight patients (CD442, CD1340, CD1342, CD1300). All four had gluten-specific CD4+ T-cell response while only one had an increase in $\gamma \delta \mathrm{T}$ cells and three had an increase in CD8 $+\alpha \beta \mathrm{T}$ cells during gluten challenge. In addition, we also obtained TCR sequences from the IEL samples of patient CD1178 who did not respond to the challenge. We primarily sorted the $\mathrm{CD} 103+$ populations with co-expression of $\mathrm{CD} 38$, but in samples where there were few CD38+ T cells we also index-sorted the CD103+CD38population to increase the number of potentially relevant cells from blood. This was in particular the case for the baseline blood samples (Fig S2). For the $\gamma \delta$ T cells, up to half of the cells sorted and sequenced were CD38+ (Fig S2a). All CD8+ $\alpha \beta$ T cells sorted from the baseline blood sample of CD1342 were CD38+ while we sorted mostly CD38- cells for the other three patients at baseline (Fig S2b). For the CD8+ T cells we obtained in total paired TCR sequences from 1310 single cells giving rise to $872 \mathrm{CD} 8+\alpha \beta \mathrm{T}$-cell clonotypes. For the $\gamma \delta$ T cells we obtained paired TCR sequences from 1200 cells giving a total of $764 \gamma \delta$ T-cell clonotypes.

We found that the TRGV and TRDV gene usage of CD103+ $\gamma \delta$ T cells found in blood were near identical to that of $\gamma \delta$ IELs (Fig 2a), and the usage and pairing preference was similar to what was observed in untreated $\mathrm{CeD}^{17}$. Likewise, pairing preference was very similar for these $\gamma \delta$ T cells (Fig 2b, c). Interestingly, $\gamma \delta$ T cells had bimodal expression of CD8 and we found that this expression varied within and between clonotypes in both blood and in tissue samples.

Next, we looked into the V-gene usage and pairing of the CD8+ $\alpha \beta$ T cells. Focusing on the top 10 gene segments, we found that both for TRAV and TRBV these were similar between gut and blood tissues and accounted for approximately $50 \%$ of the overall $\mathrm{V}$-gene usage in 
both blood and gut (Fig 2d). This TRBV gene usage was similar to what has been described to be predominant TRBV families used in the IEL or blood compartment of healthy individuals ${ }^{18}$. Of note, we did not observe any pairing preference in any of the compartments (Fig 2e, f). A complete list of all shared $\gamma \delta$ and CD8 $+\alpha \beta$ T clonotypes across time points and tissue with CD38 and CD8 status for each patient can be found in the Supplementary File 1.

\section{$\gamma \delta$ T-cell clonotypes: Sharing across tissue and time and analysis of expanded clones}

We observed extensive sharing of CD103 $+\gamma \delta$ T-cell clonotypes across tissue and time in all patients (Fig 3a). The most expanded clonotypes contributed to clonotype sharing in several of the samples (Fig S2a, Supplementary File 1). The clonal sharing also included a large fraction of $\mathrm{T}$ cells that were negative for CD38. It was only patient CD1340 who had a clear $\gamma \delta$ T-cell response in blood at day 6 . For this subject we observed clonal sharing between all time points and tissues (Fig 3a), and the highest degree of sharing was observed between day 6 in blood and day 14 in gut. Here, 13 out of 47 clonotypes (28\%) at day 6 was shared with $\gamma \delta$ IELs at day 14. Further we compared more carefully the samples with most sharing $(>20 \%,>5$ shared clonotypes and shared with gut tissue) to look for the contribution of expanded clonotypes and the data are depicted as donut charts in Figure 3b. We observed a high degree of sharing between the gut samples at baseline and day 14 for all five patients except CD1342, and the clonal sharing was dominated by expanded clonotypes compared to the non-shared clonotypes (Fig 3b). The shared cells for CD1340 between day 6 and day 14 also were from expanded clones (Fig 3b). In contrast to CD1340 and despite the small number of sequenced cells due to no clear $\gamma \delta$ response for patient CD1300 at day 6 in blood, six out of eight $\gamma \delta$ clonotypes were shared with $\gamma \delta$ IELs at baseline.

Next, we wanted to analyze the paired V-gene usage of the TCR $\gamma$ and TCR $\delta$ chains of the shared clonotypes displayed as Circos plots (Fig 3c). The shared clonotypes have the same dominating TRDV1 usage but variable TRGV usage for all patients, similar to the overall observations shown in Figure $2 b$ and $2 c$. Focusing on the expanded clones $(>2)$ and the CDR3s at day 6, no similarities in the CDR3 across the clonotypes could be discerned (Table 2). Neither did we find an overrepresentation of previously identified CeD-associated sequence motifs, specifically the H-J1 motif ${ }^{19}$ or motifs reported by Han et al. ${ }^{10}$, among these expanded clones nor clonotypes present in blood on day 6 . Altogether, these findings demonstrate that diverse CD103+ $\gamma \delta$ T-cell clonotypes found in the IEL compartment are commonly present in the circulation regardless of gluten challenge. 
CD8 $+\alpha \beta$ T-cell clonotypes: Sharing across tissue and time and analysis of expanded clones To investigate clonal relationship between $\mathrm{CD} 103+\mathrm{CD} 8+\alpha \beta \mathrm{T}$ cells in blood with those of CD8 IELs, we conducted a similar analysis as for the $\gamma \delta \mathrm{T}$ cells. Three out of the four CeD patients with paired blood and gut samples showed clonal sharing across tissues, and this included sharing prior to gluten challenge (Fig 4a). Similar to the $\gamma \delta \mathrm{T}$ cells, the most expanded CD8 $+\alpha \beta$ clonotypes could be found in multiple samples of the same patient (Fig $\mathrm{S} 2 \mathrm{~b}$ ). The four $\mathrm{CeD}$ patients examined had a CD8+ T-cell response at day 6 in blood, but we observed some interesting differences in their T-cell responses at the clonal level in these patients. Remarkably, the baseline blood sample of CD1342 consisted of many expanded clones all expressing CD38 in contrast to the other patients (Fig S2b). Altogether, $36 \%$ of the clonotypes made up $70 \%$ of the cells at baseline and these were also present in the IEL compartment at day 14 as expanded clones (Fig 4b). CD1340 and CD1300 had the highest degree of clonal sharing between day 6 in blood and in gut at day 14, while CD442 did not have many shared clonotypes despite a comparable number of sequenced cells. Unexpectedly, compared to what was observed for $\gamma \delta$ IEL clonotypes, CD8 $+\alpha \beta$ IEL clonotypes showed a much lower degree of sharing in the tissue. This observation was also similar for CD1178 who did not respond to the gluten challenge (Fig 3a and Fig 4a). Similar to the $\gamma \delta$ T cells, we wanted to explore if there were any particular TCR features between the expanded T-cell clonotypes that were present in blood and in gut tissues. The paired V-gene usage for the shared clonotypes visualized as Circos plots in Figure $4 \mathrm{c}$ did not demonstrate any TCR pairing preference across the shared CD8 $+\alpha \beta$ clonotypes. Similarly, when assessing the most expanded T-cell clones at day 6, we could not demonstrate any similar TCR features between different clonotypes within a patient or across patients (Table 3). Looking at the CDR3 $\beta$ motifs CxxxxGN (with TRBV7-9) and CxxxxGT (with TRBV7-8) as reported by Han et $\mathrm{al}^{10}$, we did not observe these in our dataset. A third motif, CxxxF (with TRBV28), that was reported by the same authors we found among 6 clonotypes from gut samples of patient CD1178. Overall, these findings demonstrate that CD103 + CD8 $+\alpha \beta T$ cells with an activated phenotype in blood are clonally expanded and shared with those in the IEL compartment without any TCR or TCR commonality standing out as shared across tissue and time or representing expanded clones. 
The frequency of gut-homing, activated $\gamma \delta$ and $C D 8+\alpha \beta$ T cells correlates with the frequency of CD4+ gluten-specific T cells in blood on day 6

In contrast to previous reports ${ }^{10,20}$, we could detect an increase of distinct $\mathrm{T}$-cell populations on day 6 only in a subset of patients. To further explore the connection between the different T-cell responses in blood on day 6, we analyzed blood from another 12 treated patients that underwent a 3-day gluten challenge. Here, 10 out of the 12 patients responded to challenge according to the elevation of HLA-DQ2.5:gluten tetramer+ CD4+ T cells on day 6 compared to baseline. Similar to the 14-day gluten challenge study, we did not observe an increased frequency of CD103+CD38+CD8+ and $\gamma \delta \mathrm{T}$ cells on day 6 in all patients. Strikingly, we observed a range in responses of all three T-cell populations, and correlation analyses demonstrated that the degree of the different T-cell responses on day 6 were highly correlated (Fig 5).

\section{Discussion}

In this study with oral gluten challenge of celiac subjects, we observed a response of HLADQ2.5:gluten tetramer+integrin $\beta 7+$ effector-memory CD4+ T cells in the majority of the subjects and less frequent responses of $(\mathrm{CD} 38+\mathrm{CD} 103+) \gamma \delta$ and $\mathrm{CD} 8+\alpha \beta \mathrm{T}$ cells. We observed CD8 $+\alpha \beta \mathrm{T}$-cell response in all individuals that displayed a $\gamma \delta \mathrm{T}$-cell response, and any of the subjects that exhibited a CD $8+\alpha \beta$ and/or $\gamma \delta$ T-cell response all had a glutenspecific CD4+ T-cell response. These results lead us to speculate that there is a hierarchy of T-cell responses during gluten exposure, initiated by the response of the gluten-specific CD4+ T cells.

A major focus of this study was analysis of TCR usage and repertoires performed at a singlecell level. In line with our previous findings ${ }^{17}$, we found that the TRGV/TRDV usage in gut IELs in CeD patients undergoing gluten challenge is similar to that observed in untreated CeD. Moreover, we observed that the CD103+ $\gamma \delta \mathrm{T}$ cells from the blood have a near identical $\mathrm{V}$-gene usage and chain pairing to that of resident $\gamma \delta$ IELs. Focusing on the top 10 used TRAV and TRBV genes due to the high TCR $\alpha \beta$ diversity, we found that the usage of both TRAV and TRBV genes were similar in blood and gut. It may be that the similar V-gene usage only reflect that certain $\mathrm{V}$ genes are more frequently used than others. In fact, the top 10 TRBV genes used here correspond well to the reportedly used TRBV families in gut and blood of healthy individuals ${ }^{18}$. Moreover, at the level of chain pairing we did not observe any pairing preference of TCR $\alpha \beta$ neither in blood nor in gut. 
Our group has previously shown that $\mathrm{T}$ cells belonging to the same gluten-specific CD4+ clonotypes can persist in both blood and gut tissues for decades, and that those pre-existing clonotypes dominate upon gluten re-exposure ${ }^{4}$. We wanted to determine if the latter is a phenomenon shared by the $\gamma \delta$ and CD $8+\alpha \beta$ T cells. In our previous study ${ }^{17}$, we highlighted the importance of accurate clonotype assignments as we observed many identical TCR $\gamma$ sequences that paired with different TCR $\delta$ sequences. In addition, the presence of dual TCR sequences even further strengthen the correct annotation of clonotypes. With this in mind, it was remarkable to detect sharing of $\gamma \delta$ and CD $8+\alpha \beta$ T-cell clonotypes across blood and gut tissues, also prior to gluten challenge. The degree of clonal sharing between the different samples appeared to be higher for $\gamma \delta$ T cells compared to CD8+ $\alpha \beta$ T cells, especially for the sharing of IEL clonotypes. As the CD8+ IELs in CeD are believed to have an oligoclonal TCR repertoire ${ }^{21,22}$, one could expect to observe a higher degree of sharing of CD8 IEL clonotypes. On the contrary, CD8 IELs in CeD patients appear to have a much more diverse TCR repertoire than previously believed. These findings suggest that clonal sharing is a common feature that is independent of continuous gluten exposure. Relevant to this, it was reported in a recent paper that small intestinal resident memory $\mathrm{T}$ cells recirculate in the blood of mice ${ }^{23}$. Furthermore, these resident $\mathrm{T}$ cells that rejoined the blood displayed a preference for homing back to their original tissue upon reactivation. While this study was performed in mice, our data indicate that a similar circulation of resident $\mathrm{T}$ cells may occur in humans as well, however further studies are needed are prove this concept. Taken together, these observations based on single-cell sequencing support the notion that the activation of clonally diverse CD8 $+\alpha \beta$ T cells in blood and gut of CeD subjects might be inflammation-induced, and where IL15 and NK-cell receptors on the T cells could be involved.

In conclusion, our gluten challenge study has revealed that there is $\gamma \delta$ and CD8 $+\alpha \beta$ clonotype sharing between blood and gut tissues and that this sharing is seen prior to gluten consumption. We found no evidence that gluten-induced immune activation in CeD involves particular patient-shared $\gamma \delta$ or CD8 $+\alpha \beta$ T-cell clonotypes. Our observations suggest that CD4+ T cells employing the disease-associated HLA-molecules as restriction elements can drive expansions of clonally diverse $\gamma \delta$ and CD $8+\alpha \beta$ T cells. 


\section{Methods}

\section{Human subjects and study design}

\section{4-day gluten challenge}

Twenty treated $\mathrm{CeD}$ patients were recruited to a clinical study with the aim to determine whether an oral gluten challenge of 14 days is sufficient to demonstrate mucosal changes in well-treated CeD patients ${ }^{16}$. Duodenal biopsies were collected prior to and at day 14 of the gluten challenge. In addition to histological assessments, eight biopsies were collected to investigate immune cells in the small intestine by flow cytometry. Blood was drawn and collected throughout the gluten challenge; at baseline, day 6 and day 14. The detailed information of the clinical study can be found elsewhere16. For this study, we obtained complete or partly complete sets of biological samples from eight of the patients from the 14day gluten challenge study.

In order to obtain single-cell suspension of the lamina propria cells of the duodenal biopsies, we first treated the biopsies with EDTA for $10-20 \mathrm{~min}$ at $37^{\circ} \mathrm{C}$ in order to remove the epithelial layer. Subsequently, the biopsies were treated with collagenase for 30-60 min, at $37^{\circ} \mathrm{C}$ with rotation. The initial isolation step allowed us to separate the intraepithelial lymphocyte (IEL) from the lamina propria cells, and the samples were cryopreserved prior to further analysis.

Peripheral mononuclear blood cells (PBMCs) were isolated using a density gradient method with Lymphoprep and directly subjected to tetramer staining and magnetic bead enrichment, as described in Sarna et al16. The tetramer-enriched sample were further analyzed while the depleted PBMC fraction were cryopreserved until further use. For patient CD1300, we suspected baseline and day 6 samples were mixed up prior to sorting due to the presence of a distinct population of $\mathrm{CD} 38+\mathrm{CD} 103+\mathrm{T}$ cells only in the baseline sample. This patient was a clear responder on all other parameters. This suspicion of sample mixup was later confirmed when this patient participated in a later gluten challenge study. Hence, the data presented here for blood samples on baseline and day 6 for CD1300 have been swapped.

\section{3-day gluten challenge}

For further analysis of the different T-cell responses on day 6 in blood, we had access to blood samples from another 12 treated CeD patients that underwent a 3-day gluten challenge. Six of the patients ate a gluten-containing, FODMAP-free, cookie for 3 days and has been described previously ${ }^{8}$. The other half ate 4 slices of white bread for 3 days. Blood was collected in BD Vacutainer Cell Preparation Tubes (CPT) and processed and cryopreserved as 
described $^{8}$. Upon analysis, the frozen samples were thawed and enriched for gluten-specific $\mathrm{T}$ cells using a cocktail of five HLA-DQ2.5 tetramers. In parallel, the depleted PBMC fraction was used for analysis of CD $8+$ and $\gamma \delta$ T-cell populations.

\section{Surface marker staining, flow cytometry analysis and single-cell sorting}

The frozen tetramer-depleted PBMCs from 14-day gluten challenge study were first thawed and filtered. We then stained the cells with PE-conjugated anti- $\gamma \delta \mathrm{TCR}$ for $20 \mathrm{~min}$ followed by an anti-PE bead enrichment step due to low frequency of CD103+ $\gamma \delta$ T cells $(<1 \%$ of total $\gamma \delta$ T cells). The $\gamma \delta$ TCR-enriched sample was used for sorting of $\gamma \delta$ T cells while the depleted fraction was used to sort CD8+ $\alpha \beta$ T cells. The samples were then stained with a cocktail of the following antibodies: CD8-PerCP-Cy5.5 (clone SK1, BioLegend), CD27-PE-Cy7 (clone LG.7F9, eBioscience), CD38-FITC (clone HB7, BioLegend), CD103-APC (clone B-ly7, eBioscience), CD4-APH-H7 (clone SK3, BD Biosciences), CD3-eVolve605 (clone OKT3, eBioscience). The depleted fraction was additionally stained with $\gamma \delta$ TCR-PE (clone 5A6.E9, Invitrogen), and a dump channel consisting of CD11c-Pacific Blue (clone B-ly6, BD Biosciences), CD14-Pacific Blue (clone M5E2, BioLegend), CD19-Pacific Blue (clone HIB19, BioLegend) and CD56-Pacific Blue (clone MEM-188, BioLegend). Cryopreserved IELs were thawed and filtered. They were directly stained without bead enrichment with a similar panel to the blood samples. The exceptions were the use of epithelial antigen-FITC (clone BerEP4, DAKO) and CD38-PE-Cy7 (clone HIT2, eBioscience).

For the additional 3-day gluten challenge studies, the cryopreserved PBMCs were thawed as described above and the samples were first subjected to PE-conjugated tetramer bead enrichment. These cells were then analyzed as described8 whereas the depleted PBMC fraction was labelled with the same panel of antibodies as described above but without $\gamma \delta$ TCR-enrichment prior to flow cytometry analysis on FACS AriaIII. Data was analyzed using FlowJo software v10 (Flowjo LLC). Gating strategy is provided in Supplementary Figure 3.

\section{Library preparation for single-cell $\gamma \delta$ and $\alpha \beta$ TCR sequencing}

Single-cell TCR sequencing of $\gamma \delta$ and $\alpha \beta$ T cells were performed as described ${ }^{4,17}$. After preparing separate $\gamma \delta$ and $\alpha \beta$ libraries, we combined the two libraries and sequenced them in the same Illumina Miseq sequencing run. Sequencing was performed at the Norwegian Sequencing Center and sequence data deposited at the European Genome-Phenome Archive (EGA) under the accession number EGAS00001004484. 


\section{TCR repertoire analysis}

Data processing and analysis was performed as described i ${ }^{4,17}$. Briefly, obtained reads from Illumina sequencing were pre-processed using selected tools from the pRESTO toolkit ${ }^{24}$. Using an in-house Java program, the $\gamma \delta$ and $\alpha \beta$ TCR sequences were subjected to further filtration and processing as previously described ${ }^{4,17}$. Only sequences with $>50$ reads were included in further analysis. We allowed for dual chains with a maximum of three chains in total. For both TRG/TRD and TRA/TRB sequences from each patient, cells were classified to the same clonotype when having identical $\mathrm{V}$ and $\mathrm{J}$ gene as well as identical nucleotide CDR3 region.

Circos plots were generated using the online circos tool (http://circos.ca/circos_online). Other graphs were made in Graphpad Prism 8 and Adobe Illustrator.

\section{Statistics}

Integrated statistical tools in Graphpad Prism 8 was used for statistical analyses.

\section{Study approval}

The studies were approved by the Regional Committee for Medical and Health Research Ethics South-East Norway (2010/2720, 2012/341 and 2013/1237). All patients gave written informed consent.

\section{Acknowledgements}

We thank all the patients that participated in this study. Further, we are grateful for the staff at the Gastro unit, S. Furholm, C. Hinrichs, and M.H. Bakke, for help with contacting patients as well as collecting biological material. This study was supported by grants from Stiftelsen Kristian Gerhard Jebsen (project SKGJ-MED-017) and by the South-Eastern Norway Regional Health Authority (projects 2011050 and 2018068).

\section{Contributions}

AC, LFR, LME, and LMS designed the study. KEAL and SZ provided patient and donor material. LME, LFR, SZ and SDK collected and processed the patient material. LME, LFR, SZ and AC acquired the data. RSN developed the bioinformatics tools. LME, LFR, AC, SZ and LMS analysed the data and wrote the manuscript. All the authors revised and approved the manuscript. 


\section{Ethics declaration}

The authors declare no conflict of interest. 


\section{References}

1. B. Lebwohl, D.S. Sanders and P.H.R. Green. Coeliac disease. Lancet 2018; 391(10115): 70-81.

2. L.M. Sollid. Molecular basis of celiac disease. Annu Rev Immunol 2000; 18: 53-81.

3. M. Bodd, M. Ráki, E. Bergseng, J. Jahnsen, K.E.A. Lundin and L.M. Sollid. Direct cloning and tetramer staining to measure the frequency of intestinal gluten-reactive $\mathrm{T}$ cells in celiac disease. European journal of immunology 2013; 43(10): 2605-2612.

4. L.F. Risnes, et al. Disease-driving CD4+ T cell clonotypes persist for decades in celiac disease. J Clin Invest 2018; 128(6): 2642-2650.

5. K.E. Lundin, et al. Gliadin-specific, HLA-DQ $(\alpha 1 * 0501, \beta 1 * 0201)$ restricted T cells isolated from the small intestinal mucosa of celiac disease patients. J Exp Med 1993; 178(1): 187-196.

6. A. Christophersen, et al. Tetramer-visualized gluten-specific CD4+ T cells in blood as a potential diagnostic marker for coeliac disease without oral gluten challenge. United European Gastroenterol J 2014; 2(4): 268-278.

7. M. Raki, et al. Tetramer visualization of gut-homing gluten-specific $\mathrm{T}$ cells in the peripheral blood of celiac disease patients. Proc Natl Acad Sci U S A 2007; 104(8): 28312836.

8. S. Zuhlke, L.F. Risnes, S. Dahal-Koirala, A. Christophersen, L.M. Sollid and K.E. Lundin. CD38 expression on gluten-specific T cells is a robust marker of gluten reexposure in coeliac disease. United European Gastroenterol J 2019; 7(10): 1337-1344.

9. R.P. Anderson, P. Degano, A.J. Godkin, D.P. Jewell and A.V. Hill. In vivo antigen challenge in celiac disease identifies a single transglutaminase-modified peptide as the dominant A-gliadin T-cell epitope. Nat Med 2000; 6(3): 337-342.

10. A. Han, et al. Dietary gluten triggers concomitant activation of CD4+ and CD8+ alphabeta T cells and gammadelta T cells in celiac disease. Proc Natl Acad Sci U S A 2013; 110(32): 13073-13078.

11. G. Mazzarella, et al. Gliadin activates HLA class I-restricted CD8+ T cells in celiac disease intestinal mucosa and induces the enterocyte apoptosis. Gastroenterology 2008; 134(4): 1017-1027.

12. S. Picascia, et al. Gliadin-Specific CD8(+) T Cell Responses Restricted by HLA Class I A*0101 and B*0801 Molecules in Celiac Disease Patients. J Immunol 2017; 198(5): $1838-1845$.

13. B. Meresse, et al. Coordinated induction by IL15 of a TCR-independent NKG2D signaling pathway converts CTL into lymphokine-activated killer cells in celiac disease. Immunity 2004; 21(3): 357-366.

14. S. Hüe, et al. A direct role for NKG2D/MICA interaction in villous atrophy during celiac disease. Immunity 2004; 21(3): 367-377.

15. B. Meresse, et al. Reprogramming of CTLs into natural killer-like cells in celiac disease. J Exp Med 2006; 203(5): 1343-1355.

16. V.K. Sarna, et al. HLA-DQ:gluten tetramer test in blood gives better detection of coeliac patients than biopsy after 14-day gluten challenge. Gut 2018; 67(9): 1606-1613. 
17. L.M. Eggesbo, L.F. Risnes, R.S. Neumann, K.E.A. Lundin, A. Christophersen and L.M. Sollid. Single-cell TCR sequencing of gut intraepithelial $\gamma \delta$ T cells reveals a vast and diverse repertoire in celiac disease. Mucosal Immunol 2020; 13(2): 313-321.

18. B. Jabri, et al. TCR specificity dictates CD94/NKG2A expression by human CTL. Immunity 2002; 17(4): 487-499.

19. T. Mayassi, et al. Chronic Inflammation Permanently Reshapes Tissue-Resident Immunity in Celiac Disease. Cell 2019; 176(5): 967-981.e919.

20. N. Lopez-Palacios, et al. Evaluation of T cells in blood after a short gluten challenge for coeliac disease diagnosis. Dig Liver Dis 2018; 50(11): 1183-1188.

21. S.P. Balk, et al. Oligoclonal expansion and CD1 recognition by human intestinal intraepithelial lymphocytes. Science 1991; 253(5026): 1411-1415.

22. C. Van Kerckhove, et al. Oligoclonality of human intestinal intraepithelial T cells. J Exp Med 1992; 175(1): 57-63.

23. R. Fonseca, et al. Developmental plasticity allows outside-in immune responses by resident memory T cells. Nat Immunol 2020; 21(4): 412-421.

24. J.A. Vander Heiden, et al. pRESTO: a toolkit for processing high-throughput sequencing raw reads of lymphocyte receptor repertoires. Bioinformatics 2014; 30(13): 1930-1932. 


\section{Figures}

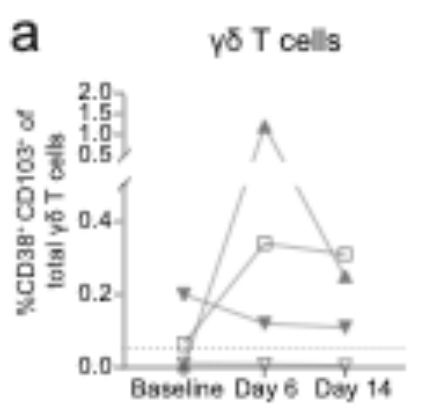

b $\quad \mathrm{CDB}^{+} \alpha \beta \mathrm{T}$ cells
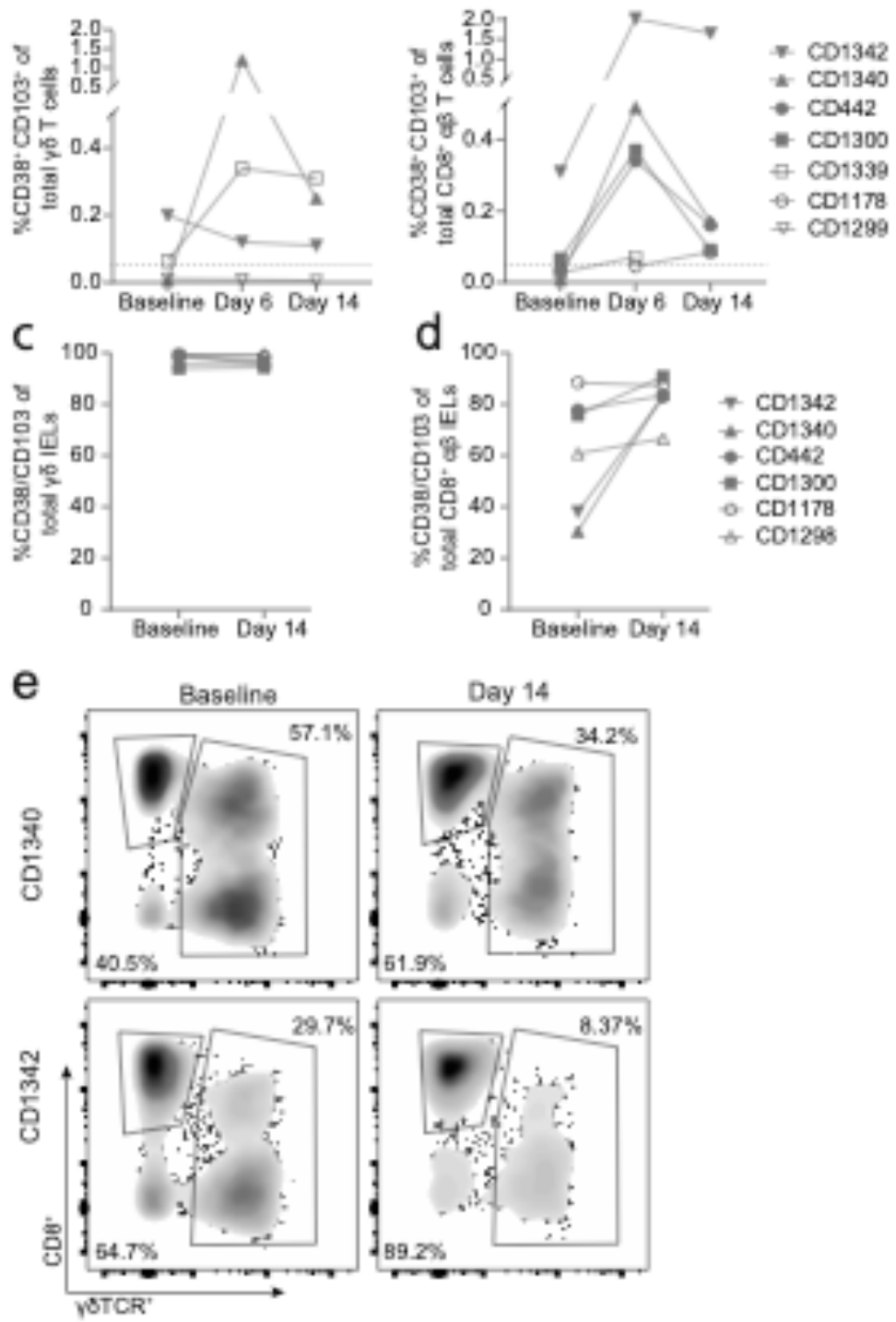

Figure $1 \gamma \delta$ and $\mathrm{CD} 8^{+} \alpha \beta$ T-cell responses during a 14-day gluten challenge. $\gamma \delta$ (a) and $\mathrm{CD} 8^{+}$ $\alpha \beta$ (b) T-cell responses in blood during a 14-day gluten challenge. Frequency of $\mathrm{CD} 103^{+} \mathrm{CD} 38^{+}$intraepithelial lymphocytes (IELs) are shown for (c) $\gamma \delta \mathrm{T}$ cells and (d) $\mathrm{CD} 8^{+}$ $\alpha \beta$ T cells. (e) Representative $\gamma \delta$ and $\mathrm{CD}^{+} \alpha \beta$ IEL flow plots shown for CD1340 and CD1342. 

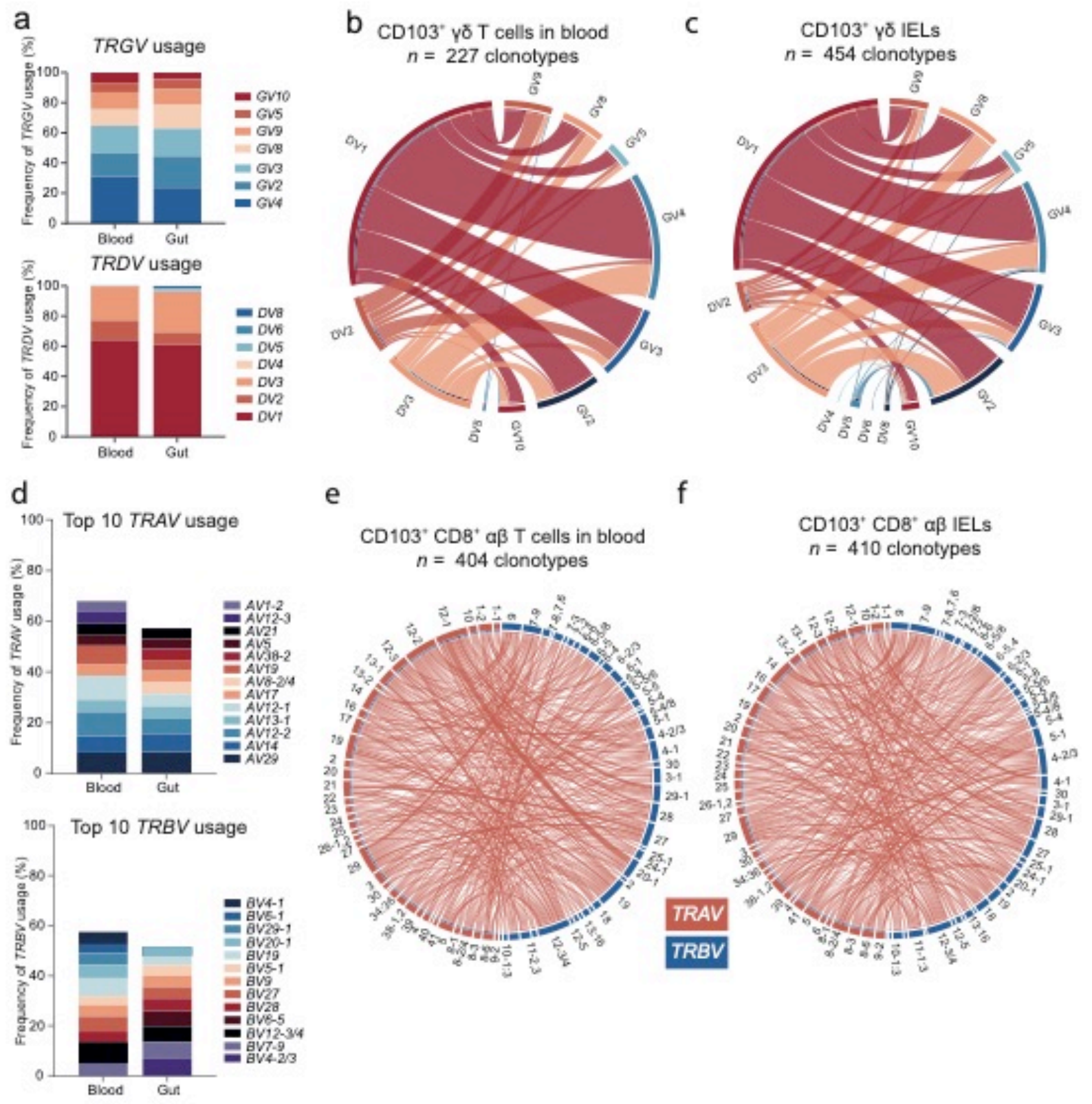

Figure $2 \mathrm{~V}$-gene usage and pairing in gut-homing $\gamma \delta$ and $\mathrm{CD}^{+} \alpha \beta \mathrm{T}$ cells. (a) The frequency of $T R G V$ or $T R D V$ usage in gut-homing $\left(\mathrm{CD} 103^{+}\right)$T-cell clonotypes from blood $(n=227$ clonotypes) and gut ( $n=454$ clonotypes) during a 14-day gluten challenge. (b,c) $T R G V$ and $T R D V$ chain pairing in blood and gut is displayed in Circos plots where ribbons connecting chains indicate frequency of pairing (blood, $n=227$, gut, $n=454$ clonotypes). (d) The frequency of the top 10 used TRAV and TRBV genes in blood ( $n=404$ clonotypes) and gut ( $n$ $=410$ clonotypes). (e,f) Circos plots representing chain pairing of $T R A V$ and $T R B V$ in blood ( $n=404$ clonotypes $)$ and gut $(n=410$ clonotypes). 


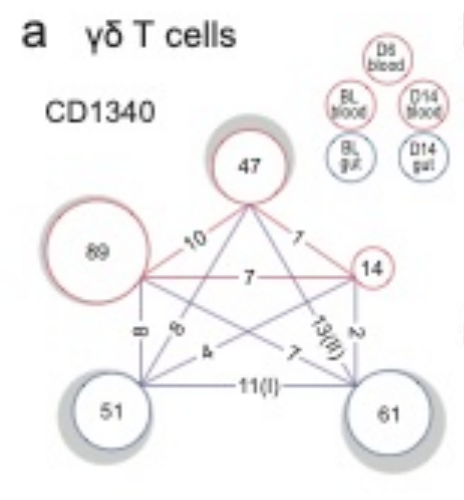

b $\quad$ c

\section{C}
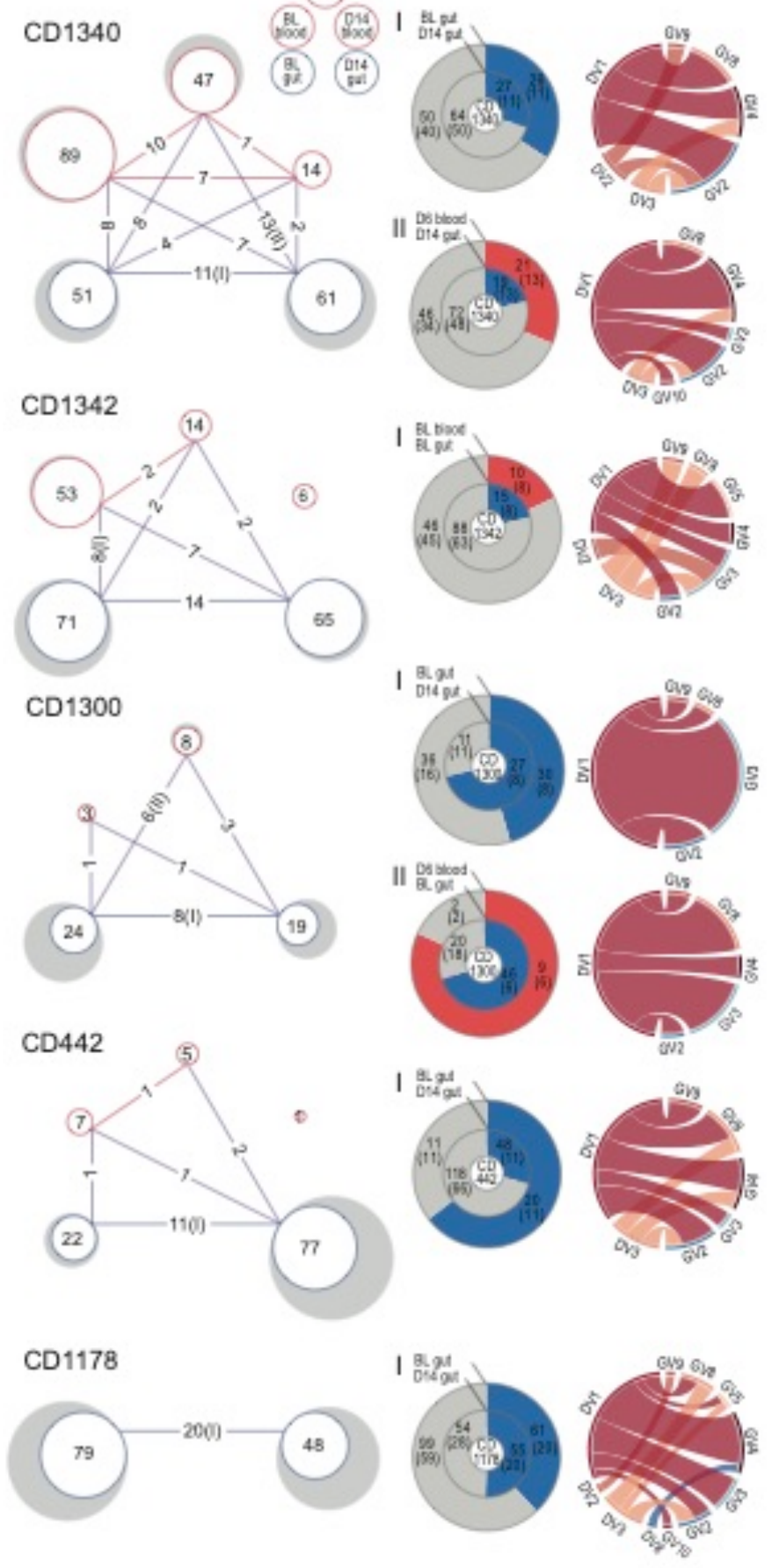

Figure 3 Sharing of $\mathrm{CD}_{103^{+}} \gamma \delta \mathrm{T}$-cell clonotypes across tissue and time. (a) All samples per patient are displayed as area-proportional circles relative to sample size and shared clonotypes between different samples are connected with a line. Gut samples are displayed in blue and blood samples in red circles with the number of total clonotypes. Grey circles proportionally represent the sample size based on the number of cells. The number of shared clonotypes is denoted on the connecting lines and samples compared in $\mathbf{b}$ and $\mathbf{c}$ are indicated in parentheses. Samples with $>20 \%$ clonotype sharing, $>5$ clonotypes and shared with $>1$ gut samples are displayed as (b) donut charts to include the total number of cells of shared (in red) and non-shared (in grey) clonotypes and (c) Circos plots to visualize the paired V-gene usage of TCR $\gamma$ and TCR $\delta$ of the shared clonotypes. 


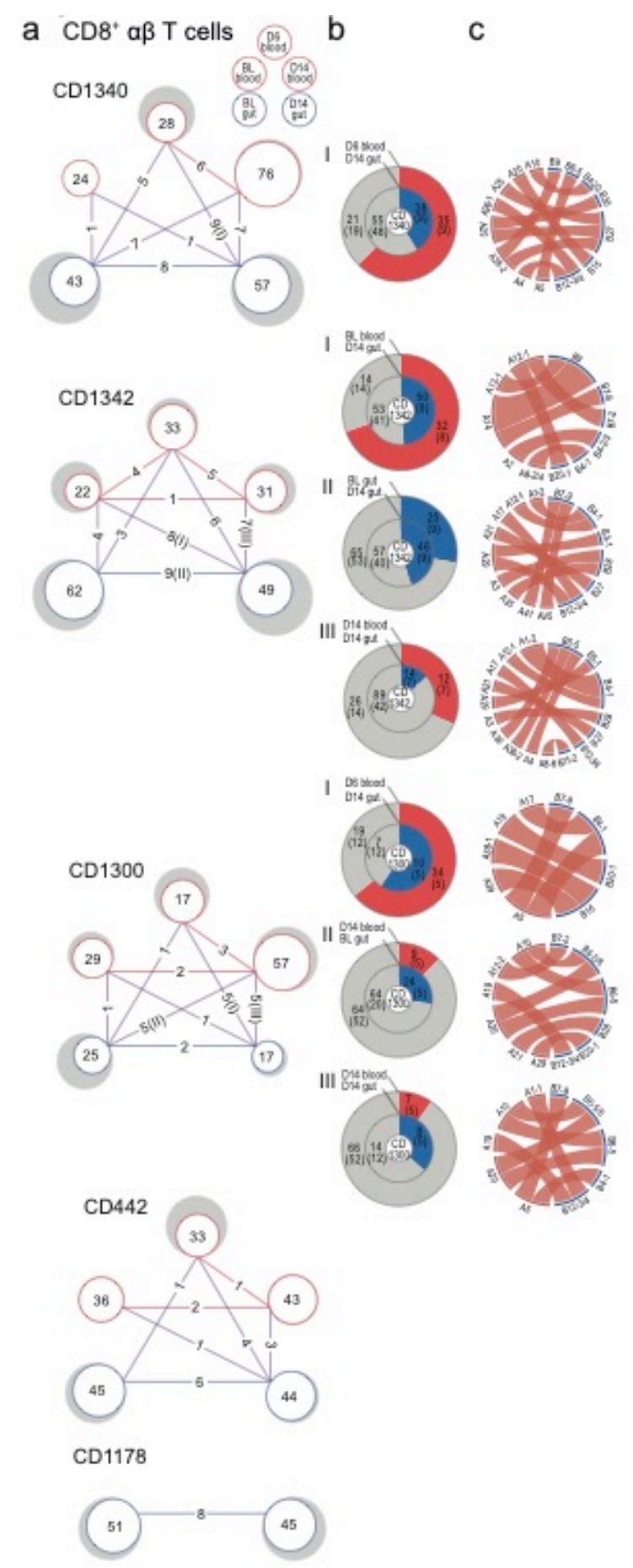

Figure 4 Sharing of $\mathrm{CD} 103^{+} \mathrm{CD}^{+} \alpha \beta \mathrm{T}$-cell clonotypes across tissue and time. (a) All samples per patient are displayed as area-proportional circles relative to sample size and shared clonotypes between different samples are connected with a line. Gut samples are displayed in blue and blood samples in red circles with the number of total clonotypes. Grey circles proportionally represent the sample size based on the number of cells. The number of shared clonotypes is denoted on the connecting lines and samples compared in $\mathbf{b}$ and $\mathbf{c}$ are indicated in parentheses. Samples with $>20 \%$ clonotype sharing, $>5$ clonotypes and shared with $>1$ gut samples are displayed as (b) donut charts to include the total number of cells of shared (in red) and non-shared (in grey) clonotypes and (c) Circos plots to visualize the paired $\mathrm{V}$-gene usage of TCR $\alpha$ and TCR $\beta$ of the shared clonotypes. 
a

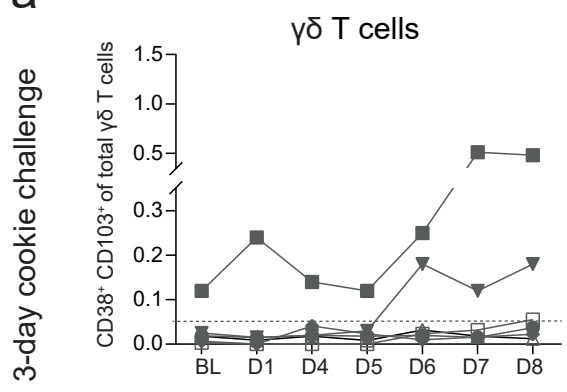

C

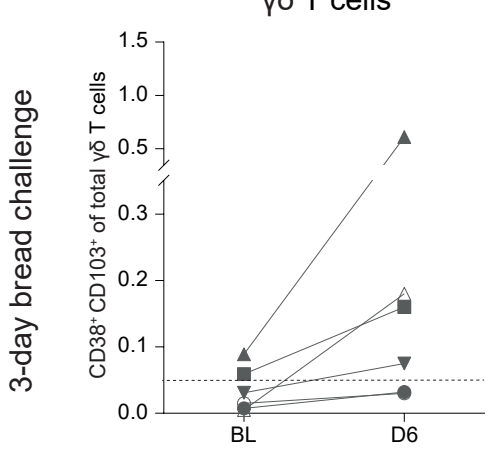

b

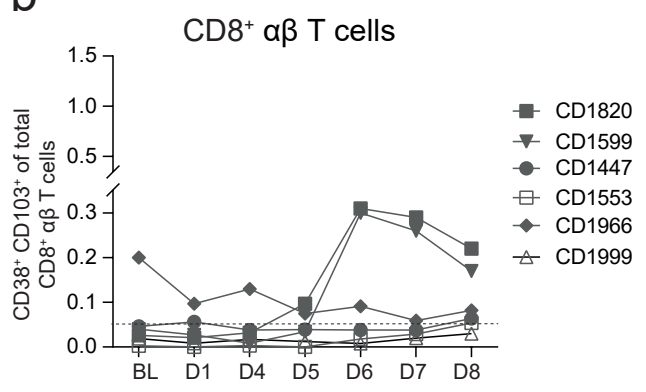

Correlation of T-cell responses in the bread challenge

$f$

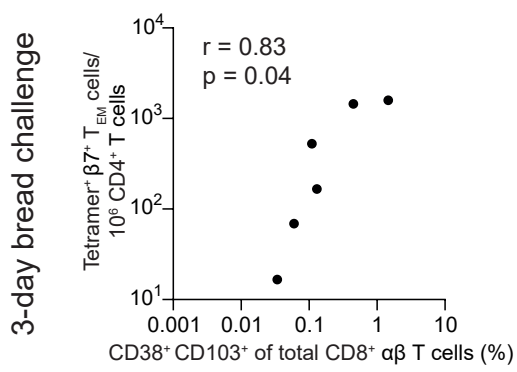

d

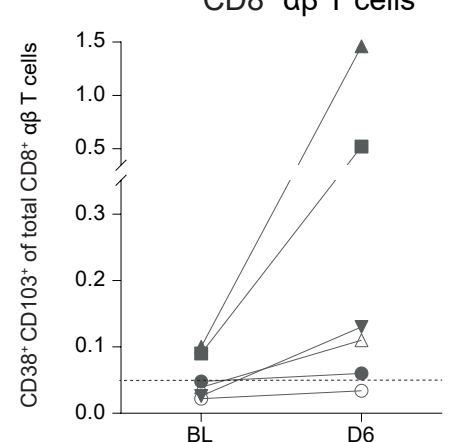

e

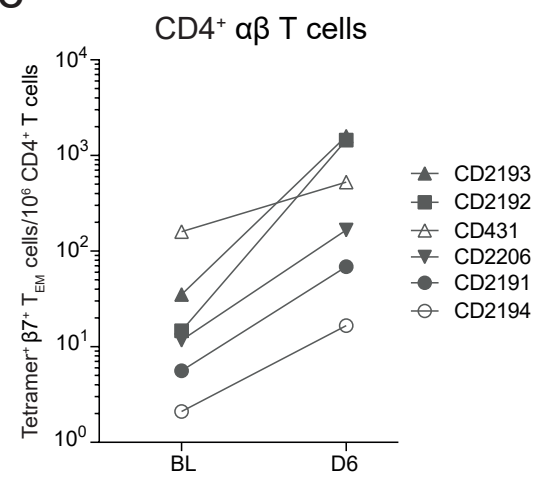

$\mathrm{g}$

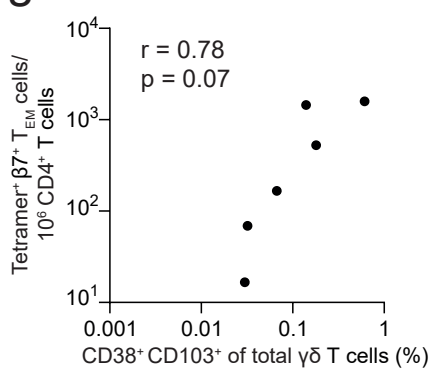

$\mathrm{h}$

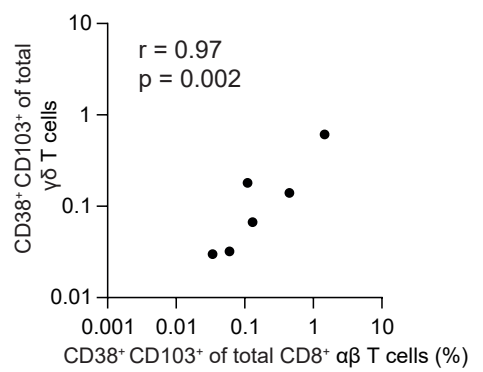

Figure $5 \mathrm{CD} 103^{+} \mathrm{CD} 38^{+} \gamma \delta$ and $\mathrm{CD}^{+} \alpha \beta$ T-cell responses during a 3-day gluten challenge. Tcell responses to 3-day gluten challenge (a) $\gamma \delta$ and (b) $\mathrm{CD}^{+} \alpha \beta$ T-cell responses to a 3-day cookie gluten challenge. (c) $\gamma \delta$, (d) $\mathrm{CD}^{+} \alpha \beta$ and (e) gluten-specific $\mathrm{CD} 4^{+} \mathrm{T}$-cell responses to a 3-day bread gluten challenge. Correlation analyses between the different $\mathrm{T}$-cell response are shown for (f) $\mathrm{CD}^{+} \alpha \beta$ and gluten-specific CD4 ${ }^{+} \mathrm{T}$ cells, $(\mathrm{g}) \gamma \delta$ and gluten-specific $\mathrm{CD} 4^{+} \mathrm{T}$ cells and (h) $\mathrm{CD}^{+} \alpha \beta$ and $\gamma \delta$ T cells. P-value (p) was calculated by Pearson correlation coefficient. 


\section{Tables}

Table 1. Various parameters of celiac subjects after 14-day gluten challenge.

\begin{tabular}{lccccc}
\hline Patient & $\begin{array}{c}\text { IEL increase } \\
\text { ( 2fold) }^{1}\end{array}$ & $\begin{array}{c}\text { Vh:Cd } \\
\text { difference } \\
\mathbf{0 . 4})^{\mathbf{2}}\end{array}$ & $\begin{array}{c}\text { Mucosal } \\
\text { damage } \\
\text { (Marsh 3) }^{\mathbf{3}}\end{array}$ & $\begin{array}{c}\text { Sero- } \\
\text { conversion }^{4}\end{array}$ & $\begin{array}{c}\text { Symptoms } \\
(\text { VAS) }\end{array}$ \\
\hline CD1342 & Yes (+++) & Yes (++) & No & No & No \\
CD1340 & Yes (+++) & No & No & Yes (+) & No \\
CD1300 & Yes (+++) & Yes (+++) & Yes (+++) & No & Yes (+) \\
CD442 & Yes (++) & No & Yes (+) & Yes (+) & Yes (+++) \\
\hline CD1339 & No & No & No & No & No \\
CD1299 & No & No & No & No & No \\
CD1178 & No & No & No & No & Yes $(+)$ \\
CD1298 & No & Yes (+) & No & No & No \\
\hline
\end{tabular}

Table summarizing the clinical outcomes of $\mathrm{CeD}$ patients undergoing a 14-day gluten challenge(40).

1) Intraepithelial lymphocyte (IEL) fold change : $+(>2$-fold). $++(>3$-fold $) .+++(>4$-fold $)$

2) Villous height-to-crypt depth (Vh:Cd) difference on day $14:+(0.4-0.7) .++(0.7-1) .+++(>1)$

3) Mucosal damage from baseline to day 14: + (Marsh 3 to Marsh 3). ++ (Marsh 1 to Marsh 3). +++ (Marsh 0 to Marsh 3 )

4) Seroconversion (anti-TG2 IgA in $U / m l . r e f<3):+(3-5)$

5) Symptoms (Visual Analogue Scale (VAS) after 6 hours: $+(20-30) .++(30-40) .+++(>40)$

Table 2. The different T-cell responses during a 14-day gluten challenge

\begin{tabular}{|c|c|c|c|c|c|}
\hline Patient & $\begin{array}{c}\text { Tetramer response } \\
\left(\mathrm{CD4}^{+} \mathrm{T} \text { cells }\right)^{1}\end{array}$ & $\mathrm{CD8}^{+} \mathrm{IEL}^{2}$ & $\gamma \delta$ IEL $^{2}$ & $\begin{array}{c}\mathrm{CD103}^{+} \mathrm{CDB3}^{+} \\
\mathrm{CD8}^{+} \mathrm{T} \mathrm{cells}^{3}\end{array}$ & $\begin{array}{c}\mathrm{CD103}^{+} \mathrm{CD38}^{+} \gamma \delta \\
\mathrm{T}^{\text {ceells }}{ }^{4}\end{array}$ \\
\hline CD1342 & Yes $(+)$ & Yes $(+++)$ & No & Yes $(++)$ & No \\
\hline CD1340 & Yes $(++)$ & Yes $(++)$ & No & Yes $(+++)$ & Yes $(+++)$ \\
\hline CD1300 & Yes $(+++)$ & Yes $(++)$ & No & No & No \\
\hline CD442 & Yes $(++)$ & Yes $(+)$ & No & Yes $(++)$ & No \\
\hline CD1339 & Yes $(+)$ & No & No & Yes $(+)$ & Yes $(++)$ \\
\hline CD1299 & Yes $(++)$ & ND & ND & No & No \\
\hline CD1178 & No & No & No & ND & ND \\
\hline CD1298 & No & No & No & No & No \\
\hline
\end{tabular}

A summary table on the different T-cell responses to a 14-day gluten challenge

1) Number of tetramer ${ }^{+}$integrin $\beta 7^{+}$effector memory (CD62L- CD45RA $)$T cells $/ 10^{6} \mathrm{CD}^{+} \mathrm{T}$ cells: $+(10-50)$. $++(50-300)$. $+++(300-1000)$. $++++(>1000)$. The total number of $\mathrm{CD}^{+} \mathrm{T}$ cells was calculated by $\%$ of $\mathrm{CD}^{+} \mathrm{T}$ cells stained in the pre-enriched sample with the total number of counted PBMC.

2) $\operatorname{CD} 8 \alpha \beta$ or $\gamma \delta$ IEL fold change: $+(>2$-fold $) .++(>3$-fold $) .+++(>5$-fold $)$

3) $\mathrm{CD}_{3} 8^{+} \mathrm{CD} 103^{+} \mathrm{CD}^{+} \mathrm{T}$ cells of total $\mathrm{CD} 8{ }^{+} \mathrm{T}$ cells: $+(0.1-0.5 \%) .++(0.5-1 \%) .+++(>1 \%)$

4) $\mathrm{CD}_{3} 8^{+} \mathrm{CD} 103^{+} \gamma \delta \mathrm{T}$ cells of total $\gamma \delta \mathrm{T}$ cells; $+(0.05-0.2 \%) .++(0.2-0.5 \%) .+++(0.5-1 \%) .++++(>1 \%)$

Table 3. Most expanded $\mathrm{CD} 103^{+} \gamma \delta \mathrm{T}$-cell clonotypes at day 6

\begin{tabular}{|c|c|c|c|c|c|c|c|}
\hline $\begin{array}{c}\text { Patient } \\
+ \text { Clone } \\
\text { ID }\end{array}$ & $\begin{array}{c}\text { Total clone } \\
\text { size }\end{array}$ & Tissue & $\begin{array}{l}\text { Time- } \\
\text { point }\end{array}$ & Clone size & $\begin{array}{c}\text { TRGV // TRGJ // } \\
\text { CDR3 } \gamma\end{array}$ & $\begin{array}{l}\text { TRDV // TRDD // TRDJ // } \\
\text { CDR3 } \delta\end{array}$ & Dual TRG/TRD \\
\hline \multicolumn{8}{|l|}{ CD1340 } \\
\hline 2 & 9 & Blood & $\begin{array}{c}\text { BL } \\
\text { D6 } \\
\text { D14 }\end{array}$ & $\begin{array}{l}2 \\
4 \\
1\end{array}$ & $\begin{array}{l}\text { TRGV4 // TRGJP1 // } \\
\text { ATWDGPGATGWFKI }\end{array}$ & $\begin{array}{l}\text { TRDV1 // TRDD2 // TRDJ1 // } \\
\text { ALGELASSYGRWGRATDKLI }\end{array}$ & \\
\hline
\end{tabular}




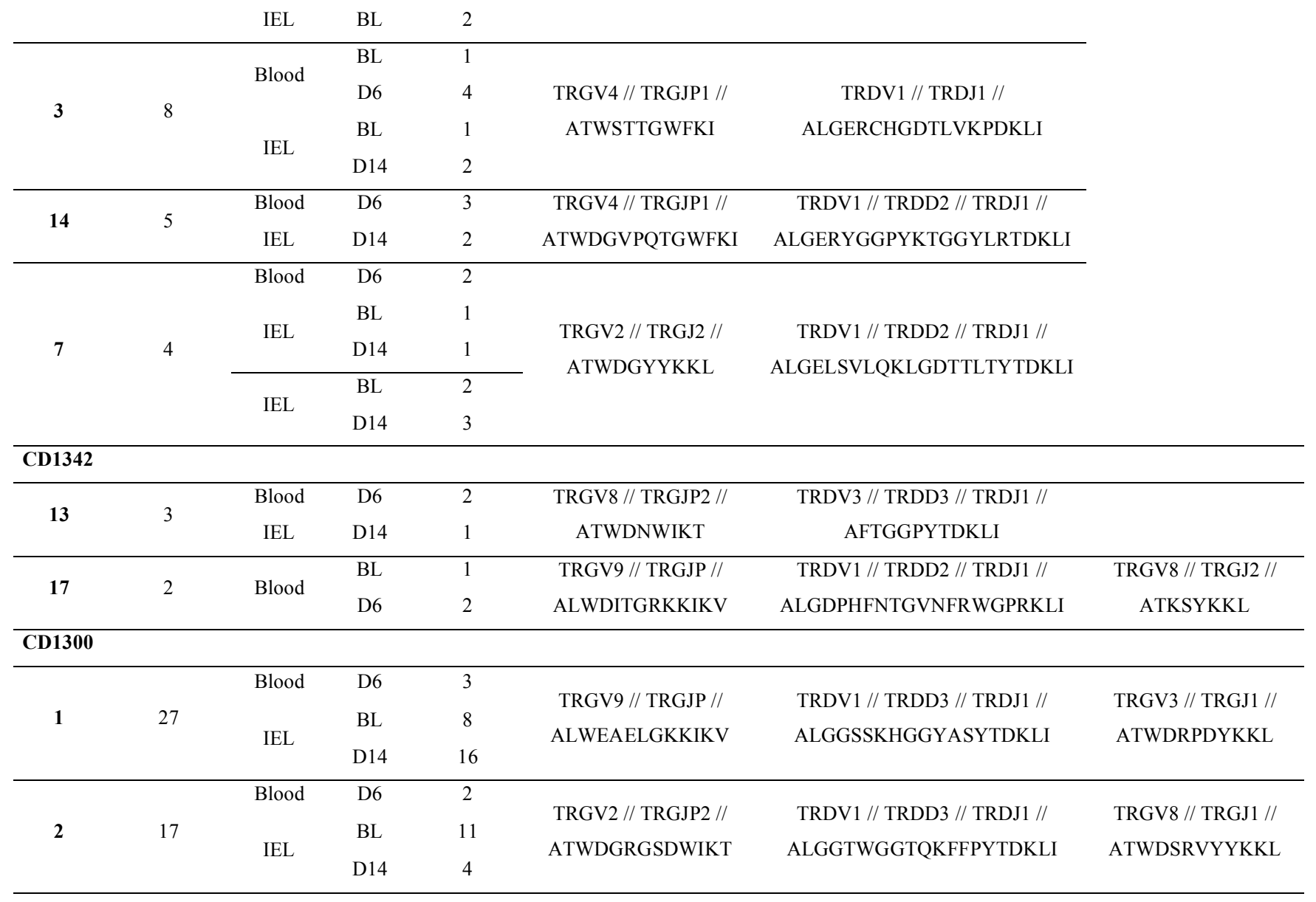

Table 4. Most expanded $\mathrm{CD} 103^{+} \mathrm{CD} 8^{+} \alpha \beta$ T-cell clonotypes at day 6

\begin{tabular}{|c|c|c|c|c|c|c|c|}
\hline $\begin{array}{c}\text { Patient } \\
+ \text { Clone } \\
\text { ID }\end{array}$ & $\begin{array}{c}\begin{array}{c}\text { Total } \\
\text { clone }\end{array} \\
\text { size }\end{array}$ & Tissue & $\begin{array}{l}\text { Time- } \\
\text { point }\end{array}$ & $\begin{array}{l}\text { Clone } \\
\text { size }\end{array}$ & $\begin{array}{l}\text { TRAV } / / \text { TRAJ } / / \\
\text { CDR3 } \alpha\end{array}$ & $\begin{array}{c}\text { TRBV } / / \text { TRBD } / / \text { TRBJ } / / \\
\text { CDR3 } \beta\end{array}$ & Dual TRA/TRB \\
\hline \multicolumn{8}{|l|}{ CD1340 } \\
\hline \multirow{4}{*}{2} & \multirow{4}{*}{21} & \multirow{2}{*}{ Blood } & D6 & 11 & \multirow{4}{*}{$\begin{array}{l}\text { TRAV20 // TRAJ26 // } \\
\text { AVQVNRGQNFV }\end{array}$} & \multirow{4}{*}{$\begin{array}{c}\text { TRBV15 // TRBJ2-7 // TRBD1 // } \\
\text { ATSPMTGGEQY }\end{array}$} & \\
\hline & & & D14 & 2 & & & \\
\hline & & \multirow{2}{*}{ IEL } & $\mathrm{BL}$ & 2 & & & \\
\hline & & & D14 & 6 & & & \\
\hline \multirow{3}{*}{3} & \multirow{3}{*}{22} & Blood & D6 & 9 & \multirow{3}{*}{$\begin{array}{c}\text { TRAV25 // TRAJ43 // } \\
\text { AVNNDMR }\end{array}$} & \multirow{3}{*}{$\begin{array}{c}\text { TRBV27 // TRBJ1-2 // TRBD1 // } \\
\text { ASSPGTGLDYGYT }\end{array}$} & \\
\hline & & & BL & 1 & & & \\
\hline & & IEL & D14 & 12 & & & \\
\hline \multirow{4}{*}{1} & \multirow{4}{*}{36} & \multirow{2}{*}{ Blood } & D6 & 6 & \multirow{4}{*}{$\begin{array}{l}\text { TRAV26-1 // TRAJ20 // } \\
\text { ISWASNDYKLS }\end{array}$} & \multirow{4}{*}{$\begin{array}{c}\text { TRBV12-3 // TRBJ1-2 // TRBD2 // } \\
\text { ASSPSPGAWYGYT }\end{array}$} & \\
\hline & & & D14 & 1 & & & \\
\hline & & \multirow{2}{*}{ IEL } & BL & 18 & & & \\
\hline & & & D14 & 11 & & & \\
\hline \multirow{3}{*}{6} & \multirow{3}{*}{7} & Blood & D6 & 2 & \multirow{3}{*}{$\begin{array}{l}\text { TRAV10 // TRAJ34 // } \\
\text { VVSALSNTDKLI }\end{array}$} & \multirow{3}{*}{$\begin{array}{c}\text { TRBV4-2 // TRBJ2-1 // TRBD2 // } \\
\text { ASSPLESYNEQF }\end{array}$} & \\
\hline & & & D14 & 2 & & & \\
\hline & & IEL & D14 & 3 & & & \\
\hline \multirow{3}{*}{7} & \multirow{3}{*}{4} & P1 & D6 & 2 & \multirow{3}{*}{$\begin{array}{l}\text { TRAV38-2/DV8 // TRAJ48 } \\
\text { // AYSDFGNEKLT }\end{array}$} & \multirow{3}{*}{$\begin{array}{c}\text { TRBV27 // TRBJ2-7 // TRBD2 // } \\
\text { ASSLSLAGDHEQY }\end{array}$} & \\
\hline & & Blood & D14 & 1 & & & \\
\hline & & IEL & D14 & 1 & & & \\
\hline
\end{tabular}




\begin{tabular}{|c|c|c|c|c|c|c|c|}
\hline 4 & 11 & $\begin{array}{l}\text { Blood } \\
\text { IEL }\end{array}$ & $\begin{array}{c}\text { BL } \\
\text { D6 } \\
\text { D14 }\end{array}$ & $\begin{array}{l}1 \\
6 \\
4\end{array}$ & $\begin{array}{l}\text { TRAV38-2/DV8 // TRAJ57 } \\
\text { // AIPQDLAQGGSEKLV }\end{array}$ & $\begin{array}{c}\text { TRBV5-5 // TRBD2 // TRBJ1-2 // } \\
\text { ASSLGSVFNYGYT }\end{array}$ & \\
\hline \multirow{4}{*}{1} & \multirow{4}{*}{33} & \multirow{2}{*}{ Blood } & $\mathrm{BL}$ & 9 & & & \\
\hline & & & D6 & 3 & TRAV3 // TRAJ8 // & TRBV28 // TRBD2 // TRBJ2-2 // & \\
\hline & & \multirow{2}{*}{ IEL } & $\mathrm{BL}$ & 2 & AVRDSQSGFQKLV & ASSLRDPGELF & \\
\hline & & & D14 & 19 & & & \\
\hline \multirow{2}{*}{6} & \multirow{2}{*}{5} & Blood & & 2 & \multirow{2}{*}{$\begin{array}{l}\text { TRAV12-1 // TRAJ17 // } \\
\text { VLYGAAGNKLT }\end{array}$} & \multirow{2}{*}{$\begin{array}{c}\text { TRBV20-1 // TRBD1 // TRBJ2-1// } \\
\text { SGGTGSHEQF }\end{array}$} & \\
\hline & & IEL & D14 & $\begin{array}{l}2 \\
1\end{array}$ & & & \\
\hline \multirow{2}{*}{12} & \multirow{2}{*}{4} & Blood & $\mathrm{BL}$ & 1 & TRAV19 // TRAJ8 // & TRBV5-1 // TRBD1 // TRBJ2-3 // & \\
\hline & & IEL & D6 & 3 & ALSEANTGFQKLV & ASSLEGQHTDTQY & \\
\hline \multirow{2}{*}{17} & \multirow{2}{*}{3} & Blood & D6 & 2 & TRAV2 // TRAJ15 // & TRBV4-1 // TRBD2 // TRBJ2-7 // & \\
\hline & & IEL & D14 & 1 & AVEDENQAGTALI & ASSQAPGNEQY & \\
\hline \multicolumn{8}{|c|}{ CD1300 } \\
\hline \multirow{2}{*}{2} & \multirow{2}{*}{17} & Blood & & 12 & \multirow{2}{*}{$\begin{array}{c}\text { TRAV5 // TRAJ45 // } \\
\text { AESGGYSGGGADGLT }\end{array}$} & \multirow{2}{*}{$\begin{array}{l}\text { TRBV7-9 // TRBD2 // TRBJ2-1 // } \\
\text { ASSLLSPQRDNEQF }\end{array}$} & \\
\hline & & IEL & D14 & 4 & & & \\
\hline \multirow{2}{*}{6} & \multirow{2}{*}{10} & Blood & D6 & 8 & TRAV19 // TRAJ36// & TRBV20-1 // TRBD2 // TRBJ1-6// & \\
\hline & & IEL & D14 & 2 & ALSEARRTGANNLF & SATETGFYNSPLH & \\
\hline \multirow{2}{*}{7} & \multirow{2}{*}{10} & Blood & D6 & 8 & TRAV17 // TRAJ49 // & TRBV4-1 // TRBD2 // TRBJ2-7 // & \\
\hline & & IEL & D14 & 2 & ASLDASFTGNQFY & ASRYTGTSVYEQY & \\
\hline 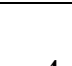 & 5 & Blood & & 3 & TRAV5 // TRAJ15 // & TRBV4-1 // TRBD1 // TRBJ2-3 // & \\
\hline 4 & 5 & IEL & D14 & $\begin{array}{l}1 \\
1\end{array}$ & AEPGQAGTALI & ASSRGPLSTDTQY & \\
\hline 8 & 4 & Blood & D6 & 3 & TRAV39 // TRAJ57 // & TRBV16 // TRBD1 // TRBJ1-1// & TRAV38-1 // TRAJ54 // \\
\hline 0 & 4 & IEL & D14 & 1 & GGSEKLV & ASSPTAASEAF & APGLLIQGAQKLV \\
\hline CD44 & & & & & & & \\
\hline 4 & 5 & Blood & D6 & 4 & TRAV5 // TRAJ4 // & TRBV9 // TRBD1 // TRBJ2-7 // & \\
\hline $\boldsymbol{7}$ & & IEL & D14 & 1 & AVELGGYNKLI & ASSVGDTPYEQY & \\
\hline & 5 & Blood & D6 & 5 & TRAV21 // TRAJ16 // & TRBV12-3 // TRBD1 // TRBJ2-1 // & \\
\hline & J & Diova & D0 & J & AVEDGQKLL & ASSLDSSYNEQF & \\
\hline & 4 & Blood & D6 & 4 & TRAV5 // TRAJ11 // & TRBV6-2 // TRBD1 // TRBJ2-3 // & \\
\hline & 4 & Divou & 20 & 4 & AVDSGYSTLT & ASSPTGGNTQY & \\
\hline & & Blood & D6 & 2 & $\mathrm{TR} \triangle \mathrm{V} 13-2 / \mathrm{TR} \triangle \mathrm{I} 41 / \mathrm{d}$ & TRRV5-5/ TRRD1 // TRR227/ & \\
\hline 1 & 4 & IEL & $\mathrm{BL}$ & 1 & AETRSGYALN & ASSLRPSLEOY & \\
\hline & & & D14 & 1 & & & \\
\hline 6 & 3 & Blood & D6 & 2 & TRAV14/DV4 // TRAJ57 // & TRBV24-1 // TRBD1 // TRBJ2-5 // & TRAV24 // TRAJ20 // \\
\hline $\mathbf{0}$ & J & IEL & D14 & 1 & GGSAQGGSEKLV & ATSDSTGVETQY & AFEVSNDYKLS \\
\hline
\end{tabular}


Table 5. T-cell responses during two 3-day gluten challenges

\begin{tabular}{|c|c|c|c|c|}
\hline $\begin{array}{l}\text { Gluten } \\
\text { type }\end{array}$ & Patient & $\begin{array}{c}\text { Tetramer response } \\
(\text { CD4+ T cells })^{1} \\
\end{array}$ & $\begin{array}{c}\text { CD103+ CD38+ } \\
\text { CD8 + T cells }^{2} \\
\end{array}$ & $\begin{array}{c}\mathrm{CD103}+\mathrm{CD38}+\gamma \delta \\
\mathrm{T} \text { cells } \\
\end{array}$ \\
\hline \multirow{6}{*}{ ن } & CD1820 & Yes $(++)$ & Yes $(+)$ & Yes $(++)$ \\
\hline & CD1599 & Yes $(++)$ & Yes $(+)$ & Yes $(+)$ \\
\hline & CD1553 & Yes $(++)$ & No & No \\
\hline & CD1999 & Yes $(+)$ & No & No \\
\hline & CD1966 & No & No & No \\
\hline & CD1447 & No & No & No \\
\hline \multirow{6}{*}{ 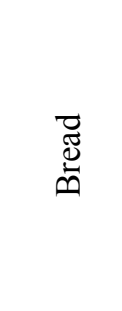 } & CD2193 & Yes $(++++)$ & Yes $(+++)$ & Yes $(+++)$ \\
\hline & CD2192 & Yes $(+++)$ & Yes $(+)$ & Yes $(+)$ \\
\hline & CD431 & Yes $(+++)$ & Yes $(+)$ & Yes $(+)$ \\
\hline & CD2206 & Yes $(++)$ & Yes (+) & Yes $(+)$ \\
\hline & CD2191 & Yes $(+)$ & No & No \\
\hline & CD2194 & Yes $(+)$ & No & No \\
\hline
\end{tabular}

Table summarizing the various T-cell responses to the 3-day cookie and bread challenges

1) Estimated number of tetramer ${ }^{+}$integrin $\beta 7^{+}$effector memory (CD62L- CD45RA) T cells $/ 10^{6} \mathrm{CD}^{+} \mathrm{T}$ cells: $+(10-50) .++(50-300)$. +++ (300-1000). $++++(>1000)$. The total number of $\mathrm{CD}^{+} \mathrm{T}$ cells was calculated by $\%$ of $\mathrm{CD}^{+} \mathrm{T}$ cells stained in the pre-enriched sample with the total number of counted PBMC(189)

2) $\mathrm{CD}_{3} 8^{+} \mathrm{CD} 103^{+} \mathrm{CD}^{+} \mathrm{T}$ cells of total $\mathrm{CD}^{+} \mathrm{T}$ cells: $+(0.1-0.5 \%) .++(0.5-1 \%) .+++(>1 \%)$

3) $\mathrm{CD}_{3} 8^{+} \mathrm{CD}_{103}{ }^{+} \gamma \delta \mathrm{T}$ cells of total $\gamma \delta \mathrm{T}$ cells $+(0.05-0.2 \%) .++(0.2-0.5 \%) .+++(0.5-1 \%) .++++(>1 \%)$ 


\section{Supplement}

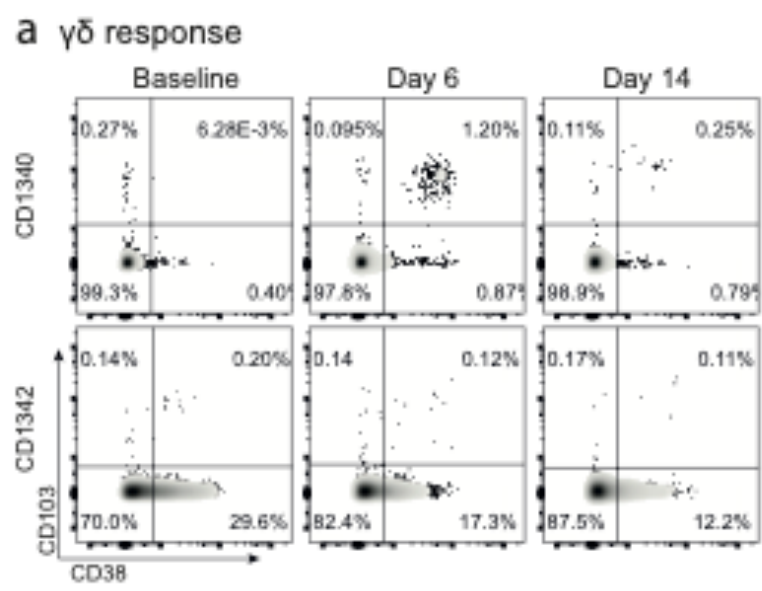

b $\mathrm{CD}^{+} \mathrm{a} \beta$ response

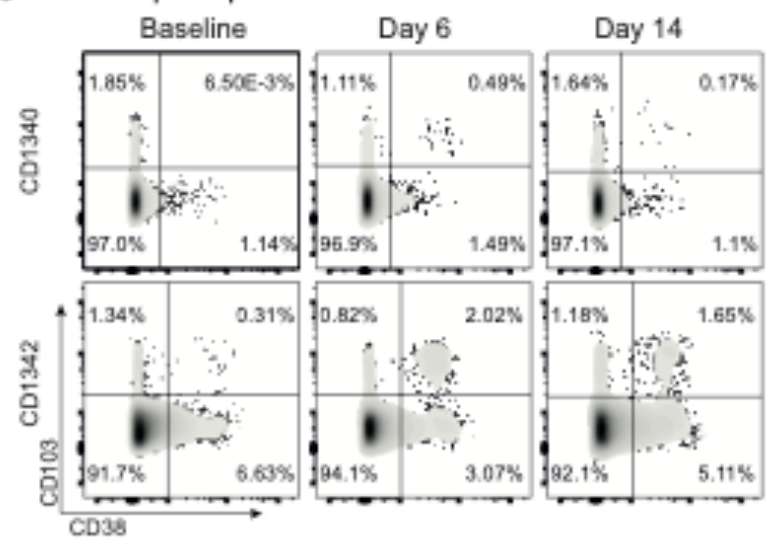

Supplementary Figure $1 \mathrm{CD} 103^{+} \mathrm{CD} 38^{+} \gamma \delta$ and $\mathrm{CD} 8^{+} \alpha \beta \mathrm{T}$-cell responses during a 14-day gluten challenge for two patients. $\gamma \delta$ (a) and $\mathrm{CD}^{+} \alpha \beta$ (b) T-cell responses in blood shown for two patients, CD1340 and CD1342. Numbers within each gate indicate per cent of total cell in each plot.

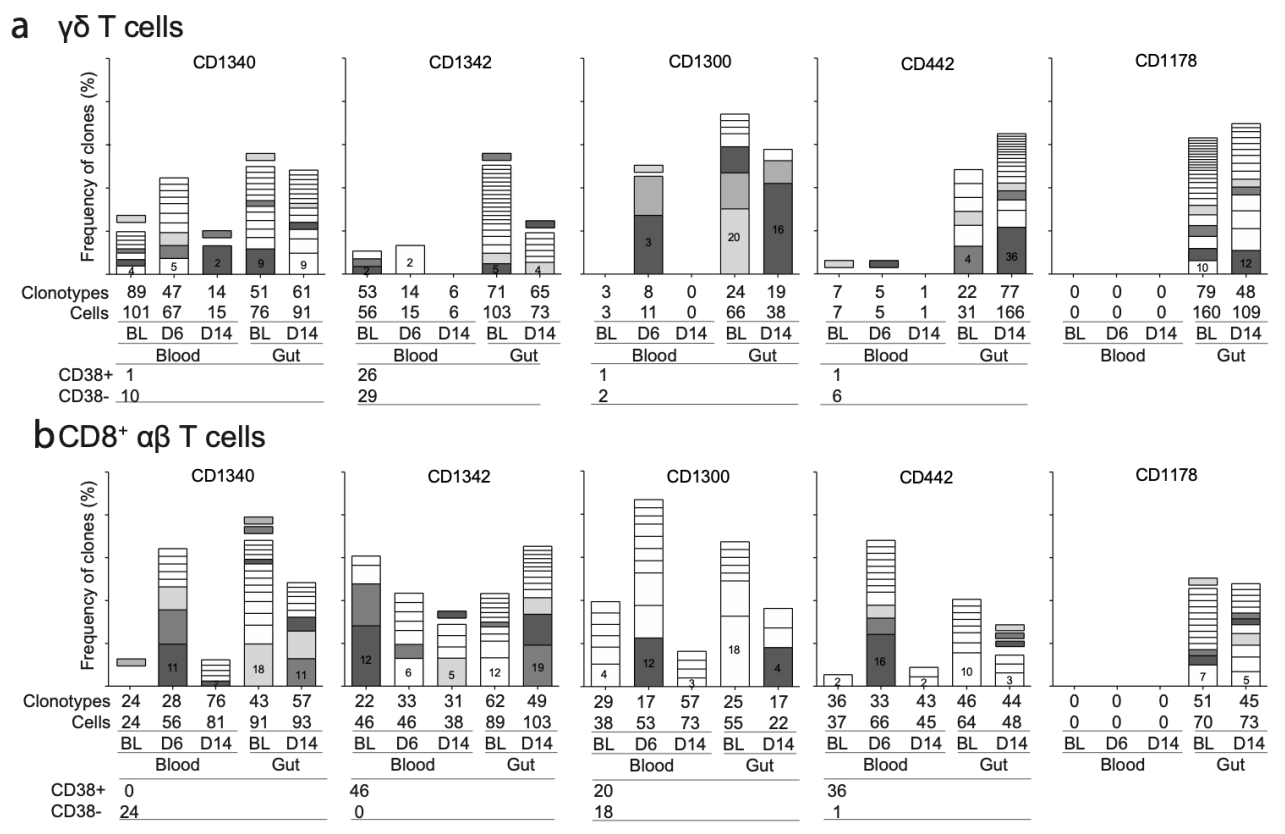

Supplementary Figure 2 Clonal diversity and distribution of $\mathrm{CD}_{103^{+}} \gamma \delta$ and $\mathrm{CD} 8^{+} \alpha \beta \mathrm{T}$ cells during gluten challenge. Clonal distribution of $\gamma \delta$ (a) or $\mathrm{CD} 8^{+} \alpha \beta$ (b) clonotypes observed in clonally expanded cells per patient. X-axis denotes the sampling time points; baseline (BL), day 6 (D6) and day 14 (D14). Y-axis shows the percentage share of each clonotype represented as slices. Only clonotypes that contain at least two cells are plotted and the most dominant clonotypes are displayed with numbers within the bars. The colored sections represent the three dominant clonotypes across the samples and shared clonotypes with clonal size one are shown by colored split slices. The total number of clonotypes and 
cells in each sample are shown below each bar. The number of $\mathrm{CD} 38^{+}$and CD38- cells are depicted below the blood baseline samples.

a
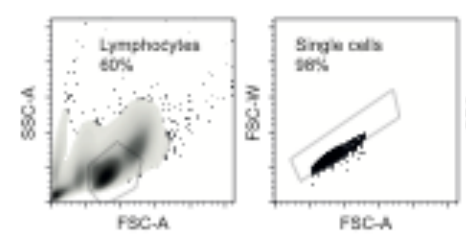

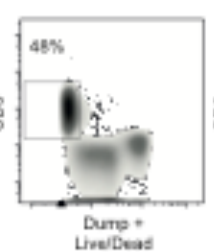

Limbers:

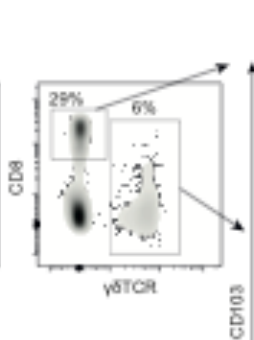

응

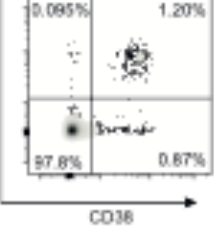

b
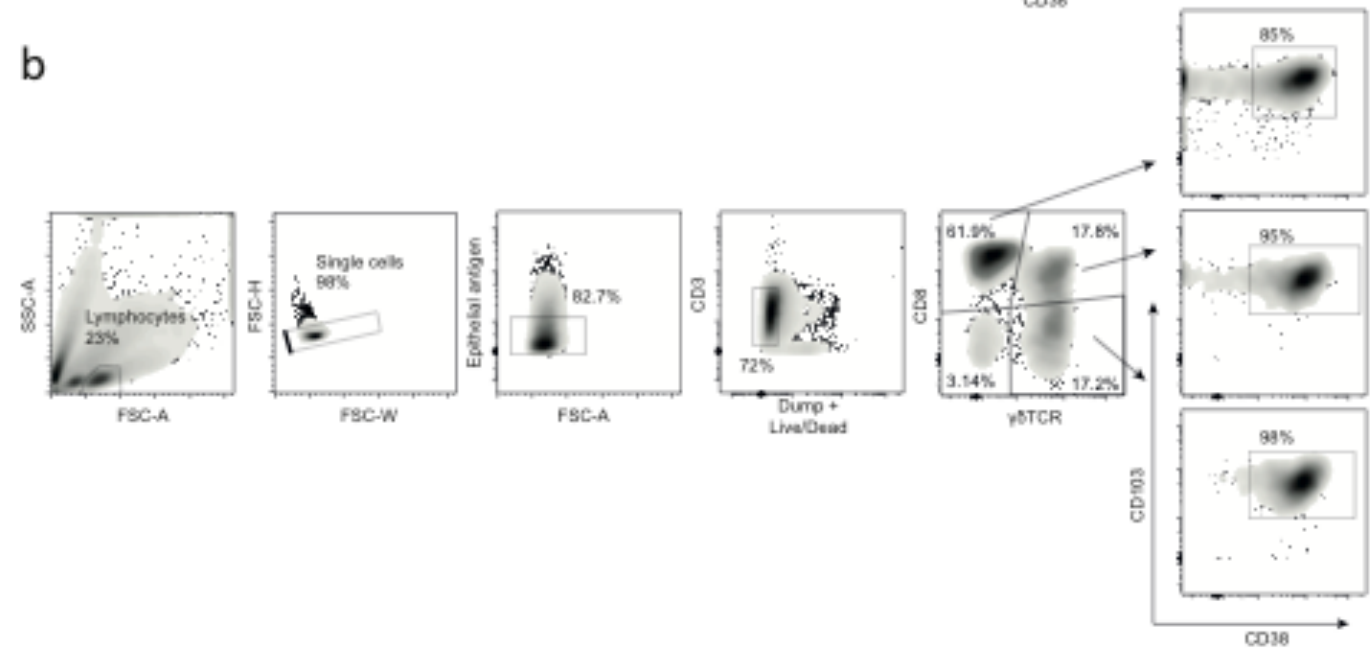

Supplementary Figure 3 Gating strategy for sorting of gut-homing $\gamma \delta$ and CD $8+\alpha \beta$ T cells. Gating strategy used when single-cell sorting CD103 $+\gamma \delta$ and CD8 $+\alpha \beta$ T cells from (a) blood and (b) gut. (a) For all blood samples, cells were gated on live singlet lymphocytes that were CD3+ CD11c- CD14- CD19- CD56-. (b) All $\gamma \delta$ and CD8+ $\alpha \beta$ IELs were gated in live singlet lymphocytes that were epithelial antigen- CD3+CD11c-CD14-CD19- CD56-CD103+CD38+. $\mathrm{CD} 8+$ and CD8- $\gamma \delta$ IELs were sorted in separate plates.

Table S1. Approximate quantification of absolute number of $\gamma \delta$ and $\mathrm{CD}^{+} \alpha \beta$ IELs based on HE-section based IEL count and $\gamma \delta \mathrm{TCR} / \mathrm{CD} 8$ flow cytometry staining.

\begin{tabular}{|c|c|c|c|c|c|c|c|c|c|c|}
\hline & \multicolumn{2}{|c|}{$\begin{array}{c}\text { IEL count } \\
\text { per } 100 \text { IEC }^{1}\end{array}$} & \multicolumn{2}{|c|}{$\begin{array}{c}\text { TCR } \gamma \delta \\
(\% \text { CD3 IEL })^{2}\end{array}$} & \multicolumn{2}{|c|}{$\begin{array}{c}\gamma \delta \text { IEL } \\
\text { per } 100 \text { IEC }^{3}\end{array}$} & \multicolumn{2}{|c|}{$\begin{array}{c}\text { CD8 } \\
(\% \text { CD3 IEL })^{4}\end{array}$} & \multicolumn{2}{|c|}{$\begin{array}{l}\text { CD8 IEL per } \\
100 \text { IEC }^{5}\end{array}$} \\
\hline Patient & $\mathrm{BL}$ & D6 & $\mathrm{BL}$ & D6 & $\mathrm{BL}$ & D6 & $\mathrm{BL}$ & D6 & $\mathrm{BL}$ & D6 \\
\hline CD1342 & 16.2 & 72.4 & 30.6 & 10.0 & 5.0 & 7.2 & 65.0 & 86.3 & 10.5 & 62.5 \\
\hline CD1340 & 21.4 & 59.5 & 56.8 & 36.0 & 12.1 & 21.4 & 38.9 & 59.7 & 8.3 & 35.5 \\
\hline CD1300 & 15.8 & 52.9 & 13.6 & 6.9 & 2.2 & 3.6 & 73.7 & 82.8 & 11.7 & 43.8 \\
\hline CD442 & 26.8 & 56.9 & 20.4 & 10.9 & 5.5 & 6.2 & 72.8 & 83.1 & 19.5 & 47.2 \\
\hline CD1339 & 29.7 & 48.4 & 30.9 & 31.7 & 9.2 & 15.3 & 62.8 & 59.5 & 18.7 & 28.8 \\
\hline CD1299 & 23.9 & 26.5 & 27 & ND & 6.4 & ND & 68.0 & ND & 16.2 & ND \\
\hline CD1178 & 24.4 & 33.1 & 22.4 & 28.5 & 5.5 & 9.4 & 72.3 & 67.6 & 17.6 & 22.3 \\
\hline CD1298 & 17.9 & 19.1 & 41.0 & 42.5 & 7.4 & 8.1 & 55.6 & 54.7 & 10.0 & 10.5 \\
\hline
\end{tabular}

1) Intraepithelial lymphocyte (IEL) count based on HE-sections.

2) Fraction (\%) of $\mathrm{CD}^{+}$cells stained positive to $\gamma \delta \mathrm{TCR}$ antibody in flow cytometry (IEL sample obtained from gut biopsies). 
3) Estimation of total number of $\gamma \delta$ IELs per 100 intestinal epithelial cells (IECs) by dividing the total number of IELs per 100 IECs by the relative number of $\gamma \delta \mathrm{TCR}^{+} \mathrm{CD}^{+}$cells measured by flow cytometry.

4) Fraction (\%) of $\mathrm{CD}^{+}$cells stained positive to CD8 antibody in flow cytometry (IEL sample obtained from gut biopsies).

5) Estimation of total number of $\gamma \delta$ IELs per 100 intestinal epithelial cells (IECs) by dividing the total number of IELs per 100 IECs by the relative number of $\mathrm{CD}^{+} \mathrm{CD}^{+}$cells measured by flow cytometry.

Table S2. Comparison of gluten-specific CD4+T cell response in different gluten challenges measured using HLA-DQ2.5:gluten tetramers.

\begin{tabular}{lcccc}
\hline Bread (3-day) & BL & D6 & $\begin{array}{c}\text { Fold change } \\
\text { (D6/BL) }\end{array}$ & $\begin{array}{c}\text { Tetramer } \\
\text { response }\end{array}$ \\
\hline CD2193 & 35.1 & 1588.2 & 45.3 & +++ \\
CD2192 & 14.7 & 1446.6 & 98.5 & +++ \\
CD431 (1day) & 159.7 & 525.6 & 3.3 & +++ \\
CD2206 & 11.7 & 166.2 & 14.2 & ++ \\
CD2191 & 5.6 & 68.8 & 12.4 & + \\
CD2194 & 2.1 & 16.6 & 7.8 & + \\
Median & 13.2 & 345.9 & 26.2 & \\
Mean & 38.1 & 635.3 & 16.7 & \\
\hline Cookie (3-day) & & & & \\
\hline CD1553 & 3.9 & 287.9 & 74.1 & ++ \\
CD1599 & 6.6 & 239.8 & 36.4 & ++ \\
CD1820 & 6.2 & 72.4 & 11.7 & ++ \\
CD1999 & 7.9 & 31.6 & 4.0 & + \\
CD1966 & 7.7 & 12.2 & 1.6 & - \\
CD1447 & 8.0 & 4.2 & 0.5 & - \\
Median & 6.6 & 72.4 & 11.0 & \\
Mean & 6.5 & 123.3 & 19.1 & \\
\hline Mueslibar (14-day) & & & & + \\
\hline CD1300 & 12.4 & 889.4 & 71.5 & ++ \\
CD442 & 63.3 & 294.1 & 4.6 & ++ \\
CD1340 & 2.9 & 171.3 & 58.4 & ++ \\
CD1299 & 5.2 & 57.7 & 11.1 & ++ \\
CD1339 & 4.1 & 25.0 & 6.0 & + \\
CD1342 & 1.7 & 22.6 & 13.1 & + \\
CD1178 & 4.7 & 2.4 & 0.5 & + \\
CD1298 & 1.7 & 1.8 & 1.0 & \\
Median & 4.4 & 41.3 & 9.4 & + \\
Mean & 12.0 & 183.0 & 15.2 & \\
\hline & & & & + \\
\hline
\end{tabular}

